\title{
A Review of GPR Application on Transport Infrastructures: Troubleshooting and Best Practices
}

\author{
Mercedes Solla $^{1, *(\mathbb{D})}$, Vega Pérez-Gracia ${ }^{2} \mathbb{D}$ and Simona Fontul ${ }^{3,4} \mathbb{D}$ \\ 1 CINTECX, GeoTECH research group, Universidade de Vigo, 36310 Vigo, Spain \\ 2 Department of Strength of Materials and Structural Engineering, Universitat Politècnica de Catalunya, \\ Campus Diagonal Besós, Barcelona East School of Engineering, EEBE, Av. Eduard Maristany, 16, \\ 08019 Barcelona, Spain; vega.perez@upc.edu \\ 3 Department of Transportation, National Laboratory for Civil Engineering_LNEC, 1700-066 Lisbon, Portugal; \\ simona@lnec.pt \\ 4 Civil Engineering Department, NOVA School of Science and Technology, 2829-516 Caparica, Portugal \\ * Correspondence: merchisolla@uvigo.es
}

Citation: Solla, M.; Pérez-Gracia, V.; Fontul, S. A Review of GPR Application on Transport Infrastructures: Troubleshooting and Best Practices. Remote Sens. 2021, 13, 672. https://doi.org/10.3390/ rs13040672

Academic Editor: Roberto Orosei

Received: 19 January 2021

Accepted: 9 February 2021

Published: 13 February 2021

Publisher's Note: MDPI stays neutral with regard to jurisdictional claims in published maps and institutional affiliations.

Copyright: (c) 2021 by the authors. Licensee MDPI, Basel, Switzerland. This article is an open access article distributed under the terms and conditions of the Creative Commons Attribution (CC BY) license (https:// creativecommons.org/licenses/by/ $4.0 /)$.

\begin{abstract}
The non-destructive testing and diagnosis of transport infrastructures is essential because of the need to protect these facilities for mobility, and for economic and social development. The effective and timely assessment of structural health conditions becomes crucial in order to assure the safety of the transportation system and time saver protocols, as well as to reduce excessive repair and maintenance costs. Ground penetrating radar (GPR) is one of the most recommended non-destructive methods for routine subsurface inspections. This paper focuses on the on-site use of GPR applied to transport infrastructures, namely pavements, railways, retaining walls, bridges and tunnels. The methodologies, advantages and disadvantages, along with up-to-date research results on GPR in infrastructure inspection are presented herein. Hence, through the review of the published literature, the potential of using GPR is demonstrated, while the main limitations of the method are discussed and some practical recommendations are made.
\end{abstract}

Keywords: ground penetrating radar; inspection; pavements; railways; bridges; tunnels; retaining walls; methodologies; limitations; benefits

\section{Introduction}

The deterioration and distress mechanisms that are active under the surface cannot be assessed with high accuracy using only traditional methods such as visual inspection, hammer sounding, chain dragging, and not even by destructive coring and test pits. Alternative methods are therefore required for a more complete inspection. Among other geophysical methods, ground penetrating radar (GPR) is widely recognized as one of the most powerful and versatile non-destructive testing (NDT) methods for routine subsurface inspections. GPR is a geophysical method that allows for the analysis of the propagation capacity of electromagnetic waves through media with different dielectric constants. A transmitting antenna emits an electromagnetic signal into the ground, which is partly reflected at the interface between two different media with sufficient dielectric contrast and partly transmitted into deeper layers. Then, the reflections produced are recorded from the receiving antenna, which is either in a separate antenna box or in the same antenna box as the transmitter. The strength (amplitude) of the reflected fields is proportional to the change in the magnitude of the dielectric constant. As the antenna is moved along the ground surface, a two-dimensional image (known as a radargram or B-scan) is obtained, which is an XZ graphic representation of the detected reflections. The $\mathrm{x}$-axis represents the antenna displacement along the survey line, and the z-axis represents the two-way travel time of the pulse emitted and received. If the time required to propagate to a reflector and back is measured, and the velocity of the signal propagation in the medium is known, the depth 
of the reflector can therefore be determined. By using three-dimensional data acquisition and imaging techniques, the reflected signals recorded by the GPR can be transformed into 3D imaging, which allows for a better perception of the underground structures. A detailed description of the methodology along with a deep theoretical background can be found in [1-3]. GPR is a portable and fast data acquisition technique that provides dense and accurate data, with a much higher resolution compared with competing geophysical approaches.

The major strengths of GPR are that the method allows for the collection of data at high speed, continuously, using mobile acquisition units and in a non-contact mode. Furthermore, it enables one to keep the prospected transport infrastructure area in-service during the GPR assessment, thus reducing costs and discomfort to users. Conversely, the main limitations occur in the presence of high-conductivity materials (such as wet clay) and in heterogeneous conditions causing signal attenuation and complex scattering phenomena, respectively. Another drawback is that the interpretation of radargrams is generally non-intuitive and requires considerable expertise to properly process and understand the measurements.

A few international organizations have promoted recommendations to properly use GPR in transport infrastructures. The American Society for Testing and Materials (ASTM) has produced a standard guide, ASTM D6432-19, that summarizes the equipment and field procedures for GPR subsurface investigation, as well as processing methods used to interpret GPR data [4]. The British Highway Agency has published technical specifications (DMRB 3.1.7 and DMRB 7.3.2) regarding the use of GPR for testing highway structures (concrete and masonry bridges) [5] and for pavement assessment [6], respectively. In Europe, the EuroGPR has produced guidelines for pavement structural surveys [7] including limitations of GPR use on pavements, survey assessment, survey specification, location referencing, data quality and backup, and data reporting. In Italy, the Comitato Elettotecnico Italiano (CEI) published the Italian standard (CEI 306-8) for performing preliminary surveys with GPR before laying underground utilities and infrastructures [8].

The use of GPR in civil engineering applications began to appear in the mid-70s and early 80s, mainly focused on the detection of hidden utilities [9-12] and pavement inspection $[13,14]$. From these first studies, the number of applications and developments of the methodology increased remarkably, being nowadays successfully and widely employed for a great variety of tasks. A comprehensive overview on the civil engineering applications of GPR can be found in [15-17].

GPR surveys in pavements (rigid or flexible) are frequently applied as a complementary technique for the assessment of roads and airport pavements. GPR images provide valuable information about the continuity of layers and their thickness, which could be combined with falling weight deflectometer (FWD) tests. In addition, GPR inspection allows for the analysis of the pavement layer's condition and locating defects, which is crucial in preserving the structure and its service life. In road assessment, the main analyses are focused on measuring layer thickness and detecting voids or delamination. Other, more recent studies are dedicated to the detection of water presence, mainly in the base and subgrade. Quality studies of the material density, water infiltration and cracking are also some examples of the applications that have been recently tested. Most of those researches are based on the analysis of the GPR images through the two-way travel time conversion into depths and the reflected wave amplitude analysis. However, during the last few years, several tests were prepared to determine additional parameters by studying frequencies.

For railway assessment, the main applications consist of ballast layer thickness measurement and detection of changes in track structure and substructure. During the last decade, a huge research effort has been carried out to improve the systematic application of GPR for ballast condition assessment, such as ballast fouling and moisture content.

In the study of retaining walls, GPR focuses on the detection of rebar in concrete retaining walls, detecting joints and dowels, and the location of damage and water infiltration. In some cases, the GPR analysis objective is the detection of the contact between the wall 
and the natural soil or between the wall and further restorations. Other applications are the detection and the analysis of the foundations. Those walls support high loads and the assessment of their state is important in maintaining or repairing parts of the structure.

Regarding masonry bridges, the main GPR applications comprehend the detection of unknown geometries such as hidden arches and ancient profiles, restorations and reconstructions in stonework, moisture content in masonry, bridge foundation, voids and cracks in masonry, filling distribution, and thickness of ashlars (e.g., voussoirs). Concerning concrete bridges, GPR evaluation encompasses the diagnosis of bridge-deck thickness, mapping rebar and tendon ducts, moisture content, corrosion assessment, and mapping delamination.

Finally, in tunneling inspection, the applications of GPR include the assessment of concrete segments and backfill grouting thickness, reinforcement, damages (e.g., cavities) in lining, moisture content and corrosion.

This paper presents a review of published works in the frame of GPR application in the evaluation of transport infrastructures, including roads, highways, airport runways, railways, retaining walls, concrete and masonry bridges, and tunnels. Although it has been demonstrated that GPR has significantly benefited the procedures for inspection and successfully solved some of the limitations of traditional methods, it also has some constraints. In order to maximize the benefit obtained through the use of GPR, it is important to be aware of these constraints and to be able to adapt the methodologies for testing and for analysis of the results to the job's specific conditions. Thus, through the review of the methodologies shown by other authors in the literature, the present paper highlights some of these best practices and recommendations (type of antennas, setting parameters, acquisition mode, processing, etc.). Moreover, some recommendations are made in terms of best practices aiming to improve the application of GPR and to avoid the misinterpretation of results.

As Supplementary Materials, different tables are addressed with a compilation of interesting published works carrying out the on-site survey of transport infrastructures. Those present a synthesis on GPR equipment, inspection methodologies, and set parameters for data acquisition and data processing, as well as the most relevant results obtained and the drawbacks identified.

\section{GPR Equipment for Transport Infrastructures Surveying}

There are several GPR manufacturers and commercial equipment available, and some experimental prototypes also exist. Different GPR systems will have different capabilities according to the type of antennas and their frequency, which affect the operating speed, the resolution, the penetration and the sampling rate $[17,18]$. The frequency and depth of penetration are related, with higher frequency pulses achieving lower penetration, but better resolution. Impulse GPR systems are the most widely used, with two main groups of GPR antennas, dipole and horn antennas, and with frequencies nowadays ranging from $10 \mathrm{MHz}$ to $6 \mathrm{GHz}$. Currently, the most commonly used technology is the time-domain impulse radar. Additionally, several investigations point to the step-frequency radar as a potential technology for broad resolution range, although these systems do not allow real-time visualization of data during acquisition.

It should be noted that there are technical standards regulating the electromagnetic emissions of GPR equipment. The following are the main standards in Europe, USA and Canada: European Telecommunications Standard Institute (ETSI) EN 203 066-1, ETSI EN 203 066-2, ETSI EN 203 489-32 and ETSI EG 202 730, USA regulations on UWB-GPR: Part 15 of Federal Communications Commission (FCC) Regulations, and Industry Canada Radio Standards Specification RSS-220 (Issue 1) “Devices Using Ultra-Wideband (UWB) Technology.

\subsection{GPR with Horn Antennas}

GPR horn antennas were specifically designed for use in transport infrastructures evaluation, since they can operate at traffic speed. In the last ten years, this type of equipment has evolved from prototype status to routine use in pavement evaluation studies. 
Horn antennas have frequencies ranging from 1 to $2.5 \mathrm{GHz}$, corresponding to penetration depths in the order of $1 \mathrm{~m}$ to $0.4 \mathrm{~m}$, respectively. The minimum layer thickness that can be detected is about $50 \mathrm{~mm}$, for $1 \mathrm{GHz}$ antennas and $25 \mathrm{~mm}$, for the higher frequencies.

The antennas are "air-coupled", and normally they work mounted on a mobile vehicle and are suspended at a certain distance from the surface (Figure $1 \mathrm{a}, \mathrm{b}$ ), typically ranging from 0.4 to $0.6 \mathrm{~m}$. They perform measurements at traffic speeds (up to $80-120 \mathrm{~km} / \mathrm{h}$ ) without any interference with traffic, and therefore they are suitable for the evaluation of in-service pavements without major disturbance to road users.
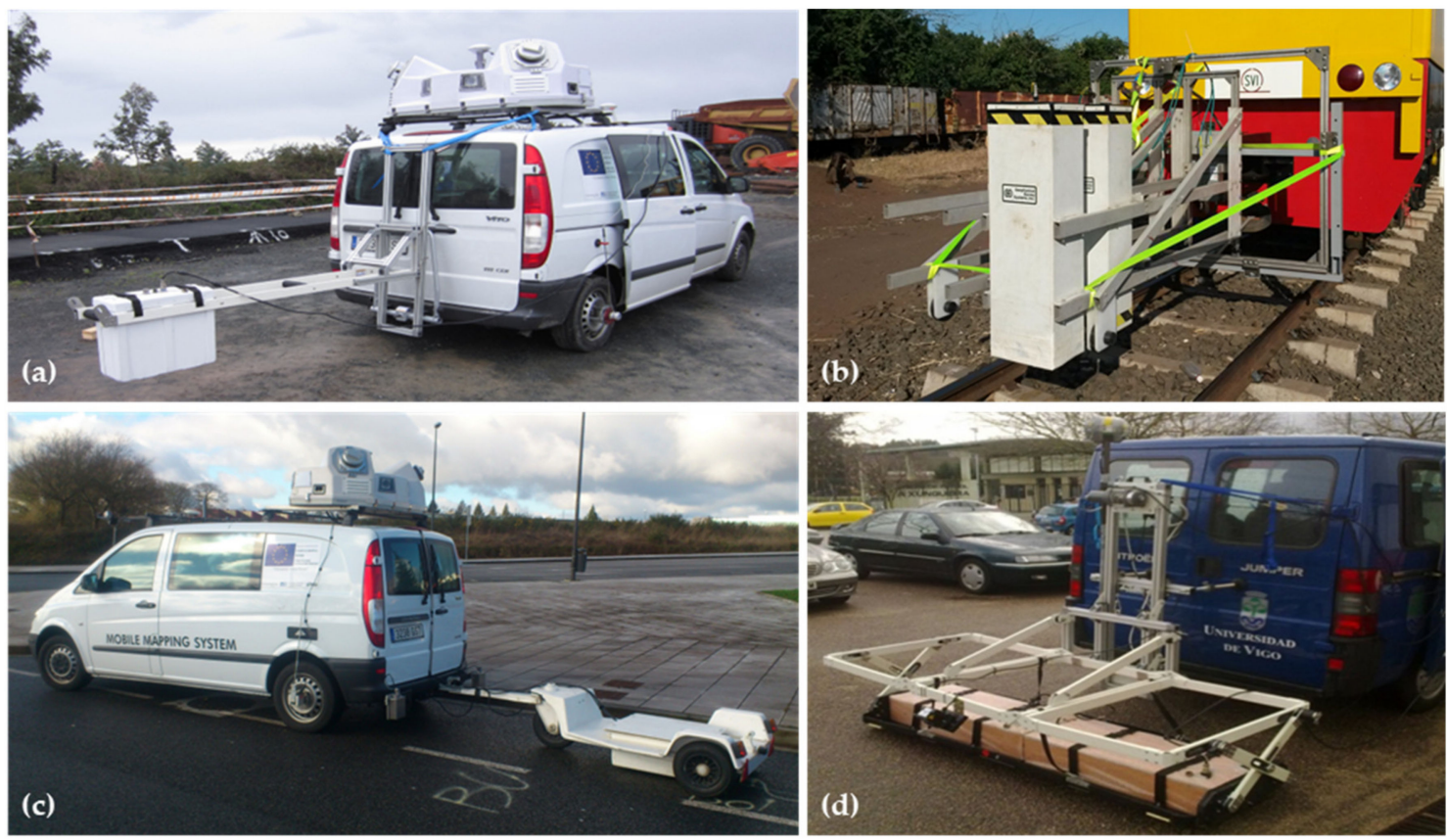

Figure 1. Different ground penetrating radar (GPR) antennas: (a) air-coupled (horn) antennas, (b) multi-antenna system (horn), (c) ground-coupled (dipole) antennas in a trolley, and (d) array multi-channel (ground-coupled) antennas.

\subsection{GPR with Dipole Antennas}

Dipole antennas were primarily developed for use in geological survey, normally ground-coupled (Figure 1c). They have frequencies ranging between $10 \mathrm{MHz}$ and $6 \mathrm{GHz}$. For transport infrastructure applications, the best results are obtained with antennas from $400 \mathrm{MHz}$ to $2.5 \mathrm{GHz}$ central frequency. In general, the higher the frequency, the lower the penetration depth and the higher the resolution is. For example, $1.5 \mathrm{GHz}$ dipole antennas will give a penetration depth of $0.50 \mathrm{~m}$, while the $400 \mathrm{MHz}$ will give a penetration of $2.00 \mathrm{~m} \mathrm{[19]}$.

Dipole antennas were mainly developed for use in contact with the surface, or suspended just above it $(2-5 \mathrm{~cm})$, and they are suitable for testing at maximum speeds of $20-30 \mathrm{~km} / \mathrm{h}$. In this condition, the radar signal is "ground-coupled". Ground coupling introduces a stronger signal into the pavement, and therefore these antennas are normally employed for detailed studies over limited areas, as they allow one to obtain higher resolution [20].

\subsection{GPR with Antennas Array Multi-Channel}

GPR array multi-channel systems consist of a large number of closely-spaced antennas recording at the same time. Different multi-channel prototypes have recently been provided with different configurations, and they can include both air- and ground-coupled antennas (Figure 1b,d, respectively). Commonly, such multi-static systems are composed of 4-16 couples of transmitting and receiving channels mounted in a parallel broadside configuration with a cross-line trace spacing of $4-12 \mathrm{~cm}$, depending on the manufacturer. 
The main advantage is that they enable faster data collection by increasing the extension of the investigated area per time unit, and they make it easier for the operator to produce 3D images.

Generally, in transport infrastructure inspection, the antennas are mounted on a mobile vehicle to minimize traffic disruption. Mobile GPR is positioned connected to an external real-time kinematic (RTK) global navigation satellite system (GNSS) for trace tagging (georeferenced data) or to a distance measurement indicator (DMI) to control the distance trace-interval and to measure the travelled distance. The system also uses a computer navigation guided system to correctly follow profile direction and keep a constant overlap among parallel profiles without any physical marker on the ground surface.

\section{Overview on GPR in Roads and Airports}

Mobility and communications are the axis of our society's development. Road transport and planes move population and merchandising, being crucial for the development of industry and the cities. The roads and airports are the infrastructures that support this high level of activity. The safety and the efficiency of the transport and communication routes require detailed maintenance plans. The plans must include detailed inspection of infrastructures and development of maintenance strategies based on this information. Damage due to age, traffic and weather highly affects this type of infrastructure and, without a careful conservation and maintenance strategies, can lead to significant financial losses and can cause accidents. Roads and airports are two types of pavement structures designed to support different kinds of vehicles. Generally, the pavement consists of several layers: the surface course (asphalt or concrete layer), the base course (usually an asphalt base layer) and the subbase course (an unbound aggregate layer). This structure is supported by the natural subsoil (subgrade layer). The number of layers and their thickness depend on the type of pavement, being different in the case of roads, airports and industrial and harbor platforms (slabs). The airport pavement layers' thicknesses are always higher than in the roads. Depending on their structure, it is also possible to distinguish between rigid, flexible and semi-rigid pavements. In the first case, the surface layer is a reinforced concrete slab (although in some cases it is overlaid with an asphalt course, becoming a semi-rigid pavement) laid over a lean concrete layer. In the case of flexible pavements, the surface course is an asphalt layer. Differences in the structure of pavements yield on differences in the pavement behavior. Deformation in flexible pavements due to normal traffic loads is generally recoverable, whereas degradation due to excessive loads in rigid pavements are permanent. Changes in temperature also induce stress in rigid pavement and significantly affect the asphalt layers' moduli that decrease with an increase in temperature, due to the viscoelastic characteristics of this material. However, the strength in the case of flexible pavements depends also on the strength and quality of the subgrade soil, whereas in the case of rigid pavements, this only depends on the concrete layer design. Therefore, rigid pavements are usually used in zones with soils that present an inadequate support condition, in bridges or to cross voids or failure zones.

The requirement in many cases of surveying without interrupting the use of roads and airports forces the use of non-destructive tests that, at the same time, can be carried out without obstructing or disturbing the traffic [21,22]. GPR assessment in flexible pavement rehabilitation is recommended in the American Association of State Highway and Transportation Officials (AASTHO) guides [23], in combination with the use of FWD to obtain the thickness and the strength of each layer. In addition, GPR evaluation is frequently used to complement the studies about the structural conditions of pavements, detecting defects that affect their service life and preservation. The study of defects in pavements by means of GPR began at the end of the 20th century. The first studies allowed one to determine the contact between the asphalt and base layers, being difficult to distinguish thinner layers and details [24]. However, the studies about the relation between the GPR images and the material parameters [25-27] allowed for the application of the technique in the assessment, focused on particular aspects such as the material density for quality controls [28], control 
of layer thickness [29-31], detection of voids [32], measuring the depth to damage, and the detection of contact between rehabilitated (new) and old pavement [33]. Figure 2 presents an example of GPR data obtained in the assessment of roads with the objective of detecting possible voids in the ground, under the structure of the pavement.
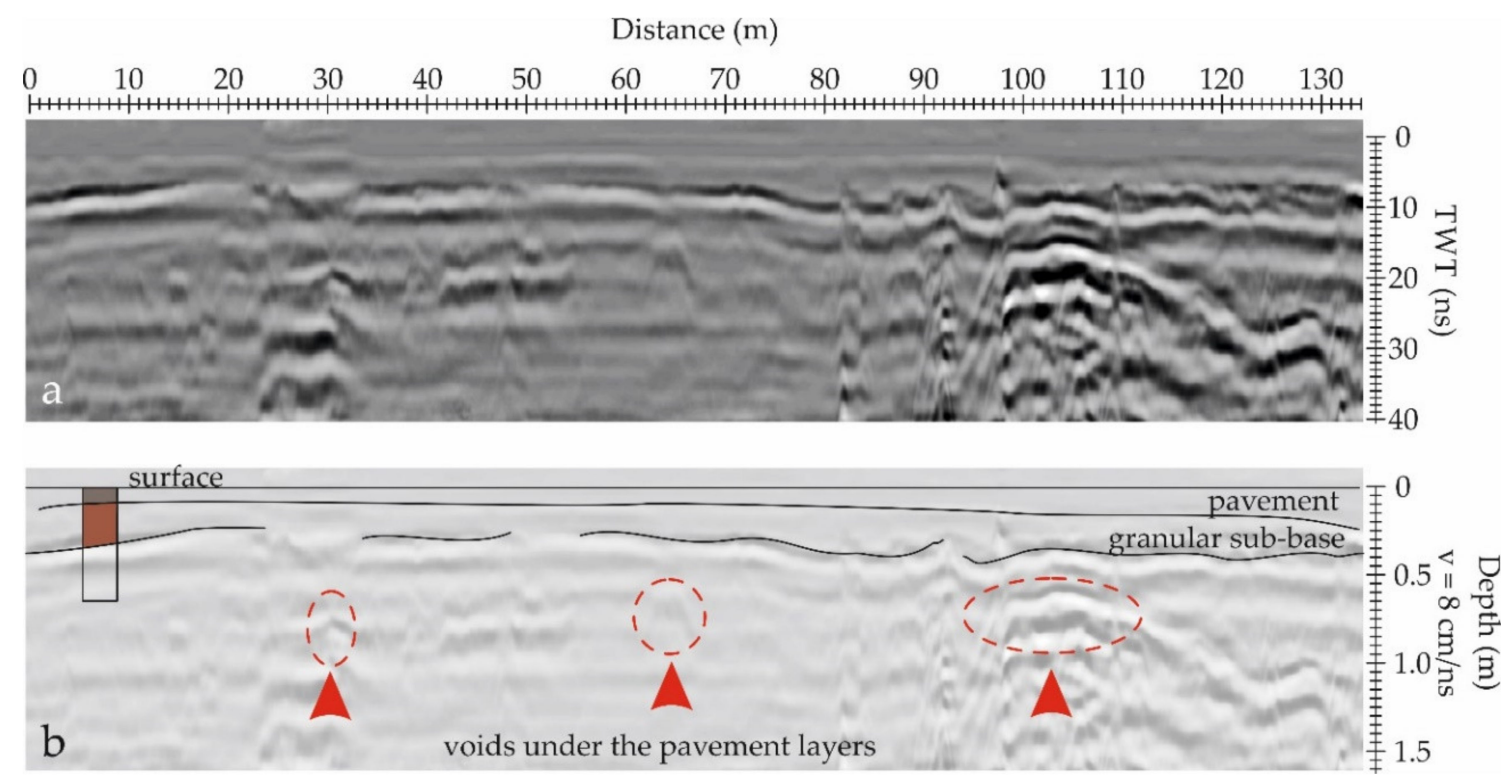

Figure 2. Detection of voids under the structure of the pavement with a $400 \mathrm{MHz}$ center frequency antenna. Red arrows indicate the location of the anomalies associated to voids under the granular subbase, but the different layers of the pavement cannot be distinguished. (a) Radargram and (b) data interpretation.

More recent applications were focused on the damage and water infiltration detection in order to analyze the bearing capacity of the pavements, highly affected by the water content underneath the asphalt [34,35]. They also include the detection of pavement layers [36-38], the analysis of material density [39], cracking analysis [40-42], water detection [43-45], and the analysis of drainage structures under pavements [46]. Other recent studies have analyzed the effect of moisture in GPR amplitudes and frequencies $[47,48]$ or delamination $[47,49]$.

\subsection{Roads}

GPR application in roads is mainly focused on the assessment of flexible pavements as a complementary survey combined with more traditional methods: visual inspection, drilling and sampling, deflections and dynamic response monitoring systems. In some cases, GPR is also combined with infrared thermography, laser scanning and accelerometers. The application of this geophysical method in the assessment of pavements is regulated and recommended in the AASTHO guides [23]. Moreover, the guide ASTM D4748-98 [50] presents the procedures for the inspection of the upper layers of both bituminous and concrete pavements, using a short-pulse GPR. The methods included in this international standard are focused on the thickness evaluation of pavement layers. The report presents the functioning principles of a short-pulse radar and the test equipment configuration. Therefore, the guide includes technical topics such as calibration and standardization, procedures, calculation and reliability of the results. The document also emphasizes the importance of safety issues in GPR survey activities, since the apparatus involves potential microwave radiation hazard. However, the different characteristics of countries have driven the European Nordic countries to develop the Mara Nord Project, in order to provide recommendations and guidelines for the use of GPR in road construction quality control [51]. This project started in 2009 and involved several research units such as universities, national transport administrations, road rehabilitation and consultant companies, 
and GPR manufacturers from Finland, Sweden and Norway. The goal of this project was to define common criteria for the equipment standards and for the results requirements.

The European Cooperation in Science and Technology (COST) Action TU1208 has published some tests and recommendations for suitable GPR system performance compliance, obtained by scientists from Belgium (Belgium Road Research Center), Czech Republic (University of Pardubice), Portugal (National Laboratory for Civil Engineering), and Serbia (Faculty of Technical Sciences, Novi Sad) [52]. The D6087-08 standard, emitted by the ASTM [53], describes four procedures for the calibration of GPR systems equipped with air-coupled antennas. After a critical analysis of those procedures, four improved tests were proposed, which can be carried out to evaluate the signal-to-noise ratio, short-term stability, linearity in the time axis, and long-term stability of the GPR signal.

GPR is also applied in the assessment of rigid pavements, with one of the main objectives being the identification of metal bars and layers thickness [54], and measuring the rebar cover depth [55]. The assessment to detect damage such as cracking and voids is another application in rigid pavements $[41,42,56]$. These studies are mainly focused on the detection of damage areas, but in some cases the origin of the damage is also investigated, including the effect of roots in pavements [57] and the impact of weather and load conditions. Figure 3 presents an example of GPR data acquired in a rigid pavement, showing the location of the rebar and the cover depth, besides the different layers and cracking.

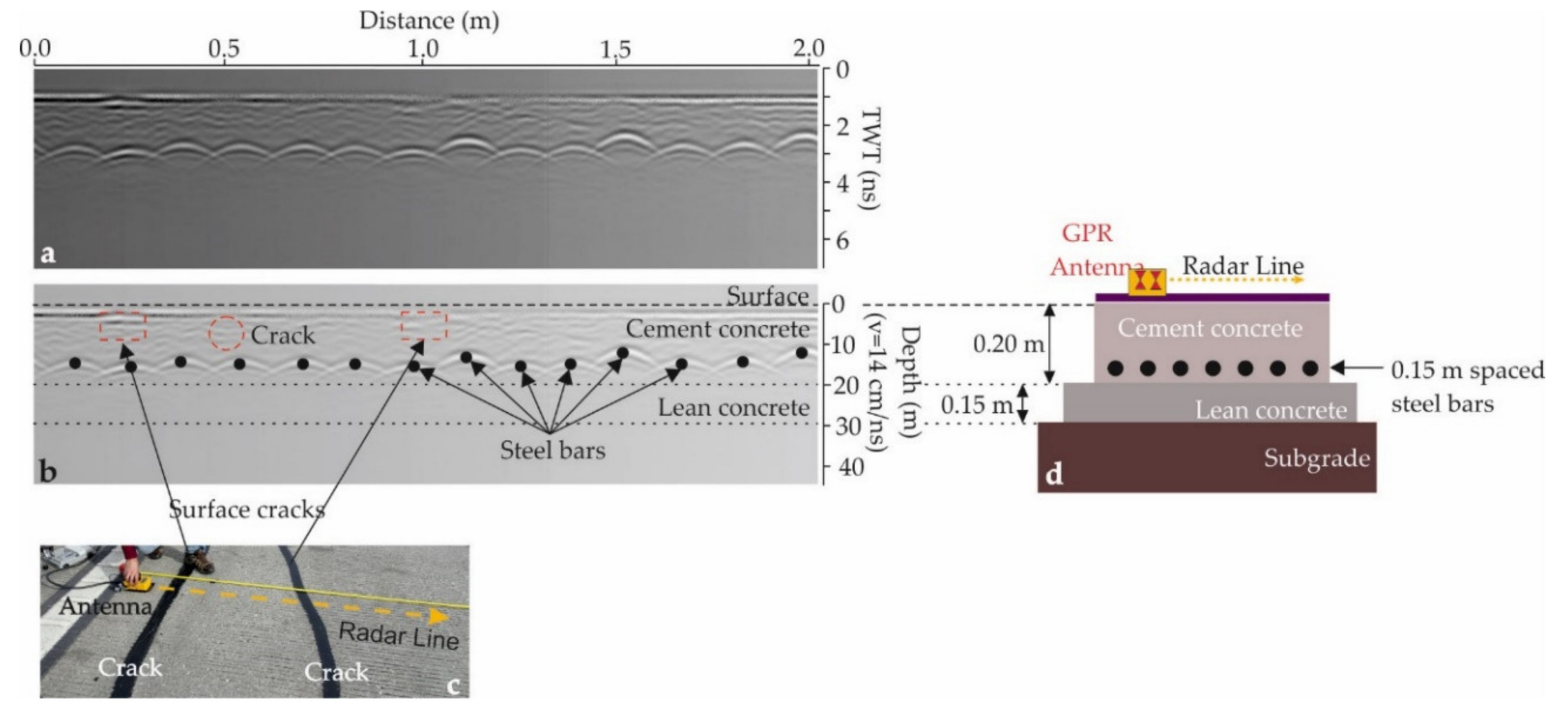

Figure 3. Results obtained in the study of rigid pavement. (a) Radargram. (b) Data interpretation highlighting the existence of cracks also visible at pavement surface (c) and cracks in the deeper layers, not yet visible. Moreover, image (b) shows the location of the rebar, the cover depth and the thickness of the different layers, obtaining a final model of the structure (d) (adapted from Rasol et al. [56]).

To summarize, GPR applications in pavement are mainly focused on:

- Measuring layer thickness [30,36,38,58-63].

- Detection of cracks and voids under the pavement, including the analysis of possible causes (weather, loads, roots, etc.) [40,56,57,64-68].

- Quality control of asphalt, mainly in the case of new pavement [69-72].

- Moisture and changes of water content detection [34,43,48,73,74].

Table S1, in Supplementary Materials, presents a compilation of the relevant on-site survey of roads.

\subsection{Airports}

The GPR assessment of airport infrastructure has the same objectives as road inspections. Most of them are focused on the detection of anomalies that could indicate damage 
in the airport runways, taxiways and apron pavements. The main difference between road and airport pavements is the layer thickness that in the case of an airport can be about $0.50 \mathrm{~m}$, while in highways and roads is about $0.30 \mathrm{~m}$ [75]. The structure in airport pavements is composed of asphalt, concrete or reinforced concrete slabs. Moreover, the pavement of airport runways has a greater durability due to the higher content of asphalt bitumen. This infrastructure is designed to support the load due to the weight of the airplanes (between $70 \mathrm{Tn}$ and $420 \mathrm{Tn}$ ). The highest loads are supported the top (headland) of the runway where the airplanes accelerate when starting the take-off and stop after landing.

Despite the great loads supported by this infrastructure and its importance in communication and transport, the examples of GPR assessment of airports that can be found in the literature are less than those found on roads. In most of those examples, the objective is determining a procedure for the location of rebar and recognition of cracks and voids (in and under the concrete slab) [76-80]. Cracks wider than $1 \mathrm{~mm}$ are also detectable [81]. Other studies are focused on the detection of pavement structures and layers, detecting the dowels, joints and expansion joints [77] and different layers thickness [75,82-84]. GPR is also used to evaluate the quality of grouting treatments [78] applied to stabilize damaged pavements. GPR is also used in the assessment of the asphalt layers' interfaces to detect debonding $[75,85]$. Other studies were focused on the analysis of airports under special conditions: (i) in the case of airports built over the sea, in order to detect the contact between the filled layers and the natural soil under the sea [86]; and (ii) in the study of airports in frozen areas, in order to detect the depth to the permafrost layer [87].

To summarize, the main applications in airport pavements are focused on:

- Measuring layer thickness [75,77,82-84].

- Detection of cracks and voids in pavement $[76,79,81,88]$.

- Detection of thin cracks [81].

- Quality control of restoration treatments [78].

- Thickness of filling layers in special airports [86].

- $\quad$ Detection of debonding [75,85].

- $\quad$ Depth to permafrost layer [87].

- $\quad$ Structures in the pavement [77].

- $\quad$ Detection of rebar in reinforced concrete pavements [80].

Table S2, in Supplementary Materials, presents a compilation of the relevant on-site survey of airports.

\section{Overview on GPR in Railways}

The railway (railroad in USA English) is a transport infrastructure energetically efficient and environmentally friendly, and it is gaining more and more importance for passengers and freight transport. The railway network use is increasing and, consequently, not only the deterioration under traffic load is higher, but also the time window available for monitoring and maintenance actions is becoming more restricted. The maintenance has to be well planned, due to the impact that it has on the railway users' comfort and safety, and to enable it, a proper inspection is essential. In this context of efficient and expedient monitoring, NDT such as GPR represents a powerful tool to assess the track condition. The information gathered with GPR is generally used together with other track inspection results, such as track geometry and both rail shape and rail integrity measurements. While the track geometry and rail condition data give an indication of track deterioration, GPR survey provides the identification of the real cause of deterioration, such as changes in structure, settlements, ballast fouling and drainage problems. The information provided by GPR is therefore crucial for the definition of efficient maintenance action and depth of the intervention, mainly if the deterioration is due to substructure defects. Some examples of GPR application to railway assessment are shown in Figure 4. 


\subsection{Ballasted Railways (Superstructure and Substructure)}

One of the first studies of GPR application to railway was performed in late 90s by Sussmann [89]. Several studies were developed since then, some of them referred to herein. Nevertheless, there are only a few guides and standards for GPR application to railways [90].

On railways, a major limitation to the systematic application of GPR is the presence of the rails, as it is a metal, and consequently an ideal reflector that can shadow the information gathered in the subsurface. To overcome this, dedicated antennas and software were developed for railway assessment [91,92], which are discussed later in this paper.

The main applications of GPR for railway infrastructure evaluation are:

- Layer thickness measurement, mainly ballast [92-96].

- Investigation of embankment defects and moisture [92,94].

- Location of ballast pockets, subsidence and trapped water areas $[92,93,95,97]$.

- Frost susceptible areas $[98,99]$.

- Fouled ballast assessment [100-104].

In order to support the knowledge and to calibrate the on-site surveys, several laboratory and real scale tests were performed, such as:

- Track substructure assessment, layer thickness (experimental test sections) [105].

- Ballast condition characterization, fouling and fragmentation (experimental test sections) $[101,106]$.

- $\quad$ Fouled ballast assessment (laboratory tests) [101,107-110].

- The influence of concrete sleepers on the assessment of ballast condition (laboratory tests) [111].

\subsection{Ballastless Railways}

The objectives of GPR application on a ballastless track are similar to other concrete reinforced structures, such as rigid pavements and bridge decks. The main applications are:

- $\quad$ Layer thickness measurement [112].

- Rebar detection [112].

- Mud detection under the slabs [113].

- Debonding between sleepers and slabs and between layers [112].

Table S3, in Supplementary Materials, presents a compilation of the relevant on-site survey of railways. 
a)

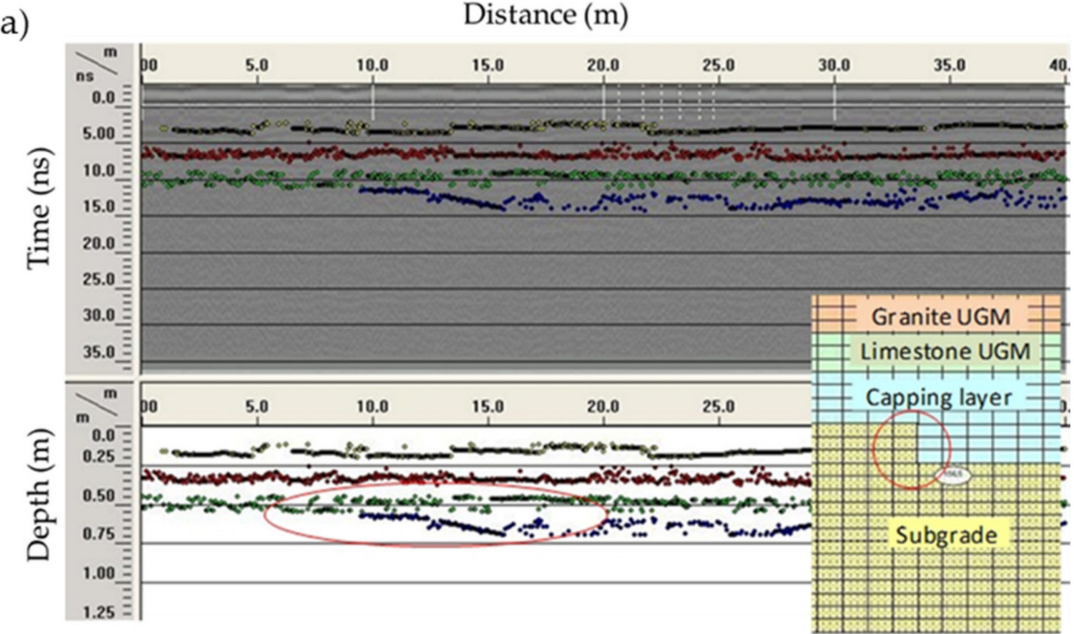

b)

Distance (m)

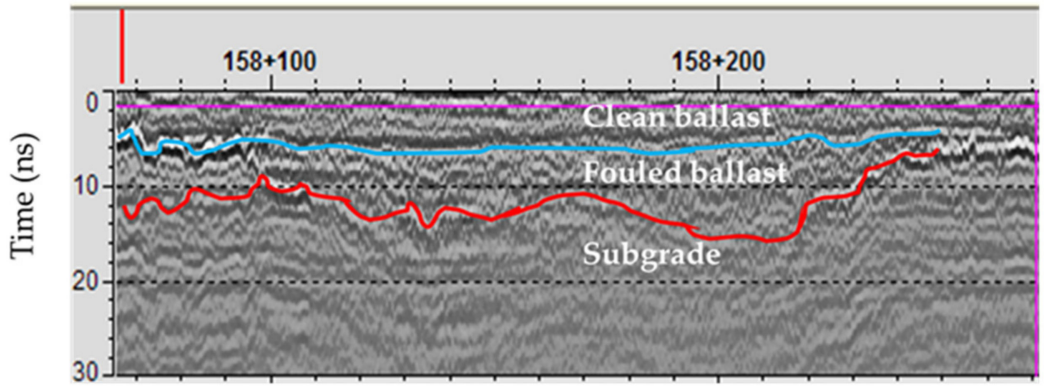

C)

Distance (m)

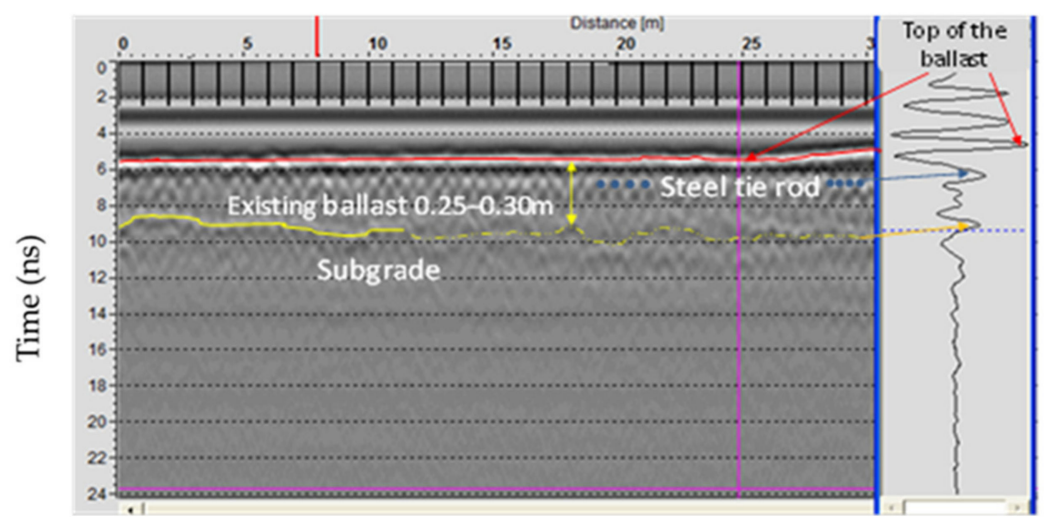

Figure 4. Example of information obtained by GPR surveying on a ballasted track $(1.0 \mathrm{GHz}$ aircoupled antenna): (a) subballast thickness and continuity in the Alcácer Bypass (Portugal) showing an increase in capping layer thickness (red ellipse); (b) an in-service national railway line (Portugal) displaying the interfaces between the clean ballast/fouled ballast/subgrade where the settlement location is evident due to weak subgrade (adapted from Fontul et al. [95]); (c) GPR record of an in-service railway line showing the metal reflection of a steel tie rod. (UGM means Unbound Granular Material).

\section{Overview on GPR in Retaining Walls}

Retaining walls are structures prepared to support the soil laterally, in order to avoid landslides. Those structures retain the soil behind them and are designed to support high pressures due to the tones of the materials. The pressures, in most cases, are increased as a consequence of soil water content. This type of structure allows one to define different levels of soil, and in most cases are indispensable constructions in roads, bridges, tunnels or railways. Depending on the construction, there are different types of retaining walls. Some of the most usual types are: 
- Gravity retaining walls, which are massive and require a significant gravity load to be stable under the soil horizontal pressures. These structures can be built with concrete, masonry, stone or precast concrete boxes filled with coarse material structures.

- Cantilever retaining walls that are usually built using concrete and reinforced with prestress concrete. These walls are composed of the stem and a base slab as a foundation. This is the most usual type.

- Anchored retaining walls, composed of the stem and cables anchored with concrete in the ground.

- $\quad$ Piled retaining walls, built with adjacent piles, making a wall.

As a consequence of aging, degradation of materials, changes in the loads (due to variations in the water content or in consequence of the construction of other structures) or changes in the temperature and moisture, the walls can suffer different levels of damage, leading even to the collapse of the structure. The detection of the pathologies reduces the possibility of the structure failure. The assessment of those walls requires the study of the structure and the analysis of the interaction between the structure and the soil. The inspection of the structures for retained soil requires the assessment of the wall that determines the decisions about the structure (repair, maintenance, change or frequency of future inspections). The assessment involves the visual inspection and simple sonic and thermographic tests. Depending on the results, more invasive tests could be needed.

Non-destructive inspection techniques are currently applied to obtain valuable information about the state of the wall. GPR is a promising technique in this field. However, the application of GPR to vertical structures still requires development. The US Department of Transportation prepared a guide for retaining wall inspection [114], including GPR as a possible technique that requires further analysis and improvement. The assessment of those structures requires the analysis of the wall conditions (damage, moisture, rebar), the study of the soil (mainly water content) and the evaluation of the supporting structures (cables and anchors) and the foundations. Therefore, the GPR applications in retaining walls focus on the detection of the rebar in concrete retaining walls [115], detecting joints and dowels and obtaining high quality 3D models [116]. The studies define the limits of the method, showing a clear first layer of rebar and a low-quality image of the second rebar layer [117]. Figure 5 presents two examples of the reinforced wall inspections. In both cases, the rebar is detected and several anomalies highlight the existence of possible damage.

Only a few applications in masonry retaining walls can be found in the literature. Those applications are based on detecting the contact with the natural soil, estimating the thickness of the structure, and changes due to old repair works and the inner structure [118], including the foundations [119]. Although in many cases, GPR data is acquired with the antenna on the surface of the wall, in some cases, the analysis of the wall acquiring data from its top part (Figure 6) could provide information about the number of stone rows and the contact between ashlars [120]. Figure 6 shows the image and the interpretation of the GPR data. In the study of those walls, the velocity could be estimated from the hyperbolas produced at the contacts between stones.

In some cases, the retaining walls are part of subterranean structures, as in the case of some Mycenaean tombs [121]. Those structures are composed of irregular stones, in two or more layers. Figure 7 is an example of the GPR images that can be obtained in this type of retaining wall. The different stone layers could be detected, and the irregular pattern of anomalies in the GPR images corresponds to the uneven stones. In addition, changes in the amplitudes could inform about the variations of physical of chemical properties of the ground or the structure, highlighting zones that could be damaged or that must be restored. 

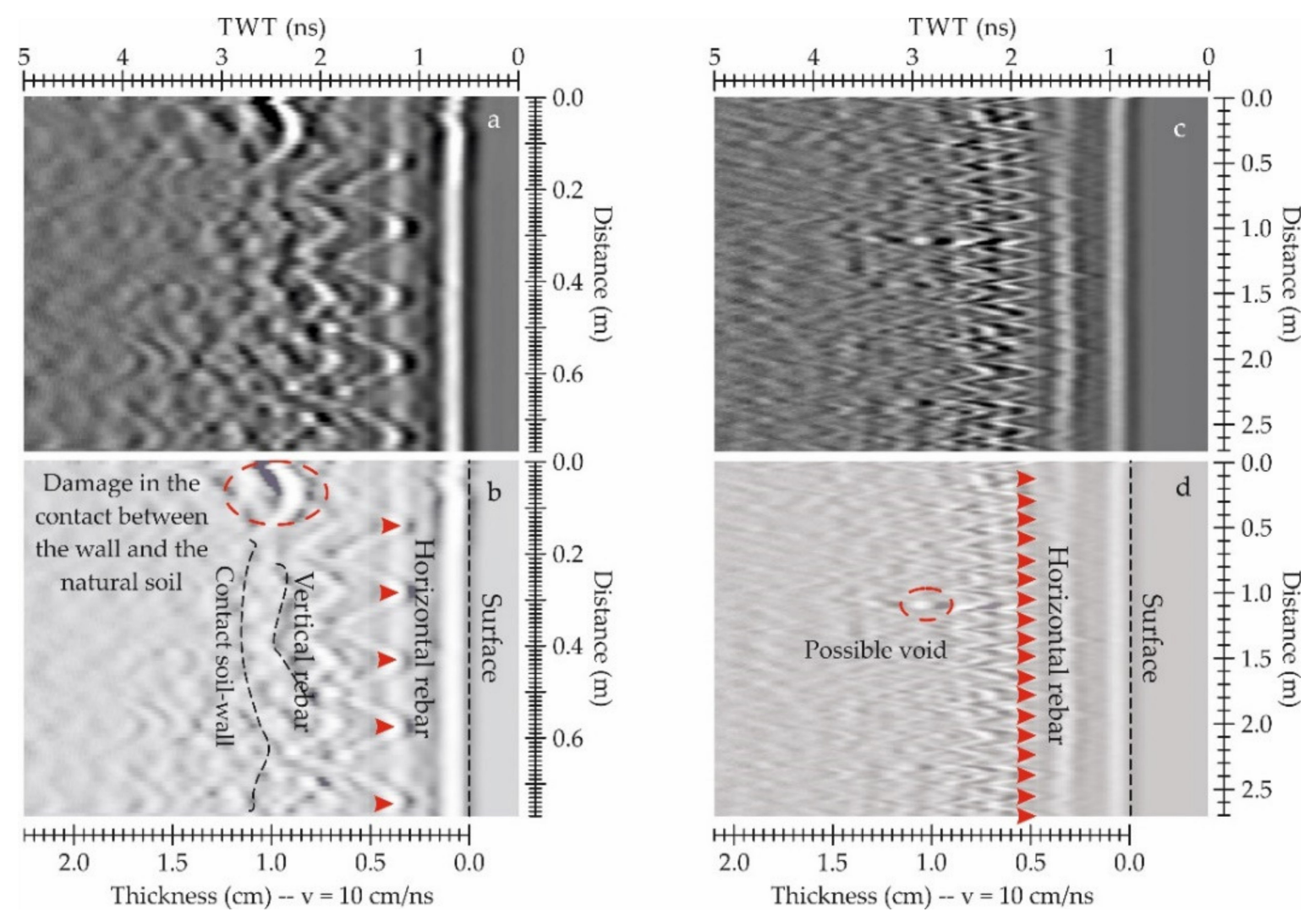

Figure 5. Two examples of GPR images (a and $\mathbf{c}$ ) obtained in reinforced retaining wall assessments with a $2.3 \mathrm{GHz}$ antenna. Both cases focus on the detection of the rebar and the location of zones with possible damage (b and $\mathbf{d}$ ).

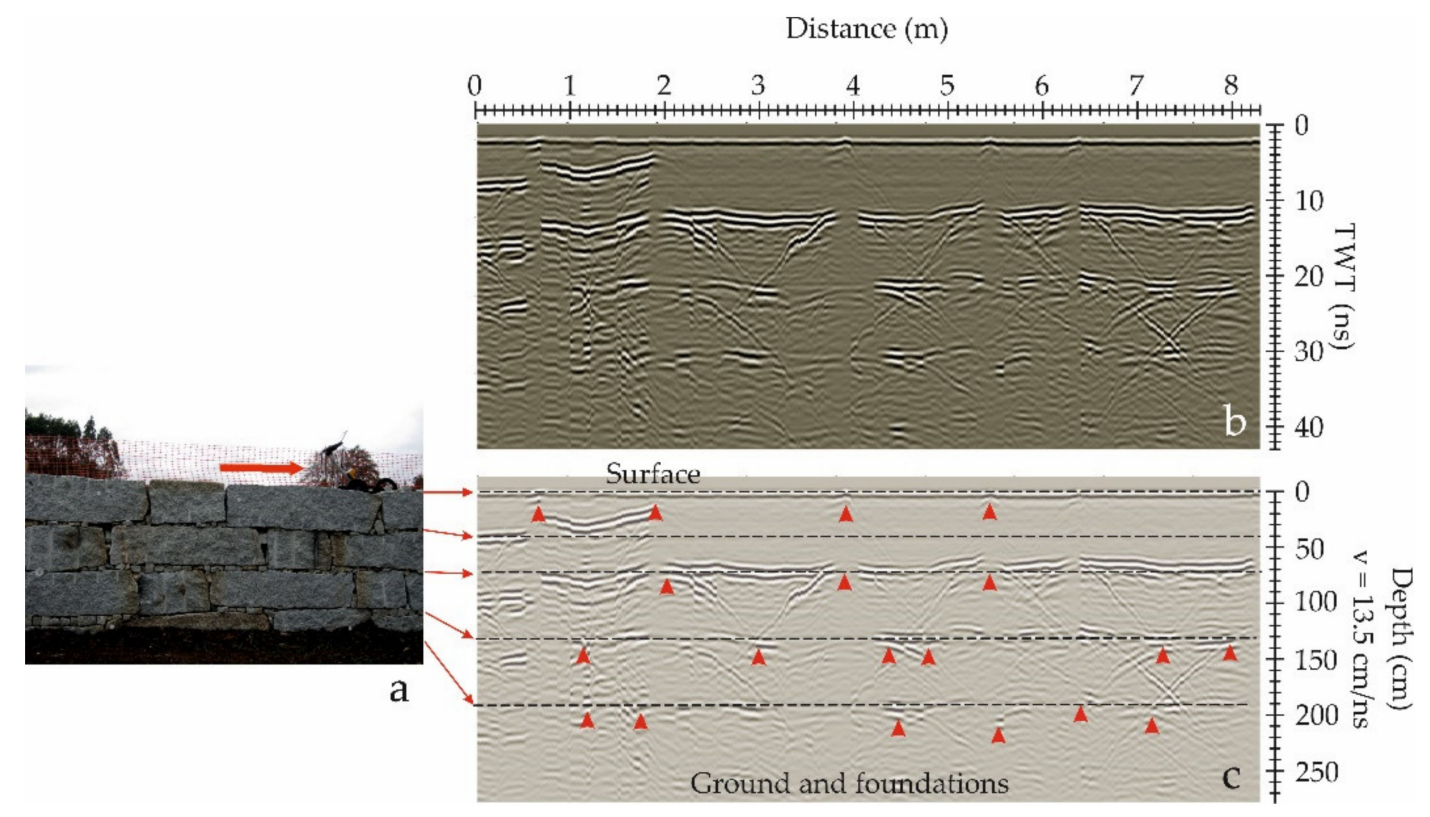

Figure 6. GPR assessment of masonry walls composed by granite ashlars. (a) The data were acquired from the upper part of the retaining wall. (b) GPR image. (c) Interpreted radargram, showing the contact between the different rows of ashlars and the anomalies produced by the contact between stones (red arrows) (adapted from Solla et al. [120]). 

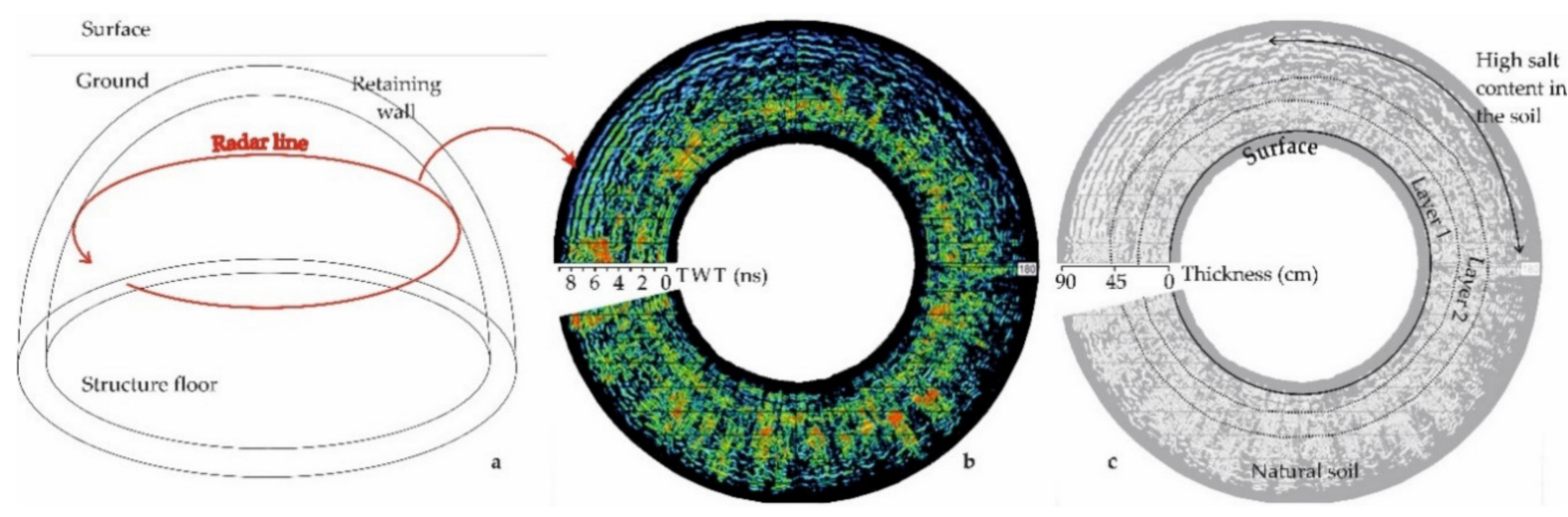

Figure 7. GPR images from the study of the retaining walls in a subterranean tomb (adapted from Santos-Assunçao et al. [121]). (a) Scheme of the structure and location of the profile line (in red). (b) Processed GPR image. (c) Data interpretation. The wall is composed of two layers of uneven stones. The contact with the natural soil is detected and the changes in the amplitude denote changes in the soil salt content, which could affect the preservation of the structure.

A particular type of retaining wall is used as a support system in deep excavations in the case of unstable soils or shallow water table. Those walls are built with concrete in different construction phases and in different sections inside the ground. The soil is excavated until the depth of the constructed section and, after that, the next section of the wall is built. This process continues until the excavation is complete. Prior to the excavation, the assessment of the already constructed wall section increases the safety of the process. Borehole GPR is a reliable method in this quality control process. The GPR images provide information about the integrity of the underground retaining wall, showing zones that must be repaired before excavation, such as damage or voids in the ground in contact with the structure that could lead to the collapse during the excavation procedure. Figure 8 shows an example of a borehole GPR image in the retaining wall during an excavation. The objective is the detection of both wall surfaces, the possible defects and voids in the concrete and in the ground behind the wall, and zones with possible changes in water content.

To summarize, the main applications in retaining walls depend on the type of the structure. However, the detection of the contact between the natural soil and the wall in order to identify possible voids, and changes in humidity or defects on the surface of the wall, is a common application in all types of walls. In masonry walls, the common objectives of surveying are the analysis of layers, the contact between blocks, and the assessment of foundations. Conversely, in concrete walls the main goal focuses on the detection of the rebar and possible defects that occurred during the construction of the wall.

Table S4, in Supplementary Materials, presents a compilation of the relevant on-site survey of retaining walls. 


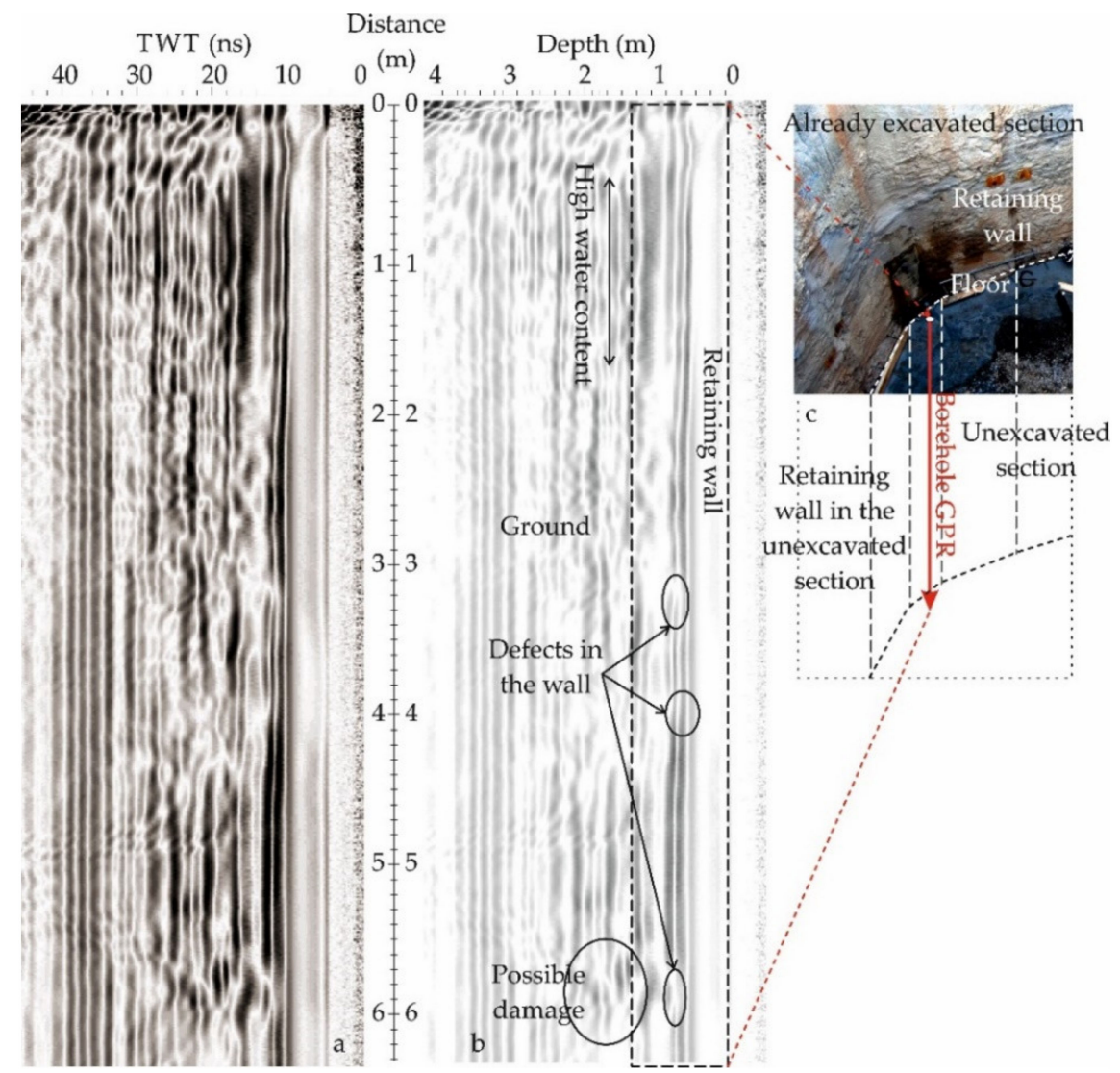

Figure 8. Borehole GPR images. (a) Radargram. (b) Data interpretation. (c) The excavation and the position of the GPR borehole. The images allow one to determine the contact between the wall and the ground, as well as zones that must be repaired or reinforced before the excavation.

\section{Overview on GPR in Bridges}

Bridges are considered vital to human life because they connect different lands and facilitate economic, industrial and social development. However, a great majority of these structures, in operation within the transportation system, require desperate repair and maintenance strategies. The condition monitoring of bridges focuses on detecting material degradation and structural pathologies aiming to accurately assess the safety and service life of existing structures. Conventionally, diagnosis is accomplished by visual inspection and assessment can therefore be difficult as there is structural design and damage of the structure inaccessible and hidden from view. Indeed, the GPR method is one of the non-destructive techniques most used in internal bridge inspections [122-126], due to its high practicality in the field in a relatively quick time and with the minimum intervention without affecting the structure's integrity. Internal damage detection can prevent the unpredictable and premature collapse of structures.

This section provides an overview of the main GPR applications on the condition monitoring of both masonry and concrete bridge structures.

\subsection{Stone Masonry Arch Bridges}

A large number of the existing masonry arch bridges still in use within the transportation network are ancient structures remaining from Roman and Mediaeval periods. In addition to their age, and environmental conditions, the stability of these bridges (both road and railway bridges) is questionable because of the actual loading, significantly higher than the estimate for their original design [127]. Consequently, they require periodic inspections of the changes in the structural condition, aiming to develop effective preventive and maintenance tasks. 
The use of NDT technology becomes essential for the health assessment of these former structures in order to preserve their historical character and structural integrity. In this context, the GPR method has been demonstrated as effective for the diagnosis of masonry arch bridges, in which the detection of the following characteristics was possible:

- Unknown geometries remaining in the interior of the bridge such as hidden arches and ancient profiles (shape) of the structure [128-130].

- Evidences of restorations and/or reconstructions in stonework [130-133].

- Existence of cavities and fractures/cracking in masonry [131,134-136].

- Moisture in masonry $[134,137,138]$.

- $\quad$ Bridge foundations $[137,139-141]$.

- $\quad$ Filling distribution in masonry [130,136,139-143].

- Thickness of ashlars (pavement, ring arch, spandrel walls, etc.) [124,130,139,140,142-146].

There are different studies combining GPR with structural assessment on masonry arch bridges. The knowledge of the internal geometry and material characterization of the bridge allows engineers to perform more accurate numerical simulations and detailed assessment of the bridge's structural load capacity and safety $[136,139,140,142,143,145-151]$.

Figure 9 presents some GPR data obtained in three different masonry arch bridges, which demonstrate the feasibility of the technique for the documentation of previously unknown information from the interior of the structure.

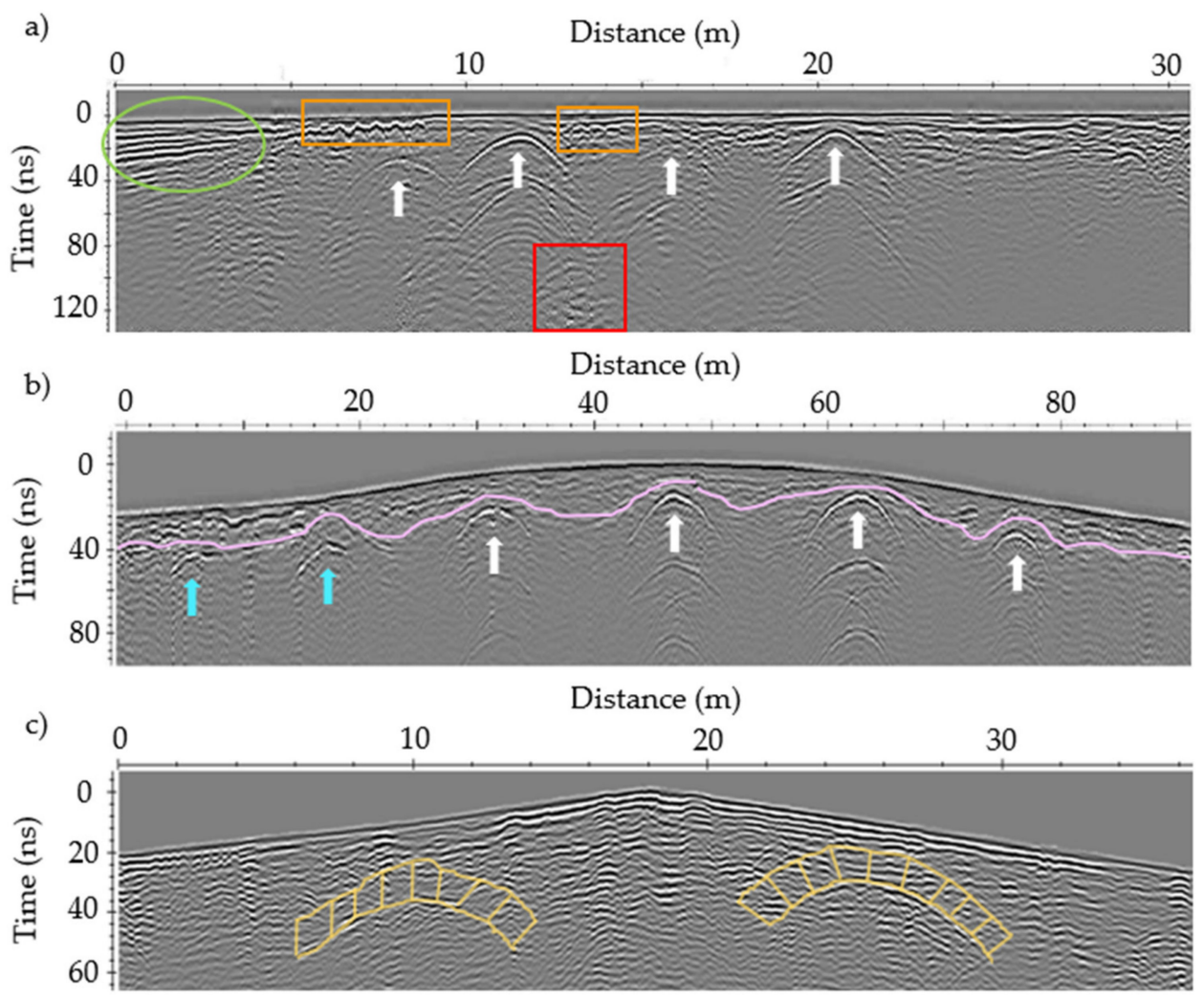

Figure 9. Examples of information obtained by GPR surveying on stone masonry arch bridges: (a) Traba bridge (Noia, Spain) showing an ancient profile (green ellipse), evidence of reinforced concrete used for restoration (orange rectangles) and presence of a void in a pier (red square); (b) Monforte bridge (Monforte de Lemos, Spain) displaying the interface between the original and the new backfill used for restoration (pink line) and the existence of two hidden arches (cyan arrows); (c) Vilanova bridge (Allariz, Spain) reproducing the voussoirs of the arch-ring (yellow lines).

\subsection{Concrete Bridges}

Bridge deck condition assessment is the most important part of concrete bridge health diagnostics and maintenance. Reinforced concrete bridges have steel bars, or rebar, which are embedded within the deck for structural strength. The corrosion of internal reinforc- 
ing bars is a major cause of concrete bridge deck deterioration and the most significant contributor to bridge deficiencies (with the formation of cracks and delamination). These deficiencies cause severe damage even on the top pavement layers, often having a crucial effect on driving safety and even structural failure. In order to prevent failure at early stages, extend the service life of concrete bridge decks, and reduce maintenance costs, proper inspection must be carried out periodically. GPR is seen predominantly as an effective NDT technique for deterioration assessment. The ASTM has a standard procedure, the ASTM D6087-08, that defines a methodology for using GPR to evaluate the condition of concrete bridge decks [53]. It is also important to mention the guidelines published by the European project-Mara Nord-for the use of GPR in bridge deck surveys [152], which describes GPR equipment, survey planning and performance, data processing and interpretation, and the reporting and delivery of results.

GPR has been successfully used in a wide range of applications in concrete bridge inspection, including:

- Estimation of concrete cover depth [153-155].

- Mapping reinforcing bars (deck and beams) [153,154,156-162].

- Location of cable ducts and other utilities such as deck joints or drain grate $[154,158,160,163]$.

- Damage detection on concrete (corrosion, cracking, spall, delamination, etc.) [157,158, 160,161,164-175].

- Moisture detection and water content estimation $[155,157,158,176]$.

When dealing with a GPR bridge inspection, a large amount of data are produced and extensive manual processing is required to extract useful information, in which the manual identification and localization of rebar is time-consuming and labor intensive. In such a context, some authors have developed algorithms for the automatic detection of rebar [157,173,174,176-182] and cracks/delamination [165,177,178].

Additionally, as in the case of stone masonry arch bridges, there are different studies that use GPR data to create structural models aiming to analyze the load-carrying capacity of concrete bridges $[159,183]$.

Table S5, in Supplementary Materials, presents a compilation of the relevant on-site survey of masonry and concrete bridges.

\section{Overview on GPR in Tunneling}

Tunnels are essential civil engineering structures that constitute an important part of roadways, passages, sewer systems, utility networks and railways. There are various categories of tunnel construction, including bored, drill and blast, horizontal directional drilling, and pipe jacking/microtunnels. Moreover, the bored tunnel can be divided into two subcategories, controlled bored tunnels and tunnel boring machine (TBM) tunneling. Shield tunneling is the typical method used for railways, which is considered a more stable method than mining.

Tunnel distresses might not be visible, and it is therefore necessary to conduct regular inspections during its service life in order to ensure safety and long-term viability. Various processes and subsequent failures may cause damage to tunnel structural integrity; those that occur during construction (ground settlement) and after opening to service (aging, physical and chemical agents, etc.). Undoubtedly, the frequency of periodic inspection should be increased when the tunnel has become aged. If potential and hidden deficiencies of the tunnel are detected in advance, and treated in time, many accidents may be avoided, whereas excessive repair and maintenance costs can be saved. Firstly, the geological and hydro-geologic conditions in which tunneling occur are essential factors in the structural integrity. Secondly, more and more problems appear in the lining with aging, such as water leakage, cracks, spalling and voids behind the lining, which greatly affect the safety of the tunnel and the users. The thickness distribution of the grouting layer behind lining segments is a crucial factor to control the quality of the tunnel and it directly affects the overall bearing capacity and structural adhesion of the tunnel. Overall, based on the International Tunneling and Underground Space Association (ITA/AITES) [184], the stresses 
and settlements that appear at the surface of the lining are indicators of an inadequate TBM method on shield tunnels: (i) over-excavation, (ii) the ploughing/heading effect and steering, (iii) lining deformation and insufficient grouting and (iv) swelling/consolidation of the surrounding ground.

Conventional methods for tunnel assessment are destructive and have great limitations and uncertainties in obtaining a representative model of the overall structure. Nowadays, the stability of tunnels is being assessed more and more often through geophysical surveys. In fact, geophysical NDT technology is meant to obtain a rapid analysis of rock shearing and concrete lining quality. The ASTM produced a standard guide, ASTM D6429-99, to provide assistance in selecting the most appropriate geophysical method for a range of geologic, geotechnical, hydrologic, and environmental investigations [185]. Hence, the GPR method has demonstrated its reliability in quality testing, since it provides continuous measurements of grouting distribution. Some examples of GPR application to tunneling inspection are shown in Figure 10.

This section provides an overview of the main GPR applications on the condition monitoring of tunnel structures. Currently, the most common applications include the following objectives:

- Thickness of concrete segment/lining [186-199].

- Thickness of the backfill grouting layer $[187,189,193,196,198,199]$.

- Damages in concrete lining and grouting layer [186,188,192,194,196,200,201].

- Damages (e.g., cracks / fissures, fractures and voids) behind tunnel linings [188,195, 197,200-205].

- $\quad$ Moisture/water content $[186,188,195,203,204,206]$.

- Depth and location of reinforcement (rebar) [189,192,194,195,201,207,208].

- Inspection of other reinforced concrete structures (e.g., steel arch and shotcrete layer) $[188,197,204,206-208]$.

- Location of immersion joints [207,208].

- Identification of depth and presence of insulation material [208].

a) Distance (m)

b) $\quad$ Distance $(\mathrm{m})$
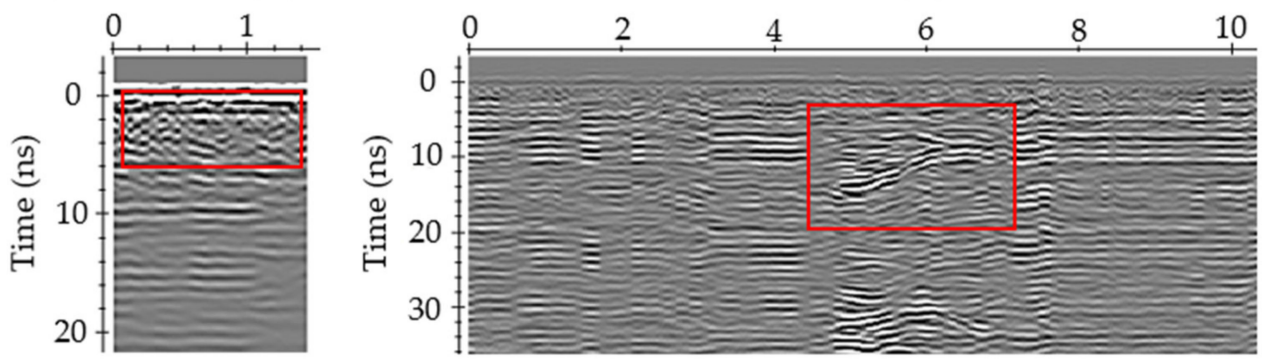

c)

Distance (m)

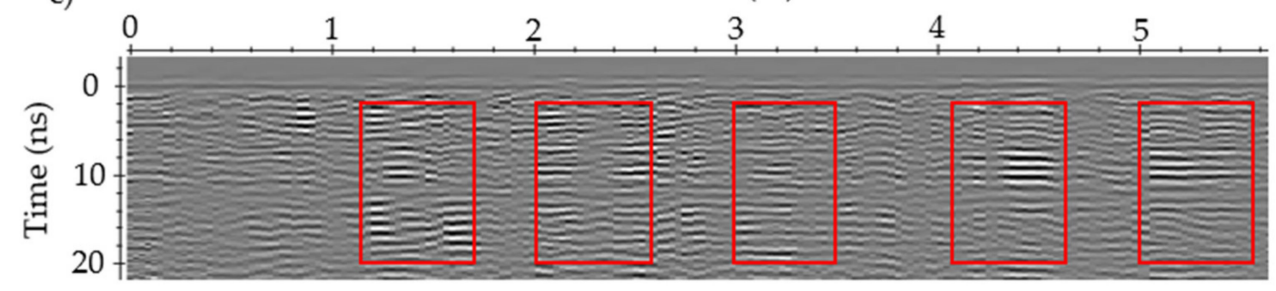

Figure 10. Results obtained from a GPR tunneling inspection: (a) shotcrete layer, (b) cavity and (c) embedded steel arch (adapted from Prego et al. [204]).

Table S6, in Supplementary Materials, presents a compilation of relevant on-site survey of tunnels. 


\section{Discussion Table on Limitations and Best Practices}

\subsection{Roads and Airports}

GPR surveys in pavements are most likely some of the most common and developed inspections. Generally, the main objectives are focused on the detection of layer thickness and damage in the pavement layers or under the road structure. Therefore, the application is included in several regulations $[7,50,53,149]$. The standard ASTM D4748 [50] defines the GPR test method for the determination of pavement layer thickness, advising of two potential complex scenarios (extremely wet pavement or saturated pavements, and high iron content in the aggregates) at which attenuation could affect the data interpretation. The ASTM D6087-08 [53] develops the test methods to assess the asphalt covering concrete decks with GPR. Both standards cover flexible and rigid pavements. However, these standards are only recommendations, and the application depends on the different countries' regulations. In Europe, there are no specific common guidelines about the application of GPR in pavement surveys, even though some proposals are developed in different countries [209]. Examples of those guidelines are in the Mara Nord Project [51] and in the British [5,6] and Belgian [210] regulations. Many authors declare that an optimal pavement assessment requires a GPR calibration process. The studies demonstrate that the correct calibration causes an extreme decrease in the error in the estimation of the pavement thickness. The analysis of the uncertainty of GPR data interpretation in the study of pavements demonstrates that the calibrated data is closer to real data than non-calibrated data [211], being the results and the interpretation affected by the calibration process. The divergence between GPR data and real data is produced by several factors, such as: (i) the distance between the antenna and the pavement surface; (ii) the pavement age; (iii) the heterogeneity of the medium (changes in water content, presence of cracks, changes in density, etc.); (iv) the wave attenuation; (v) the scatters at the pavement surface (depending on its roughness); (vi) water, leaves or sand presence at pavement surface; (vii) changes in the time-zero; (viii) clutter; and (ix) changes in the data acquisition velocity $[75,84,212]$. The analysis of different calibration algorithms demonstrates that all of them diminish the systematic error during the data acquisition [212], and the tests allow one to evaluate the operation and the stability of the GPR system [213]. In some cases, calibration consists of comparing GPR data with cores, obtaining radar-wave velocities by comparing the thickness of each layer with the time to each continuous anomaly in the B-scans. In other cases, it consists of determining the dielectric permittivity of the surface layer comparing the amplitude of the reflected wave at the surface with the amplitude of the wave reflected on a metallic plate. However, in other cases, the dielectric permittivity of the layers can be determined with common midpoint (CMP) or wide-angle reflection and refraction (WARR) measurements. In the case of rigid pavements, the wave velocity in the concrete layers can be estimated considering the hyperbolic anomalies produced on GPR data as a consequence of reflections on the rebar [80]. An error less than 3\% is observed in the thickness concrete layer estimation using this method [55].

Some of the authors use ground-coupled antennas $[47,48,214]$. In some cases, when surveying is dedicated to limited sections of the roads, the antenna is manually moved or mounted on a cart survey. Nevertheless, for large-scale surveying, the ground-coupled antenna is generally mounted on a vehicle that uses special devices and moves at a traffic speed. These devices are usually platforms or trailers that support the antenna at a certain distance from the surface of the road or the airport platform. The platforms are built with wood [84,215], plastics [21] or fiberglass [75] in order to reduce as much as possible clutter in the radar data. However, in some cases the survey is carried out using a platform in contact with the pavement, connected to the vehicle. The ground-coupled antenna is placed on that platform, assuring the maximum contact between the antenna and the pavement surface [216], and the maximum transmission of the wave into the medium. This type of data acquisition reduces the velocity of the vehicle during the survey, with the speed between $16 \mathrm{~km} / \mathrm{h} \mathrm{[216]} \mathrm{and} 25 \mathrm{~km} / \mathrm{h}$ [217], but increases the penetration depth, compared with a survey using the same frequencies but with the antenna suspended at a certain 
distance from the pavement surface. In general, surveys with ground-coupled antennas are designed to place the antenna as close as possible to the pavement surface. In most cases, pavements are surveyed with air-launched antennas [217]. These devices are suspended at a distance between $150 \mathrm{~mm}$ to $500 \mathrm{~mm}$ from the surface of the pavement $[17,75,80,84,216]$. Those devices provide clean GPR images, allowing surveys at a traffic speed (up to about 90 to $120 \mathrm{~km} / \mathrm{h}$ ) [75,84,218], but the penetration depth is less than in the case of groundcoupled antennas in contact with the surface of the medium. The comparison between the data obtained with each one of those antennas epitomizes the change in the direct and reflected wave, depending on the distance between the antenna and the surface of the pavement $[75,219]$.

Some of the most recent assessments use an array of antennas, combining in many cases ground-coupled and air-launched antennas [216,220]. In [63] the use of a single transmitter and five receiver Vivaldi antennas is proposed, obtaining results in tests and pavement surveys with an error less than $10 \%$, which is in the same level of other methods, including drilling. Other studies use a step-frequency array system [221] detecting shallow and deeper features. Dérobert et al. [222] demonstrate that a combination of UWB antennas, ranging from $500 \mathrm{MHz}$ to $6 \mathrm{GHz}$ central frequency, detected the second course in the base of the pavement structure and thin layers of about $2.5 \mathrm{~cm}$. In addition, controlled tests based on the detection of pavement layers and damage conclude that GPR is a useful tool that could be implemented as a quality control tool during the construction of new pavements or in the assessment of already existing structures, indicating that survey speed during the data acquisition velocity must be different, depending on the antenna [218].

Even though in many of the applications the study is based on the analysis of anomalies in B-scans $[82,86,87]$, in some cases those analyses are combined with other analyses from amplitudes and data obtained in CMP or WARR surveys [85], detection of reflections patterns in A-scans and B-scans [76], and velocity analysis [81]. In addition, many applications propose the use of arrays and multi-frequency antennas $[77,81,83,85]$.

\subsubsection{Soil Subgrade Assessment and the Detection of Bedrock}

Some of the first studies in pavements were focused on the analysis of the soil subgrade. This layer is highly sensitive to the environmental changes, being also affected by the traffic loads [223]. Saarenketo [69] points to three applications:

- Analysis of new road alignments, studying the ground materials and the depth to the bedrock and to the water table, reaching in some cases a depth of about $5 \mathrm{~m}$.

- Assessment of existing roads in order to detect filling materials [86], voids or weak zones under the pavement $[40,56,64-68]$.

- Quality control of restorations [69-72].

One of the most important difficulties in the assessment of the subgrade is the wave attenuation. Two possible causes are the clay content in the soils and the existence of a significant water content [102,223], which recommends the use of different center frequency antennas to improve the data interpretation. In general, a combination of several assessment techniques is the most useful tool to detect the anomalous zones in the subgrade, being applicable in the quality control of roads under construction [223]. The tests presented by [223] are a clear example of the use of combined methodologies and types of antennas to enhance the final results. They conclude that air-coupled antennas are more appropriate in detecting interfaces between layers and with the subgrade; whereas the ground-coupled antennas are more appropriate in determining anomalous zones that could be associated with damage.

Related to the detection of the subgrade, there are two main types of studies: (i) the analysis of the ground under the pavement and (ii) the estimation of the depth to the bedrock. The location of the bedrock is essential, mainly in the design of road lines. In these applications, the attenuation causes an extreme decrease in the signal-to-noise ratio at higher depths, being difficult to distinguish clearly the contact with the bedrock or the existence of fractures and stratification in the ground under the pavement. These 
geological features could affect the stability of the road. Moreover, the data accuracy in the data interpretation depends on the precision in GPR wave velocity estimation [224], being a complex task in heterogeneous media. The studies presented in [224] propose the $450 \mathrm{MHz}$ ground-coupled antenna as the most appropriate system, because it offers higher resolution than antennas between $100 \mathrm{MHz}$ to $200 \mathrm{MHz}$ central frequency. This result is a consequence of the GPR wave attenuation, allowing for the detection of discontinuities until a maximum depth of $5 \mathrm{~m}$ in all cases, based on the observation of different textures in the B-scans. The authors recommend the combination of GPR with electric resistivity tomography (ERT) in the case of: (i) bedrock at depths higher than $5 \mathrm{~m}$ and (ii) soils with superficial conductive clays. Those clays produce an extreme attenuation of the GPR signals. Other studies demonstrate that GPR is effective in determining the asphalt layers, being moderately successful in the detection of base thickness and shallow stratigraphy and is not applicable in the location of the near-surface bedrock [225]. However, other studies demonstrate that a $600 \mathrm{MHz}$ center frequency antenna allows the detection of the bedrock contact and also changes in the compaction of the subgrade, locating areas under the pavement with poor soil compaction [226]. Low compaction of the subgrade soil could be the cause of road degradation, and GPR assessment could be a support in the strategies for road restorations. Saarenketo and Scullion [69] warn about the weak anomalies that could be associated with the bedrock contact depending on the dielectric properties of the pavement and the soil and the rock; hence concluding that the anomalies will probably be weak and non-continuous reflections.

\subsubsection{Pavement Layer Thickness Analysis}

Pavement is usually assessed with GPR in combination with FWD [223,226-228]. In these studies, one of the most common analysis is the determination of layer thickness $[30,36,38,58-63,75]$. This analysis requires high-frequency antennas, in all cases with a central frequency higher than $800 \mathrm{MHz}$. For example, [36] uses a $2 \mathrm{GHz}$ antenna, while [229] reports the application of a $1.5 \mathrm{GHz}$ ground-coupled antenna for the layer thickness determination, and [48] compares the results obtained with two antennas with $800 \mathrm{MHz}$ and $900 \mathrm{MHz}$ central frequency. The detection of the contact between layers is observed in the B-scans as a continuous anomaly produced by the reflection of the radar-wave at the interface between two media with different dielectric permittivity. The studies point to the easier detection of boundaries in the case of asphalt layers than in the case of concrete layers $[17,84,228]$. The results indicate that the error in the layer thickness determination is higher in the case of thinner layers and deteriorated structures. Errors less than $10 \%$ are reported in several works referring to new pavements $[36,63,75]$. Another analysis observes an error of about $12 \%$ in the surface asphalt layer with a common data processing method, but about 3\% when the deconvolution is applied to separate the anomalies [60]. The analysis developed by [230] obtains the following results: (i) with air-coupled antennas of $1.8 \mathrm{GHz}$ central frequency and the CMP (common mid-point) survey, the error in thinner asphalt layers ranges between $6 \%$ and $18 \%$; and (ii) with ground-coupled antennas of $1.5 \mathrm{GHz}$ central frequency and the $\mathrm{CO}$ (common offset) mode, the error ranges between $1 \%$ and $26 \%$. This study highlights the importance of the data processing for the proper picking of anomalies associated with reflections in the base of thin layers. It is noticeable that both methods introduce the same error (an average value of $7 \%$ ) in the case of thicker layers. This study also notices the influence of dust or sand on the surface of the pavement for the analysis of the dielectric permittivity using ground-coupled antennas, although the error depends on the thickness and the depth to the layer. In [216] an average error of $6.8 \%$ was reported for pavement thickness layers ranging from 280 to $350 \mathrm{~mm}$, while for pavement thickness layers ranging from $100 \mathrm{~mm}$ to $200 \mathrm{~mm}$ the error was $3.8 \%$. Other authors also conclude that the error in the bituminous layer differs from the error in the granular layer. In [231] an average error of $7.5 \%$ was obtained for asphalt surface layers ranging from $5 \mathrm{~mm}$ to $500 \mathrm{~mm}$ thick, but this error increased until it was $12 \%$ in the case of granular base layers ranging from $150 \mathrm{~mm}$ to $330 \mathrm{~mm}$ thick. A higher error was also 
obtained in [230] for thinner layers, observing a correlation between the thickness of the layer and the error in the case of CO surveys. However, no correlation was observed in the case of CMP surveys.

Additionally, the error depends on the quality and homogeneity of the layers. Al-Qadi et al. [232] observe lower errors in the case of plain concrete layers; whereas the studies in old pavements [216] and in new pavements [217], show an important change in the error comparing both studies in new and old pavements.

The error diminishes in the case of a proper calibration using several cores [36,214,223], although the accuracy depends on the number of cores. The results obtained without calibration present higher errors and demonstrate that the GPR used as a unique NDT assessment of the pavement is only useful for a quick and rough evaluation, being nonetheless a satisfactory technique.

\subsubsection{Damage Assessment: Detection of Voids and Cracks}

In most surveys, the objective is determining a procedure for the recognition of cracks and under-slab voids, as well as the rebar location in reinforced concrete slabs [76-81,88], being mostly used the $\mathrm{CO}$ acquisition mode and determining anomalies in B-scans. However, Yi et al. [81] observed that thin cracks are not detected using the common reflection analysis, and propose a 3D CMP using an array of antennas in order to determine slight changes in the radar-wave velocity that could be associated with zones affected by cracks wider than $1 \mathrm{~mm}$.

On-site measurements compared with cores highlight that clear images of cracks in the B-scans correspond to large fissures (several centimeters wide), in many cases filled with foreign material [42,56]. Early fissures are not visible in GPR images because the anomaly is masked with the anomalies produced in the grains and heterogeneities of the layers [66]. However, zones affected by many smaller early cracks produce in some cases blurred images in GPR B-scans. This effect can be used to select possible zones with early damage. The effect of internal small cracks is also visible in the frequency spectrum. The heterogeneity due to the existence of cracks, mainly in the subgrade, increases the energy dispersion and subsequently attenuates the signal, generating an irregular image [81] with vague boundaries [66]. The radar-wave velocity in damaged areas differs slightly from the radar-wave velocity in undamaged asphalt [81]. In addition, the amplitude of the frequency spectrum decreases, which denotes the existence of possible anomalous zones [47].

Several tests report that $1 \mathrm{GHz}$ center frequency antenna $[40,41,65]$, or even larger frequency antennas [66], are valuable systems to characterize vertical pavement cracks. However, lower frequency antennas, for example $250 \mathrm{MHz}$, are in many cases more effective for detecting cracks because the larger wavelength is less affected by the heterogeneities and the aggregates grading of the layers [65]. In consequence, most pavements are assessed with antennas presenting a range of frequencies. For example, the studies in [68] explore depths between $50 \mathrm{~mm}$ to $160 \mathrm{~mm}$ using antennas with central frequency between $2.5 \mathrm{GHz}$ and $700 \mathrm{MHz}$; [233] obtains details of the top structure and the subgrade soil with $1.5 \mathrm{GHz}$ and $400 \mathrm{MHz}$ center frequency antennas, respectively; [234] explores the bituminous layer with a $1.6 \mathrm{GHz}$ center frequency antenna and the underneath structure (base, subbase and subgrade) with a $600 \mathrm{MHz}$ center frequency antenna; [235] combines $800 \mathrm{MHz}$ and $500 \mathrm{MHz}$ center frequency antennas to detect subsidence in a port area, showing visible deterioration in paving blocks and loss of filling; and [221] uses an array of antennas with central frequencies ranging between $50 \mathrm{MHz}$ and $3050 \mathrm{MHz}$.

Many works are devoted to laboratory tests and controlled measurements in order to determine the limits in the detection of cracks. The laboratory tests described by [56] in specimens representing rigid pavements are focused on detecting the bottom of the cracks depending on its width, length, and filling material. The results conclude that it is possible to detect $2 \mathrm{~mm}$ wide cracks, and the presence of material filling the crack increases its detectability, being possible to determine the bottom of the cracks: (i) wider than $5 \mathrm{~mm}$ and filled with saturated sand; and (ii) wider than $15 \mathrm{~mm}$ and filled with 
dry sand. The detection also depends on the depth of the crack and its position in the pavement structure. The controlled field studies described in [65] also present the detection of the bottom of the cracks in asphalt pavements, concluding that the stronger anomaly is obtained when the bottom of the crack intersects the bottom of the asphalt pavement. The results obtained in the laboratory experiments presented in [67] highlight that the stronger response depends on the contrast between adjacent layers in the case of cracks crossing the entire upper layer. The analysis presented in [40] determines an error of about $5.5 \%$ in the estimation of the length of the cracks when the bottom is detected. In those experimental tests, additional computational methods (e.g., finite-difference time-domain (FDTD) modelling) were applied to compare synthetic data with laboratory and controlled measurements.

To summarize, different authors point to the applicability of GPR in the detection of cracks and voids inside different layers of the pavement structure. The method provides clear images in the case of large cracks, although small cracks (until $2 \mathrm{~mm}$ ) can be detected in the upper layers. The existence of zones with a large number of thin or early cracks can be also detected because of the changes in the radar-wave velocity with respect to the velocity in undamaged pavement. In addition, the bottom of the cracks can be also detected in the case of large and superficial cracks or in the case of cracks filled with water or saturated sand. The dielectric permittivity of those materials differs strongly from the dielectric permittivity of the pavement layer materials. More heterogeneous layers, presenting different grading, make the detection of cracks or voids more difficult. Cracks crossing one entire layer are more detectable, especially in the case of a large contrast in their dielectric permittivity.

\subsubsection{Damage Assessment: Debonding}

The loss of adhesion between adjacent pavement layers produces a change in the behavior of the pavement, which can contribute to its early failure, producing permanent deformations or superficial cracks and adversely affecting its performance. This problem is considerably severe in the case of airport pavements that undergo high shear stresses during the landing and take-off of the planes. The early detection of debonding is therefore crucial for pavement assessment. The application of GPR in the detection of debonding is usually combined with FWD analysis [75,85], with consistent results validating each other. In addition, the analysis of the GPR signal frequency indicates that the spectrum is sensitive to the structural condition of the pavement, correlating the results with the standardized deflection tests [47] in roads: when comparing damaged zones with undamaged zones, the spectrum bandwidth reduces while the amplitude and the central frequency decreases. However, the clear detection of debonding is only possible in the case of water presence in the debonded zone. Another analysis focused on the assessment of airport pavements [85] refers that the identification of such damage is difficult because it is usually produced at the shallow zone of the pavement structure (within the first several centimeters). However, GPR lateral wave in the CMP data acquisition is highly sensitive to the material properties, and the amplitude maps have proved to be efficient in determining debonding zones in which the high amplitude corresponds with the damaged zones detected by acoustic sounding methods. Methodologies based on linear prediction and supported by vector regression have been proposed and tested using a $10 \mathrm{GHz}$ bandwidth antenna in an accelerated pavement testing facility [236], providing promising results in the detection of thin debonding. Another proposal was the application of a support vector machine to the A-scans, allowing for the detection of horizontally stratified debonding and geotextiles between the two upper pavement layers [237].

\subsubsection{Damage Assessment: Moisture}

The analysis of changes in water content in the different pavement layers of the substrate was analyzed in a laboratory [238], in controlled field tests [43], and in specific zones of roads $[48,73,74]$. Some results epitomize the ability of GPR to reveal variations in the 
water content in the pavement layers beneath the asphalt layer. Comparing GPR data with direct measurements of gravimetric water content reveals the ability of GPR to detect changes in moisture and also to assess the functionality of the drainage layers [34]. The results presented in [74] compare $1 \mathrm{GHz}$ and $2 \mathrm{GHz}$ center frequency antennas, concluding that, although data was similar in both cases, the higher penetration depth with the $1 \mathrm{GHz}$ center frequency antenna makes it more appropriate for detecting zones affected by moisture. In addition, the existence of high water content in fractures [42] and debonding $[47,48]$ between layers is a particular condition for the best detection of those damages. The representation of A-scan datasets in time-domain and in frequency-domain, obtained in wet and dry parts of the pavements, illustrates the great difference in amplitude due to the difference in dielectric permittivity contrast. In many assessments, the moisture damage is detected by observing the amplitude of the maximum peak in the time-domain. However, Zhang et al. [45] propose the use of more properties of the dataset to detect wet zones, considering statistical properties that are affected by moisture, selected with linear discriminant analysis. The comparison of results from GPR tests and passive microwave radiometry demonstrates that GPR is able to detect water content at higher depths, enabling the detection of water table in the soil under the structure [237]. Nevertheless, the identification in the B-scans of the anomaly associated with water table can require different seasonal measurements in order to determine the permanent and variable reflectors, which allows one to distinguish between natural layers or pavement structures, and water table.

The central frequency of the antennas recommended for the detection of moisture ranges from $900 \mathrm{MHz}$ (to analyze moisture in the ground under the pavement [239]) to higher frequencies such as $2.5 \mathrm{GHz}$ (to determine the existence of water in porous layers of the pavement structure [45], between those layers or inside cracks and voids).

The frost susceptibility is another issue to be treated in pavements placed in zones with extreme temperature changes. It is related to water content and drainage of the subgrade. In roads affected by frozen water, a strong reflection is produced at the interface between frozen and non-frozen sections when the subgrade presents high dielectric permittivity and subsequent high frost susceptibility [69].

\subsubsection{Quality Control of New Structures: Asphalt Air Void Content and Segregation}

Quality control is important in the construction of new pavements and in the restoration of already existing roads and airfields $[78,240,241]$. The analysis requires the improvement of signal-to-noise ratio of the GPR scans. Bianchini Ciampoli et al. [240] present and discuss a processing flow to improve the GPR images during the quality control of structures. In these applications, a previous calibration is required to obtain accurate results [217].

Quality control involves the thickness control during pavement construction [217], the quality analysis of the layer bonding [209,242], the porosity of the materials [71] and the analysis of thin layers overlaid on old and rehabilitated pavements [217].

The existence of thin layers over the pavements, added as a rehabilitation of damaged zones, produces an overlap between the wave reflected on the surface and the wave reflected on the contact between the thin layer and the old pavement, making the detection of the anomaly and the thickness estimation of the rehabilitated layer difficult. The existence of those thin layers considerably degrades the accuracy of the GPR interpretation of the layer's thickness and, therefore, accurate signal processing can be required. GPR surveys provide precise results in the estimation of the layer's thickness when used to assess the quality control of flexible pavements during their construction, allowing traffic speed velocities during the data acquisition (up to $90 \mathrm{~km} / \mathrm{h}$ with air-coupled antennas and $25 \mathrm{~km} / \mathrm{h}$ with ground-coupled antennas [217]). Nevertheless, the use of air-coupled antennas is highly recommended [217].

The analysis of quality in the pavement layer bonding is based on the water accumulated in the debonded zones. GPR is an efficient tool because of its sensitivity to changes in water content. Furthermore, it has been observed that GPR is also sensitive to changes in 
the quality of the material in the case of new pavements [242]. These changes are perceived mainly as a consequence of changes in the travel wave velocity. However, it is difficult to discern between the real cause of changes in the wave travel time: changes in the material conditions or variations in the layer thickness.

The void content in the asphalt pavement is related to the dielectric permittivity values that are obtained when calibrating the wave velocity by comparing GPR data to cores [72]. Dielectric permittivity ranges between 4.5 and 6.5 in dry aggregates while the asphalt permittivity varies between 2.6 and 2.8 [71]. Saarenketo [71] introduces an empirical relationship between the air voids content and the measured dielectric values from GPR data, with an accuracy of about $90 \%$. The uncertainty in these kind of studies can be reduced by comparing GPR data to cores [28]. The analysis presented in [71] also detects the damage in pavements as a consequence of segregation, which is produced in small zones of the shallow layers of pavements with low density materials. This segregation is also associated with an excess of coarse aggregates. The proposed analysis is based on the estimation of the surface dielectric permittivity using GPR data, in which extremely low values could be associated with segregated zones [69]. Computational methods corroborate the occurrence of changes in the GPR signal when variation exists in the pavement density. The A-scan's amplitude increases when the asphalt pavement density increases because of the higher dielectric permittivity, also showing an augment in the amplitude of the frequency range [243].

\subsubsection{Rebar Detection and Corrosion}

In rigid and reinforced pavements, a usual assessment also involves the detection of the rebar [42], [56], [80] and the cover depth to the rebar [55], obtaining an average error of about $2.6 \%$ when comparing GPR results with cores. The estimation of the cover depth is based on the analysis of hyperbolas produced by reflections on the rebar. The analysis of the rebar location is, in most cases, based on B-scans acquired along the pavement surface. However, in many cases the 2D horizontal analysis can provide accurate and effective images of the rebar distribution inside the rigid pavement. Those images can be obtained from a grid of B-scans obtained in profile lines separated by $10 \mathrm{~cm}$ [244]. Combining GPR with other techniques such as electromagnetic induction, it is possible to determine the position of the rebar, the cover thickness, and the rebar diameter [245]. The main limitation occurs in the case of a densely-meshed rebar, requiring antennas with narrower transmission energy cones. The proposal of applying deep learning techniques to B-scans suggests accurate results in the classification of the rebar and other buried objects in pavements after building a data library for pavement objects. The technique is based on the recognition of changes in the GPR data amplitude and the anomalies associated with interfaces. The results presented in [246] allowed to automatically detect both the hyperbolas and the interfaces.

Another aspect in the rebar assessment of rigid pavement is the analysis of corrosion. Some studies have analyzed the GPR response due to corrosion of the rebar in reinforced structures: the damage obscures the B-scans and the amplitude of the hyperbolas produced by a corroded rebar decreases extremely when compared with the amplitude of the hyperbolas obtained from the reflection by a non-damaged rebar [247,248].

In addition, the existence of water with high salt content facilitates the corrosion of those elements. GPR B-scans show an important attenuation in the zones affected by high salt content water, which allows for the detection of possible problematic zones [247]. Detailed studies indicate that the reflected wave amplitude is sensitive to mapping corrosion in the rebar while the direct wave frequency amplitude is sensitive to chloride content [249], where the dispersion of the energy acts as an indicator of the cracks most likely produced in the concrete around rebar in later stages of corrosion process [248]. Other studies correlate damage in the surface of rigid pavements with the corrosion of the rebar [168]. 


\subsubsection{Recent Developments and Applications}

The most recent developments in the pavement assessment are focused on four main purposes: (i) controlled experiments, (ii) deep learning and automatic detection of damage and layers, (iii) antenna positioning, and (iv) design of new devices.

Some of those more controlled experiments are realized in testing sites on roads, comparing GPR results to other complementary tests and cores. Other tests are developed in a laboratory, using specimens prepared to simulate damage and structures. Many tests are prepared to analyze the effect of different conditions on the GPR images and to monitor damages. The experimental tests address the evaluation of different problems. In this way, for example, Rasol et al. [56] present the effects of size and filling of cracks on the GPR images, and Baltrušaitis et al. [250] use the GPR results in order to estimate the quality of materials by determining the bulk density of bituminous mixture, and [251] determines the bitumen content in different mixtures. In all cases, the measured parameter is the dielectric permittivity, and mathematical models are compared to cores and experimental results.

Regarding laboratory tests and field surveys, some developments applied neural networks in data analysis, deep learning techniques and automatic detection of damage by means of post-processing techniques. For example, Zhang et al. [45] propose a training convolutional neural network structure for moisture damage detection from GPR B-scans, which works by using an incremental random sampling method to automatically select the most appropriate plot scale at each radargram. Other authors, such as Kim et al. [246], propose the reconstruction of GPR data to detect underground objects under pavements in urban areas using deep learning techniques, concluding that the precision of the results depends directly on the quality and number of field training data. In this work, four features were studied: (i) pavement layer interfaces, (ii) the existence of a manhole cover in the surface, (iii) the detection of buried targets that produce hyperbolas, and (iv) subsoil background. More complex elements in the study could require a larger number of training data. Larger databases are compiled and used in the study of pavement distress using deep learning methods, showing that the frequency of the antenna also affects the results because of the detail loss [252]. In [253] a review of deep learning applications in GPR is presented, comparing the results and grouping the works depending on the type of data used. The conclusion is that the methods using A-scans $[254,255]$ present slightly better results than those using B-scans $[252,256]$ or C-scans $[257,258]$. However, the best spatial information is obtained from C-scans, and the most recent works [257] are focused on 3D GPR data. Notwithstanding, this processing requires more complex architecture and a large volume of datasets. The optimal solution to achieve a proper development in the deep learning based on C-scans is to create a big GPR dataset, sharing data from research around the world [253].

The efficiency of the monitoring, at high speed, turns the GPR into an important tool when combined with new loading tests devices, such as FWD and, more recently, with TSD (traffic speed deflectometer) [259-262]. For studies at the network level, in some countries the use of GPR is already considered mandatory for layer thickness assessment due to its efficiency to support pavement management system decisions [263]. The joint interpretation of GPR with load tests, such as FWD and TSD, has also led to changes performed on the GPR system in order to better process the data collected. For this purpose, a dedicated GPR, a noise-modulated ground penetrating radar (NM-GPR), was developed in Australia [259]. This GPR variant uses coded signal modulation and efficient receiver hardware to enable traffic speed multi-channel performance and consists of hardware receivers combined with an array of ground-coupled antennas and custom damping systems in a trailer format to collect 3D data while travelling at speeds of up to $100 \mathrm{~km} / \mathrm{h}$. The NM-GPR is used for the assessment of calibrated road layer depth measurements and quantitative moisture mapping. Geospatial views, developed to align and join the data gathered with NM-GPR, TSD and FWD, represent an important tool for understanding these complementary data together and in the context of the surrounding environment [259]. 
Other new developments are focused on finding antenna setups (positioning systems) that can be used in different scenarios. In that way, the studies by Yuan and Cai [264] propose a mechanism to automatically adapt the antenna trajectories. The methodology consists of comparing synthetic data obtained for different angles between the antenna and the target with field data, thus contributing to automation in the antenna positioning. The self-detection of the antenna position is possible using fixed reflectors on the surface [265] or using a geodetic network in order to georeference the position of each A-scan and the anomalies in the radargrams [266]. The work by Gabrys and Ortyl [267] compare several georeferencing systems in GPR surveys for the detection of layers and pipes under the pavement in C-scans. The position was determined using a GPS synchronized with the UTC time and a total station. The results demonstrate that the higher accuracy in the anomaly position is obtained with the synchronized GPS, although in some cases the system does not provide the correct antenna trajectories. This is caused because this system is based on signals from satellites and in some circumstances, as in dense cities, the horizon visibility is limited. In those cases, the most efficient position is obtained with the total station.

Finally, the design of new devices for GPR surveys also includes the positioning of the antenna with robotic systems. In the field of road inspections, a few more developed prototypes have been built with the objective of early detection and repairing damage, using cameras for visual inspections. Wu et al. [268] design and test (in controlled experiments) a six-channel antenna mounted on a robotic system, and [269] proposes and constructs a robotic system with 3D printing, with the scope of using the prototype both for assessing damage and repairing early cracks. In addition, some works suggest pavement surveys by using drones [270]. The UAVs (unmanned aerial vehicles) are flexible platforms that could support different types of remote sensing sensors [271] and, in the inspection of roads, have a low impact in the traffic while allowing one to obtain images from several lanes at the same time and build 3D images [272].

\subsection{Railways Inspection}

Although GPR is applied in several railways for monitoring, as it provides a rapid continuous measuring, its application presents limitations that have to be considered. The GPR setup has to be chosen according to the scope of the study. On the one hand, GPR assessment can be applied at different stages of railway life cycle, during construction of new lines, for in-service monitoring or for rehabilitation purposes. On the other hand, GPR can be used for distinct diagnosis goals, such as detecting settlements of deeper layers, ballast quality evaluation, debonding and crack detection. The specific requirements for an efficient application of GPR on railway assessments and the main limitations, together with advice in overcoming them, are referred herein.

Designated inspection vehicles are used in railways to assess the railway condition, through inclinometers, digital videography, laser scanning and, most recently in Europe, USA and Australia, the GPR. This inspection enables a diagnosis of railway elements related to traffic safety and comfort, such as track geometry, rail profile, and sleeper and fastening defects. Based on this assessment, maintenance works are planned when the track condition reaches a pre-defined level, known as the "intervention level" $[107,273]$. The main maintenance intervention on the railway is tamping, performed when the settlement of the rail is occurring, and consists of adding a ballast below the sleepers to raise the rail level [274]. This is an action that corrects the track geometry but does not solve the deterioration causes, which are mainly due to substructure settlements $[17,96,97,107]$, that can be only detected by GPR, thus exemplifies its importance.

GPR had been initially been applied to railway diagnosis in the 90s, at research level, using ground-coupled antennas $[84,89,275]$ and, some years later, using high-frequency aircoupled horn antennas $[97,276,277]$ that enable non-contact tests at higher speeds. Some key limitations delayed the GPR application to railways. One is the nature of track elements, ballast and sleepers, that are rough contact surfaces for the ground-coupled antennas. 
These factors, together with the safety of the technicians that perform the measurement, represented challenges to the testing process.

The GPR railway monitoring is usually performed along the track, on longitudinal alignments. At least one testing profile is measured between the rails, on the track axle. Additionally, another two profiles can be measured laterally, on the right and left ballast shoulders, in order to obtain information on the transversal condition of the track [89-91,96,276]. Generally, the central frequency of the antennas for the middle and lateral profiles is the same. Ground-coupled antennas were adapted for air-coupled measurement, and their dimension and location, on being installed on the inspection vehicle, were chosen in order to comply with the railway loading gauge requirements, which is the case of $400 \mathrm{MHz}$ and $500 \mathrm{MHz}$ center frequency antennas [95,102,278]. Nevertheless, in order to perform a thorough diagnostic of the railway, antennas with different central frequencies are required, depending on the objectives of the tests, for example:

- Subgrade and platform assessment: low-frequency antennas are employed (from $100 \mathrm{MHz}$ to $400 \mathrm{MHz})[98,105,279]$.

- Ballast and subballast layer thickness: medium-frequency (from $400 \mathrm{MHz}$ to $1 \mathrm{GHz}$ [ [90-92,94-96], most commonly used at network level.

- Moisture and fouling detection: high-frequency antennas (from $1.2 \mathrm{GHz}$ to $2 \mathrm{GHz})[90,93,101,103,104,106,280,281]$.

Not only are the antennas different, but the signal processing is also distinct, according to the purpose of the measurement. Although the reflection picking method is sufficient for layer thickness assessment, in the case of moisture and fouling evaluation, more complex signal processing is required, such as signal scattering [281] and the time-frequency approach $[93,282,283]$. This also requires different antenna configuration [284] and testing methodology, such as the CMP approach [279]. Nevertheless, dedicated software is needed for moisture and fouling detection. It is shown in the bibliography that, using specific software, moisture and fouling results can be obtained even with lower center frequency antennas (400 MHz) [94,100,102,278].

In order to study and validate the ballast quality assessment, several studies, in a laboratory and on-site, were undertaken in the last decade. These works have studied several aspects in order to enable better GPR results on railways from the type of antennas (high-frequency, ultra-wide band, etc.) $[93,102,109,278]$ to antenna configuration during tests $[106,279,280,284]$ and signal processing (scattering [267], time-frequency domain analysis [93,101,106,280,282,283], multi-channel analysis [285], and entropy-based analysis [107]).

After all these years, the GPR is still used, mostly for the assessment of ballast layer thickness (which is the same as in road investigations, where it is mainly used for estimating the thickness of layers). The ballast dielectric characteristics depend on the type of material (e.g., limestone or granite), on the grading level (maximum diameter and discontinuous grading), on the fouling level (clean or fouled) and on water content. In addition, it is dependent on the central frequency of the antenna. Compared with roads surveys, the test pits are more difficult to perform, due to train circulation (that has to be suspended during works), and due to ballast properties that roll into the test pit when clean, which is a challenge for digging. Those test pits are used in the railway assessment to confirm the ballast layer thickness and the fouling level. On the one hand, the dielectric properties are highly influenced by moisture (water relative dielectric permittivity is 81 ). The moisture trapped in the ballast is due to ballast fouling, resulted from ballast particle fragmentation and from subgrade soil migration into the ballast, mainly in ancient lines with no subballast layer $[275,286]$. Due to these particularities, it is difficult to assume a default value for the ballast dielectric constant, so several laboratory tests were performed to determine ranges of variation for this parameter $[89,101,107,109,110,276,278,280,285]$. It is always recommended to perform test pits to confirm the GPR results. On the other hand, the fact that a fouled ballast is propitious to increase moisture content enables an overall estimation of the fouling level when comparing testing campaigns performed in dry versus 
wet seasons. It is possible, in this way, to identify rail sections where fouling and moisture are present $[107,283]$.

Other limitations of GPR application to railways are:

- Measuring below clay or very clayish layers.

- The presence of steel sleepers in railways [287].

- The gradual increase in fouling in depth that make the interface between the ballast and soil undetectable.

- The rail presence that, as a metal, can result in a constant reflection, masking in most cases the information at the depth corresponding to the distance between the antenna and the rail (e.g., if the lateral antennas are too close to the rail, the measurement in depth becomes very difficult as the rail reflection is strong and in many cases a ringing effect appears).

The GPR tests can be performed and analyzed together with other NDT, either geophysical or that assess the track geometry and stiffness, as referred to in the beginning of this subsection.

The use of other geophysical methods together with GPR aims mainly to complement it and, in general, they are localized tests instead of continuous measurements such as GPR. Among those complementary methods are: electrical resistivity tomography (ERT), seismic wave propagation, microgravimetry, the impact-echo method (IEM) and the ultrasonic test $[112,113,288]$.

The information obtained with GPR represents an important tool when evaluating the railway condition together with the parameters continuously measured by the inspection vehicle, such as track geometry $[108,283]$. In this regard, the Federal Railroad Administration Report DOT/FRA/ORD-20/07 [289] presents the results regarding the development of a probability model for the occurrence of track geometry defects as a function of subgrade parameters showing a statistically significant relationship to be used in predictive analysis. Two parameters, assessed by GPR, are referred to in this report as crucial: the ballast layer thickness and the fouling index. GPR information can also complement other nondestructive load tests, such as a stiffness assessment with a rolling stiffness measurement vehicle [290], a falling weight deflectometer (FWD) [95] and a light FWD [17,95,286,291], a dynamic cone penetrometer [90], a geo endoscopy test [90], [292] and light detection and ranging or laser imaging detection and ranging (LiDAR) [293]. The use of a multi-temporal InSAR (interferometric synthetic aperture radar) for transport infrastructure monitoring has also been significantly increasing during the last few years [294-296]. Studies undertaken on railways have shown the potential of the applicability of InSAR together with GPR, mainly for the detection of causes of track subsidence [297], and to monitor subsidence at the transition zones of railway bridges [298]. It is important to highlight the relevance of the GPR, which can be synergistically used with other NDT to validate the results obtained by InSAR and to identify the possible causes of the displacements detected.

The TRACKSCAN project, financed by H2020 from 2015-2016 [299], has developed a dedicated device to perform GPR measurements on railways on all the assets: ballast, subballast, tunnels, retaining walls and culverts. The project has highlighted not only the crucial importance of GPR for "seeing" beyond the surfaces, but also the complexity of GPR interpretation [300]. The GPR results support management decisions on maintenance actions, by the timely detection of defects.

Between 2015 and 2018, a large project, also financed by H2020, was developed in Europe, DESTinationRAIL [301] that provided a decision support tool for rail infrastructure managers based on the FACT (find, analyze, classify and treat) principle. This research addressed several rail structural elements from bridges, earthworks and track, and contributed to the improvement of different phases of rail management including monitoring, data analysis, regulations, risk assessment and recommendations for optimal intervention programs for railway maintenance. One of the most important tools studied for monitoring process was the GPR, used for several scopes. Thus, GPR was applied for the detection of potential hot-spots on substructure, such as ballast pockets and mud pumps, for the 
detection of water content changes during rainfall and, as a novel approach, for the location of soft clay and peat deposits that can cause accelerated ground settlements under dynamic amplification caused by high-speed trains (over $200 \mathrm{~km} / \mathrm{h}$ ). This research made extensive recommendations for conducting GPR investigations on railway lines, which included the application of optimal system configuration consisting of ground-coupled and air-coupled antennas. More details can be found in specific Deliverables (D), namely on GPR applications referred to above in D1.2, the joint interpretation of GPR with track geometry in D2.4, a novel damage detection methodology developed for bridge assessment in D 2.2 and the assessment of earthworks in D2.3 [301].

At the same time, the Federal Railway Administration (USA) has also financed a project aiming to develop a device for rail scan and guidelines for GPR implementation on rail assessment [90]. A GPR system was installed on a survey vehicle for field-testing and the integration of GPR results with track stiffness and geometry was also addressed. Several tests and calibrations were performed for over $130 \mathrm{~km}$ and improvements were made, mainly to the signal quality of shoulder antennas. In addition, dynamic cone penetrometer (DCP) tests, test pits and laboratory tests were performed to validate the results for fouling and moisture assessment. The system installed consists of three $2 \mathrm{GHz}$ horn antennas and one $400 \mathrm{MHz}$ ground-coupled antenna that can measure at a maximum speed of $120 \mathrm{~km} / \mathrm{h}$. The specificities of the approach are: i) automated processing software that handle large volumes of data for rapid reporting and ii) the integration of GPR data with the track geometry and gage restraint measurement system (GRMS) data generated by the T-20 car [90]. Based on this extensive research, GPR indexes were defined depending on four parameters, namely ballast fouling, ballast depth, layer roughness and moisture detection. Those indexes were then combined with track roughness assessed through track geometry, and a track substructure quality index (TSQI) matrix was developed and implemented. Nevertheless, the study highlights the need for additional research: i) on the ballast fouling index sensitivity to type of fines and ii) to improve the shoulder antennas' results, namely the signal penetration and reflection characteristics as they are highly influenced by the edge of the tie.

It is clear that there is a general interest in GPR application for railway studies, given the importance of this test for the detection of real causes of track deterioration and to support the maintenance management decisions. Nevertheless, in spite of the studies developed so far there is still the need for future research to improve the testing methodology and data processing in order to make the GPR application more user friendly and time efficient.

In the case of ballastless railway tracks, GPR application is similar to other concrete reinforced structures, such as pavements and bridge decks. The main challenge is to select the frequency to be applied in order to measure the slab thickness and the base layer thickness and condition, as generally the slab is laid over a lean concrete layer. The central frequency of the antenna has to be lower in order to detect the interface between the lean concrete and soil, as the GPR wave dissipation in concrete is higher than in asphalt or in aggregates. Similar to ballasted railways, antennas with different central frequencies can be used for different purposes. In this case, the lower frequencies for layer thickness, and void and mud detection under the slabs [113], and higher frequencies for detecting debonding between sleepers and slab, cracks at the interface, and the rebar location [112]. In the case of ballastless railways, GPR is generally applied together with other NDT methods, such as the impact-echo method (IEM) and ultrasonic testing.

It can be concluded that GPR represents an important tool for railway assessment in order to support the asset management of this transport infrastructure.

\subsection{Retaining Walls}

GPR assessment of retaining walls is focused on many cases in the detection of the contact between the wall and the natural soil, in the search of voids or changes in water content. Other objectives depend on the type of wall. 
In the case of most of the cantilever walls and concrete retaining walls, one of the objectives is the detection of the rebar $[115,116]$. In those cases, the application is similar to other usual inspections of concrete structures [302], and antennas with central frequencies higher than $900 \mathrm{MHz}$ are normally used because the presence of metal mesh makes difficult the signal penetration to deeper targets, in the case of high density of rebar. However, several layers of reinforcement could be mapped and represented using 3D images of GPR slices [116], with the rebar position and structure perfectly detected and even including other reinforcement structures such as dowels [116,302]. The main difficulty for an accurate $3 \mathrm{D}$ representation of the vertical and horizontal rebar structure is the control of the exact position of the antenna [302]. Tests in different types of structures indicate that the accuracy of the antenna position in order to obtain precise 3D images is within $1 \mathrm{~cm}$ for $\mathrm{m}^{2}$ [303]. Hugenschmidt and Kalogeropoulus [116] propose a $1 \mathrm{~cm}$ separation between the profile lines, and develop and use a survey apparatus based on guides for the antenna and an electric motor to move up and down the antenna on the wall, covering the entire surface with precision. Another important step in 3D imaging is the processing that requires in all cases an appropriate migration [116,303]. Hugenschmidt et al. [117] test different processing strategies, comparing results from the most classical $2 \mathrm{D}$ filter sequence and 3D processing with an inverse scattering followed by data fusion. The results show that the most classical processing allows for the detection of the top layer of the rebar, which decreasesing the resolution extremely, and focuses on the second layer of vertical bars, although the 3D processing followed by fusion showed the vertical and horizontal bars in the top layer of the rebar. The most complete map of both rebar layers was obtained with the inverse scattering and data fusion. However, the second rebar layer is defined with a lower quality image. The authors suggest that the influence of the concrete, acting as a low-pass filter, and the screen effect of the top rebar layer mask the deeper targets, highlighting the limits of dataset. Other authors also suggest the application of inverse scattering techniques in the assessment of reinforced concrete walls focused on the rebar location $[304,305]$.

Therefore, concerning the detection of inner damage or the contact between the wall and the natural soil, the result depends on the rebar density. Hugenschmidt and Kalogeropoulus [116] and Hugenschmidt and Mastrangelo [302] test the results comparing three different center frequency antennas: $1.5 \mathrm{GHz}, 900 \mathrm{MHz}$ and $400 \mathrm{MHz}$. The results epitomize that, although the resolution decreases as the central frequency decreases, as expected, the lower frequency does not allow greater penetration into the medium. Hence, the inspected depth is the same in all cases as a consequence of the screen effect of the metallic rebar.

GPR assessment is also a promising tool in the case of quality control of retaining walls in deep excavations in unstable soils. In those cases, borehole GPR could be used before the excavation in order to check the integrity of the structure, detecting zones with possible defects, and increasing the safety of the dig. There are few applications of borehole GPR in the literature, most of them being in tunnels during the excavation [306] and in mining and geological explorations. The highest difficulty in this survey is determining the azimuthal position of the targets, mainly in the case of single borehole GPR [307].

The objectives in the assessment of stone and masonry retaining walls include the detection of foundations [119,120], the study of the structure [119], analyzing the contact between stones [120] and determining layers in the wall [121]. In addition, different damages or possible causes of damage are also examined. The most common analysis focuses on the study of voids [308], cracks and discontinuity between stones [120]. In some cases, the inspection focuses on the detection of changes in the mineral composition of the ground that could affect the wall. This is the case in the analysis of changes in the soil salt content [121] or sulphate and chloride content [309]. Changes in the aggregate size also produces changes in the GPR images, showing a large scattering [310]. This effect has been detected in the ground studies [311,312]. Those inspections require the detection of both surfaces of the wall, as it is important to detect the contact between the 
ground and the wall. Therefore, the central frequency of the antennas used depends on the aspects under interest. Beben et al. [115] utilize dual center frequency antennas of $200 \mathrm{MHz}$ and $600 \mathrm{MHz}$ to analyze the wall and the foundations and, depending on the terrain conditions, an antenna with a central frequency of $80 \mathrm{MHz}$. Solla et al. [120] inspect a stone retaining wall with a $1 \mathrm{GHz}$ center frequency antenna, with survey lines in the top of the wall to detect the different stone layers and the contact between the wall and the ground, and the foundations. Santos-Asunçao et al. [121] use an $800 \mathrm{MHz}$ center frequency antenna to detect a buried structure, and the $1 \mathrm{GHz}$ and $2.3 \mathrm{GHz}$ center frequency antennas in the assessment of the state of the buried walls, obtaining 3D images and GPR slices. Wiggenhauser et al. [310] check the inner structure of walls using two antennas with lower central frequencies of $200 \mathrm{MHz}$ and $400 \mathrm{MHz}$. In addition, several tests in laboratory [313] or in field surveys [115] recommend the use of a high-frequency microwave synthetic aperture radar between $1 \mathrm{GHz}$ and $6 \mathrm{GHz}$ in order to obtain B-scans or to generate 2D slice images.

Wiggenhauser et al. [310] highlight the difficulty of the GPR and other NDT in the inspection of masonry retaining walls as a consequence of the limited access to the surfaces and their different stages of deterioration, whereas Santos-Assunçao et al. [121] remark the problem in accurate data acquisition due to irregular stone surfaces and also the importance of the precise position of the antenna, proposing a laser guide marking for the profile lines.

In general, although there are promising results in the assessment of retaining walls, two of the main difficulties are the uncertainty because the different targets could produce similar anomalies and the accurate position of the antenna, because in many cases data are gathered on hard-to-reach surfaces or over irregular surfaces. Different authors propose methodologies and apparatus to facilitate accurate data collection in these difficult conditions. Another inconvenience that affects the assessment of concrete reinforced walls is the limit in penetration depth due to the screening effect of the rebar and the low-pass filter effect of concrete. Although there is the application of accurate data processing, the detection of the contact between the wall and the natural soil is not possible no matter the frequency used. In the case of masonry walls composed of irregular stones and irregular surfaces, ringing noise usually appears in the images that makes the detection of pathologies (voids and cracks) difficult. In addition, there is not a standard procedure or guideline in order to apply GPR surveys to the different types of walls, excepting the guide proposed by the US Department of Transportation [114] and technical reports that include the GPR between the NDT methods for retaining wall inspection [309] or define GPR procedures [308] applied to different case studies. Finally, GPR wall inspection is usually combined with a preceding visual inspection and other tests such as laser scanning [120], infrared thermography, acoustic methods and X-Ray fluorescence material identification through samples [309].

\subsection{Bridges Health Assessment}

Surveying stone masonry or concrete bridges differ in the GPR equipment and in data acquisition methods used. Thus, the discussion on these types of structures reported herein is presented separately.

\subsubsection{Stone Masonry Arch Bridges}

The application of GPR aims to reach the bridge foundations while analyzing the shallower filling and structural elements. The $250 \mathrm{MHz}$ and $500 \mathrm{MHz}$ center frequency antennas are therefore more commonly selected as the most suitable due to their optimal compromise between penetration and resolution. Ground-coupled antenna configurations, usually single antennas mounted on a trolley or manually on a survey cart, are used in this type of bridge surveying. Alani et al. [132], Fauchard et al. [135], Pérez-Gracia et al. [140], Solla et al. [128-131,137,144], Lubowiecka et al. [142] and Arêde et al. [145] employed a combination of low (200-250 MHz) and medium (500-600 MHz) center frequency antennas to evaluate the stone masonry health assessment. Additionally, higher frequencies were 
used in the $800 \mathrm{MHz}$ to $2 \mathrm{GHz}$ frequency range to estimate the thickness of masonry walls and arches [124,132,134-136,138,140,141,143].

Longitudinal profile lines crossing the bridge in the common offset (CO) mode are recommended, with the antenna polarization being orthogonal to the direction of acquisition. Generally, the GPR data acquisition is based on distance intervals, and the trace-interval

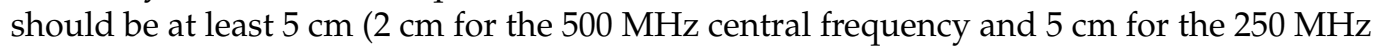
central frequency). To measure the profile lengths and to control the trace distance interval, an odometer wheel is usually attached to the GPR system. However, some stone masonry arch bridges have a surface pavement composed of large irregular blocks, which make measurements difficult, as the continuous movement of the survey wheel is often interrupted. In such circumstances, the survey wheel should be previously calibrated on-site to avoid inaccuracies in spatial trace positioning. Moreover, for these ancient structures that have suffered several restorations or reconstructions throughout history, causing heterogeneity in filling, it is recommended to survey more than one profile line in order to prevent inappropriate data interpretation. Note that GPR profiles should be collected at a prudent distance from the parapets of the bridge that may lead to airwave events (noise) coupled to the reflected signal.

Testing standards for masonry arch bridge inspection were provided by the International Union of Laboratories and Experts in Construction Materials, Systems and Structures (RILEM) Technical Committee (TC) 127-MS “Non-Destructive Tests for Masonry Materials and Structures - test MS.D.3: Radar Investigation of Masonry" [314].

There are a large variety of processing filters to reduce clutter and any unwanted noise in the GPR data collected over stone masonry bridges, in which complex reflection patterns occur due to internal heterogeneity. The processing objectives are: (i) to correct the downshifting of the radar section due to the air-ground interface (e.g., time-zero correction or max. phase correction), (ii) to amplify the received signal in order to mitigate possible losses or attenuations (e.g., gain function, automatic gain control or geometrical divergence compensation), (iii) to suppress the continuous component (e.g., DC removal or dewow), (iv) to remove horizontal continuous low-frequency reflectors (e.g., subtracting average or background removal), (v) to remove both low- and high-frequency noise (e.g., band pass), and (vi) to suppress strong clutter (e.g., deconvolution or migration). Additionally, ancient bridges usually present a double-slope or steep profile, and topographic corrections are therefore required to improve the accuracy in imaging subsurface features.

Some limitations were reported when measuring the thickness of voussoirs (or ring stones) composing an arch from GPR data collected over the bridge's pathway $[144,145]$. The conjunction of both the internal heterogeneity in filling and the more irregular internal shape of the voussoirs yields heavy signal scattering that often masks the reflection produced at the filling-stone interface. To overcome this drawback, some authors [143] have proposed to collect the GPR profiles directly through the inferior face of the vault. However, this methodology is only operational if the vault intrados surface is accessible. Another crucial piece of information for more accurate analytical calculations and structural assessment of bridge structures is the thickness of the spandrel walls $[143,149]$. In this case, the GPR profile lines should be conducted through the vertical walls of the bridge. It is important to also mention the technical difficulties experienced during data acquisition, firstly due to the difficult accessibility to the upper stonework of the bridge and, secondly, due to the excessive weight of the antennas, especially with the $500 \mathrm{MHz}$ antenna. Hence, the use of a ladder is recommended to access the higher parts of the structure, as well as the support of at least two operators in order to maintain both the GPR antenna and the survey wheel in contact with the surface [149]. Further developments should include the design of a measurement device and innovative methods for the acquisition of GPR data through the less accessible parts of a bridge structure (e.g., vaults' intrados, piers, and spandrel walls).

The analysis and interpretation of GPR data is often difficult due to the complexity of stone masonry bridge structures and the heterogeneity of the building materials. In order to understand the propagation of the GPR signal through media and its response (scattering), 
several electromagnetic simulators have been developed, in which particular scenarios and soil properties can be modelled. One of the most employed is the finite-difference time-domain (FDTD) algorithm, which is based on a discretization of both space- and time-domain. Previous studies have demonstrated that realistic and large-scale models can thus be simulated, which allows for a better approximation and comparison to real data in order to assist interpretation. Solla et al. $[130,133,137]$ present an interesting approach to elaborate FDTD models using real geometries based on orthoimages of the bridge structure provided by geomatics techniques (photogrammetric or laser scanning methods). However, this simulation in fine detail requires excessive computational resources and time. In this regard, Diamanti et al. [315,316] develop a numerical approach in which the subgridding method was implemented into the standard FDTD method. Thus, micro regions can be created, with different spatial-steps (or space discretization). Very fine spatial-steps would be exclusively used to simulate smaller geometries such as cracks or delamination; hence, the calculation time required to simulate the entire model is reduced.

The combination of GPR with complementary geophysical techniques (e.g., sonic/ultrasonic testing, electric resistivity, infrared thermography, etc.) is highly recommended. Each particular method provides different information owing to the physical properties of the construction materials, which allows for a more detailed investigation in the diagnosis of bridge stability. Orbán and Gutermann [124] combine GPR, sonic testing, and infrared tomography (IRT) to investigate hidden geometry, voids and cracks and moisture distribution in masonry and fill, as well as to define wet areas. Trela et al. [134] use geoelectrical measurements of spectral induced polarization (SIP), combined with GPR, to evaluate the moisture distribution inside the masonry. Fauchard et al. [135] present a combination of GPR and electrical resistivity tomography (ERT). The GPR revealed internal damage such as voids and delamination, while the ERT allowed one to characterize the transition zone between the bridge and the riverbanks. Solla et al. [317] combine GPR and IRT, together with FDTD modelling, to analyze the moisture in a medieval arch bridge. More recently, Biscarini et al. [318] use GPR and IRT, together with UAV photogrammetry (RGB imaging), to analyze material degradation and its causes in a Roman masonry bridge. Additional information was found regarding the construction phases and restoring interventions of the bridge. Furthermore, Alani et al. [319] present a holistic approach using GPR and InSAR technologies to investigate both the subsurface geometry and the structural displacements of masonry arch bridges certainly caused by water floods and the riverbed soil expansions. Apart from non-invasive geophysics, there are a large variety of conventional NDT methods that complements the GPR surveys. In this frame, Arêde et al. [145] conduct an integral campaign using GPR with other non-destructive and slightly-destructive techniques oriented to estimate physical and mechanical parameters such as on-site stress and masonry deformability (dynamic probing super heavy (DPSH), Ménard pressuremeter (PMT) and flat-jack tests). Finally, it is possible to find several studies focused on the structural assessment of stone masonry arch bridges that combine the use of GPR with complementary geomatics techniques. Generally, these works use geomatics and GPR data to create the model of the bridge structure to be simulated using the finite element method (FEM) analysis $[143,146,149,150]$. Hence, the complex external geometry (metric information) of the structure is provided through geomatics-terrestrial laser scanning (TLS) or photogrammetry - while the GPR gives information of its internal composition [320]. More exhaustive and robust modelling integrates GPR and complementary NDT, such as vibrant ambient noise $[136,140,141,148,151]$, sonic testing $[141,148,151]$, impact-echo tests $[141,151]$ and thermography [136].

\subsubsection{Concrete Bridges}

GPR surveying of concrete bridges is mainly focused on rebar detection and mapping, the estimation of deck thickness, damage detection such as cracking or delamination, moisture and corrosion; as well as other deeper aspects such as foundations and pier 
assessments. The GPR systems, testing methodologies and analysis to be applied for all these aspects are herein discussed.

Depending on the extension of the surveyed area, the depth required and the traffic flow conditions, both ground-coupled and air-coupled antenna systems can be employed in inspecting this type of bridge. Herein lies the difficulty of providing good quality data sets while being completed rapidly and safely for both operators and users. Firstly, in order to avoid traffic disruption, the air-coupled systems allow measuring at a higher speed (with lower resolution measurements) as they are generally mounted on a van or a vehicle. Next, measurements can be conducted for the whole length of the bridge or only for selected areas of interest in both longitudinal and transversal directions. For small survey areas and vertical surfaces, when a more detailed analysis is required (e.g., abutments, girders and piers), single ground-coupled antennas are most commonly used. Conversely, for large survey areas, and particularly to map utilities and reinforcement, the use of multi-channel systems is highly recommended. Array multi-channel systems are preferred because they cover wider width measurements, which shorten the surveying time, increasing the productivity, and benefiting $3 \mathrm{D}$ visualization and the reconstruction of underground network. Moreover, these systems may use antennas arranged with different polarizations. For instance, the optimization of antenna orientation to take advantage of signal polarization is an important feature for successfully locating reinforcement; hence, a hyperbolic reflection is obtained if the GPR profile line is conducted perpendicular to the object direction.

Most commonly, the GPR was used to specifically locate the presence of any cracking and delamination, moisture and corrosion, and to locate the rebar and ducts within the concrete slab. For this purpose, the GPR systems generally used have frequencies higher than $1 \mathrm{GHz}$ (up to $2.6 \mathrm{GHZ}$ ). The $1 \mathrm{GHz}$ frequency is capable of investigating up to $100-150 \mathrm{~cm}$ depth from the concrete surface, while the higher radar frequency has lower depth of investigation, up to $15-20 \mathrm{~cm}$, but means more resolution and accurate data acquisition (it supports a higher sampling rate). For example, regarding resolution, the $2.0 \mathrm{GHz}$ frequency can guarantee a theoretical resolution of $1.25 \mathrm{~cm}$ (quarter of a wavelength criteria) in concrete.

Based on 20 years of operational experiences, Rhee et al. [175] propose a sampling rate for bridge deck inspection using $1.0 \mathrm{GHz}$ air-coupled GPR antenna sets between 12 and $14 \mathrm{scans} / \mathrm{m}$ depending on the highway speed. A sampling rate of $12 \mathrm{scans} / \mathrm{m}$ means one scan per every $80 \mathrm{~mm}$ (with the vehicle where the GPR system is mounted driven at the speed of $80-100 \mathrm{~km} / \mathrm{h}$ ). This sampling rate is much lower than the common sampling rate for ground-coupled GPR operated by normal walking speed, about 50-200 scans $/ \mathrm{m}$. In this regard, the recommendation in the Mara Nord's project guidelines [152] states that with air-coupled antenna systems, the sampling rate should be at least $10 \mathrm{scans} / \mathrm{m}$, while with ground-coupled antenna systems, a sampling rate of $100 \mathrm{scans} / \mathrm{m}$ is recommended.

The ground-coupled GPR system is usually mounted on a survey cart with an integrated encoder wheel that serves to measure the profile lengths and to control the trace-interval. However, to obtain a good reconstruction of the surveyed area, the system requires a good positioning, using a high precision global positioning system (GPS), a total station, or even a local system of coordinates. On the other hand, the air-coupled GPR systems are most commonly mounted on vehicles or other automatic measuring equipment. The latter employs a differential RTK GPS and an encoder-based distance measuring instrument (DMI) for real-time positioning. This global positioning eliminates the need for predefined profile lines and provides a safer data acquisition, because the driver of the mobile system can pay attention to the traffic flow instead of a predefined reference, without reducing the accuracy of relative positioning. Another benefit of a good global positioning is the fact that georeferencing allows for the integration of results obtained from multiple technologies in a geographic information systems (GIS) environment, which contributes to identify the location and extent of defects [169]. 
The presentation of GPR data is usually carried out in the form of 3D maps, or timeslices, at different depths. According to the recommendations provided by Mara Nord's project guidelines [152], for an accurate 3D data acquisition, the distance between parallel profile lines should be a maximum of $50 \mathrm{~cm}$ with a 2D system and a maximum of $12 \mathrm{~cm}$ with a 3D system. Then, the most generalized results on surveying bridge decks are 3D maps of amplitude, which can be produced showing two types of information at the same time [172]. Firstly, the rebar will appear as the most prominent (the steel/metal is a complete reflector of the radar energy). Secondly, the corroded areas will be detected as having low amplitudes (due to the lower dielectric permittivity than healthy rebar areas). Additionally, potential areas of deterioration appear as zones of signal attenuation, and the rebar will appear deeper (lower signal velocity) due to higher moisture and chloride content. Color contour maps of deterioration can be therefore produced, mainly defining moisture, delamination and corrosion. Deterioration maps should be created at different depths in the concrete deck slab in order to estimate the extent of deterioration.

There are different regulations and standard test methods describing processing methodologies to quantitatively analyze the GPR data that generally employ reflection amplitudes. Stryk et al. [321] present an overview of existent recommendations for bridge inspection, namely: the American standard ASTM D6087-08 "Standard Test Method for Evaluating Asphalt-Covered Concrete Bridge Deck Using Ground Penetrating Radar" [53], the American SHRP 2- report S2-R06A-RR-1 “Nondestructive Testing to Identify Concrete Bridge Deck Deterioration" [322], the Mara Nord Project "Recommendations for guidelines for the use of GPR in bridge deck surveys" [152], the British technical specifications DMRB 3.1.7 "Design Manual for Roads and Bridges, Advice notes on the non-destructive testing of highway structures—advice note 3.5 BA 86/2006: Ground Penetrating Radar (GPR)" [5], the German BASt-report B55 “Examination of GPR in combination with magnetic techniques for the determination of moisture and salinity of concrete bridge decks with asphalt cover" [323], and the German document B10 "Recommendation for nondestructive testing of civil engineering structures by GPR" [324]. Additional standards including the assessment of bridge decks are: The American AASHTO R 37-04 "Standard Practice for Application of Ground Penetrating Radar (GPR) to Highways" [325], the American ACI 228.2R-98 "Nondestructive Test Methods for Evaluation of Concrete in Structures" [326], and the American NCHRP RR 848 "Inspection Guidelines for Bridge Post-Tensioning and Stay Cable Systems Using NDE Methods" [327].

The typical post-processing includes time-zero correction (set ground surface), background removal (remove horizontal banding), band pass filtering (remove high- and low-frequency noise), and gain (amplify the received signal across depth range). Migration is also recommended when identifying the rebar in a concrete slab in order to reduce or eliminate hyperbolic diffraction patterns in the data [180]. Thus, each pixel in the original GPR images will be migrated focusing energy on the true rebar locations; hence, the intensity values of the pixels at a true object location will end up having the sum intensity value of all the pixels on the hyperbolic signature (the energy will be focused therefore on those pixels). Moreover, a procedure known as depth correction is commonly applied [178], where linear regression is used to normalize amplitudes in order to obtain a correct deterioration map. The signal strength (amplitude) decreases with rebar corrosion, but also with variation in the rebar depth. Reflections from deeper rebars are more attenuated than those from shallower rebars due to a larger two-way travel time and, therefore, it is important to apply this correction in order to minimize the effect of the rebar depth such that the overall amplitude variation in the entire bridge deck will be only indicative of corrosion.

Although GPR data collection can be fast and efficient when surveying concrete bridges, the interpretation of GPR data is a very time-consuming task and depends on the interpretational abilities of the operator to provide accurate information and reliable results. For example, for rebar detection application, and for a bridge deck with thousands of rebars, it takes an extensive amount of time to manually identify and measure the amplitude value of each rebar. Extensive literature exists, therefore, regarding the 
automatic detection of rebars in concrete bridge decks, which is based on detecting reflection hyperbola patterns. There is a large variety of computational methods that can be applied, such as interpolation functions, a histogram of oriented gradients (HOG), a feature descriptors-based multi-layer perceptron (MLP) classifier, a support vector machine (SVM), a convolutional neural network (CNN), the limited and simplified hyperbolic summation (LSHS) technique, partial differential equations (PDEs), the hidden Markov model (HMM), a genetic algorithm, and the fuzzy logic approach. These computational methods are described and applied in some relevant and recent studies [177-181] and, in most cases, with accuracies greater than $95.0 \%$. On the other hand, algorithms are also implemented to extract the GPR amplitudes automatically from both the whole GPR signals and the rebar peaks detected [165], [171], [174], generally after applying a migration procedure.

Some limitations can occur during concrete bridge inspections. Firstly, the steel/metal is a quasi-perfect reflector of the radar-waves, which facilitates the rebar detection, but deeper targets can be masked if it is a tight mesh. In this regard, collecting data in both polarizations (with the dipoles perpendicular and parallel to data collection direction) has benefits because the reflections produced by metallic targets perpendicular to the data collection direction are weakly seen in data collected with dipoles parallel to the scanning direction, so that other potential targets below them can be more easily detected. Secondly, overlapping reflections are usually observed between consecutive bars that is dependent on the spatial resolution of the antenna (higher frequencies provide a higher resolution), which may lead to the misinterpretation of closest or smaller-diameter bars. Resolution problems can also occur in sections with a too small concrete cover when measuring pavement thickness. The selection of the most appropriate central frequency of the antenna is therefore crucial herein. Moreover, another important parameter affecting the location accuracy is the horizontal sampling. Dense horizontal sampling (scan spacing), gives more accuracy on positioning and good quality data for further amplitude analysis, although its main consequence is a decrease in the survey speed. Conversely, using a low sampling rate may limit data visibility in the field and cause inaccurate adjustments of hyperbolas peaks when processing. Thirdly, the 3D data acquisition (especially with single GPR antennas) may incur an incorrect distance encoder calibration, position of the antenna on starting/ending grid lines, improperly configured survey grid, georeferencing, etc. The use of antenna arrays or automatic scanner systems makes the acquisition of 3D data easier and thus encourages a wider use of 3D techniques although, in practice, these systems usually have an excessive cost. For example, a higher sampling rate (higher number of traces recorded) decreases a survey speed, which could result in higher survey costs and, more importantly, could interrupt the traffic flow. Fourthly, the amplitude value is highly dependent on various factors such as different depth to the top mat of the reinforcing steel, weather conditions (e.g., humidity) during data acquisition, and concrete properties (e.g., density, porosity, etc.), which makes the detection of corrosion and delamination only difficult from the analysis of amplitude maps. Confirmation with the additional analysis of other signal attributes (e.g., signal attenuation, signal-to-noise ratio and velocity of propagation) or complementary NDT should be part of the process whenever possible.

Regarding the combined used of GPR with other complementary NDT, Sun et al. [174] compare delamination maps from acoustic surveys with deterioration maps (signal attenuation maps) from GPR. The results demonstrate that combining both techniques will provide a complementary and comprehensive evaluation of concrete bridge decks, although GPR detected more defects than acoustic methods. The acoustic method can only detect near surface delamination, while GPR signals can penetrate concrete. Rathod et al. [162] combine GPR with a rebar detector (profoscope), which uses electromagnetic pulse induction technology to measure rebar diameter, spacing and cover depth which are required to assess the load capacity of bridge decks. The results suggest that GPR gives more consistent and accurate data with regards to spacing and cover. Dabous et al. [169] successfully integrate infrared thermography (IRT) and GPR, mainly in indicating the subsurface delamination of concrete bridge decks. In addition, the study demonstrates 
the feasibility of integrating the collected data into GIS for enhanced visualization of the inspection results, which allows integrating data and gives a full-scale representation of the condition of the inspected area. Other authors, such as Janků et al. [161] combine IRT and GPR, but also ultrasonic pulse echo (UPE), for the detection of delamination in concrete bridges. The results revealed the limited capability of GPR to detect cavities located just beneath the surface, while UPE failed to detect such defects completely. On the other hand, IRT was very successful at locating cavities near the surface, but only under convenient weather conditions. GPR and UPE are better suited for locating deeper defects inside the material. Dinh et al. [160] employ electrical resistivity (ER) and half-cell potential (HCP) in order to validate the corrosion detected by GPR automatically from amplitude maps. Barnes et al. [164] apply HCP and chain drag data as thresholds for an accurate damage estimate from GPR amplitude maps. Abouhamad et al. [168] propose GPR in conjunction with HCP and hammer sounding resistivity to find the appropriate GPR threshold and use this information to correctly assess bridge deterioration. Alani et al. [183] use GPR and IBIS-S (deflection and vibration detection sensor system with interferometric capability) techniques for bridge assessment, which provide valuable information such as rebar position, moisture ingress and deflection. To determinate the bridge condition, a FEM (finite element model) of the bridge was then created using information obtained from the NDT results and compared with the dynamic behavior of the bridge without defects. Varela-Ortiz et al. [159] combine non-destructive load testing with GPR to obtain the safe load-carrying capacity of concrete bridges. Thus, field load testing allowed one to calibrate a FEM analysis and to accurately characterize the structure's live-load response, while GPR provided reliable information regarding the internal reinforcement and the condition of the concrete. Varnavina et al. [172] use LiDAR technology and ultrasonic surface wave (USW) testing to corroborate the spatial distribution of corrosion estimated by GPR.

\subsection{Tunneling Inspection}

GPR measurements in tunnels are generally conducted using $250 \mathrm{MHz}, 500 \mathrm{MHz}$ and $1 \mathrm{GHz}$ center frequency antennas according to the requirements of resolution and depth. When detecting the backfill grouting (grout mortar is commonly injected between the inner lining and bedrock), low frequencies (200-100 MHz) are recommended to better penetrate reinforcement, although results show a poor resolution. However, high frequencies (from 1 to $2 \mathrm{GHz}$ ) have shallower detecting depth, leading to a near-surface survey (e.g., detecting rebar and defects or damage in lining). Both air-coupled and ground-coupled systems can be used in tunnel diagnostics.

Generally, tunnels are inspected manually, by maneuvering the GPR antenna over the surface of the tunnel, with single ground-coupled antennas using the mode of continuous acquisition, which is very slow and inefficient. In the process of tunnel inspection, longitudinal survey lines are most commonly arranged, with a range of three to six serial lines located at the vault, the left hance, the right hance, the left sidewall, the right sidewall and the inflected arch. It should be mentioned here that the connection with external GPS devices for data referencing is obviously limited when surveying the interior of a tunnel structure. Therefore, wheel encoders are used during data acquisition to ensure the accuracy of ranging (trace interval) and location. Typical trace interval distances are: $5.0 \mathrm{~cm}(<200 \mathrm{MHz}), 2.5 \mathrm{~cm}(250 \mathrm{MHz}), 2.0 \mathrm{~cm}(500 \mathrm{MHz})$ and $1.0 \mathrm{~cm}(>1 \mathrm{GHz})$. So far, the following practical problems that typically occur are: (1) loss of contact between the antenna and the surface (the operator should ensure both the antenna and the survey wheel are in contact with the surface, while keeping a constant (uniform speed) and continuous rotation); (2) deviation of the antenna with respect to the radar line (the operator should ensure the antenna position is consistent with the location of the acquisition line); and (3) the presence of cables and conduits on the walls of the tunnel that makes it impossible to collect data in those areas.

Due to the shortcomings of existing techniques using manual (hand-held) antennas or even hydraulic supporting systems (mainly a vehicle bracket with an arm or a lifter to reach 
the top $[188,191-193,195,328])$, new GPR devices have been developed for higher speed data collection and complete cross section scanning. In this regard, Balaguer et al. [329] describe the current trends towards fully automated tunnel inspection, and introduce new technologies such as robotic platforms, control algorithms and decision-making strategies. Zan et al. [197] develop a train-mounted GPR system with multi-channel air-launched antennas, and absolute positioning technology using GPS and GIS systems, in order to not interrupt normal railway operation. In this system, recording data is controlled by a distance sensor pulse, allowing for data collection to be fully automated. Using six sets of $300 \mathrm{MHz}$ air-launched antennas forming a full-section detecting system, with a traceinterval of $5 \mathrm{~cm}$, the maximum test speed can reach up to $175 \mathrm{~km} / \mathrm{h}$. A set of machinery was designed by Xie et al. [330] consisting of arc-tracks connected to a shield tunnel machine in order to detect grouting in real time during the construction phase. Both $500 \mathrm{MHz}$ bowtie and Vivaldi antennas were used, which automatically move along the tracks.

As previously mentioned, the detection efficiency is quite low when using groundcoupled antennas, as they must be put close to the tunnel wall or roofs, which usually requires traffic disruption due to slower survey speeds. Conversely, air-launched antennas can be mounted on a vehicle with a certain distance to the wall. However, due to the diffusion attenuation, some energy is lost in the air and the probing depth is shallower than ground-coupled antennas. The American SHRP-2 report S2-R06G-RR-1 entitled "Mapping voids, debonding, delamination, moisture, and other defects behind or within tunnel linings" [331] recommends the use of air-coupled GPR antennas for detecting areas of high moisture or low density, whereas ground-coupled antennas are recommended for detecting defects at different cover depths within or behind the tunnel linings.

The extraction of information from the GPR data is often not a simple process. In order to obtain a more distinct image, the radargrams are therefore enhanced using postprocessing filters. Most commonly, minimal filters are applied to ensure the minimal loss of data. Time-zero is firstly corrected as the actual detection surface and the DC component is then removed to normalize voltage. The dewow filter, band pass filter and deconvolution are vertical (temporal) filters generally applied to remove DC. Gain is applied afterwards to equalize the signal amplitude (e.g., linear and exponential gain or automatic gain control) and, lastly, horizontal (spatial) filtering (e.g., subtracting average, background removal or running average) can eliminate the noise or uncertain fluctuations in a given window.

Lyu et al. [332] apply the reverse-time migration (RTM) algorithm to improve the detection accuracy of tunnel lining cavities. Compared with the Kirchhoff migration, the RTM can better focus the energy of the diffraction wave on the position of the reflector and reduce clutter (random scattering and multiple reflections from reinforcement), which greatly improves data interpretation.

However, there are some negative factors adversely affecting the GPR detection. Firstly, there are so many noisy signals from utilities (e.g., power cables) or metal (reinforcement) in the tunnel. Shotcrete-containing steel fibers cannot be inspected because fibers generate random electromagnetic scattering. Secondly, detecting grouting thickness requires enough dielectric permittivity contrast between the grout and the soil to easily detect the boundary between layers. In this regard, Zhang et al. [189] report that contrast in the dielectric constant between the grout and the soil appeared to be sufficiently large fourteen days after the grouting treatment.

In complex structures such as tunnels, the comparison of measured field data with synthetic data has been proved to be a useful assisting tool for data interpretation. Numerical simulations are set up to predict the performance of the radar-wave and to recognize typical reflection patterns, which allows one to obtain an accurate interpretation more easily. There are some noteworthy studies showing that additional forward modelling has increased the reliability of GPR results when inspecting internal rebar location and possible damage, or even thickness of segments and grouting [189,194-196].

The GPR method was also applied in combination with other NDT methods in tunnel diagnostics. Karlovšek et al. [333] include an overview of the non-destructive methods 
used for possible testing bored tunnels' integrity (such as GPR, impact-echo, ultrasounds, etc.), in which their pros and cons are briefly discussed. Cardarelli et al. [202] present an integrated study using GPR, seismic refraction and seismic transmission tomography to investigate tunnel stability. The interpretation of integrated data from GPR and seismic tomography allowed for the detection of discontinuities in the rock (most likely associated to open fractures), while the integration of GPR and seismic refraction is appropriate to identify the loosened zone around the tunnel. Abraham and Dérobert [186] successfully use GPR and seismic refraction to detect damaged zones and specific material properties in fired tunnel walls. Xie and Zeng [193] combine GPR and 3D laser scanning for the evaluation of a shielded tunnel condition, which demonstrates that GPR leads to the detection of cavities behind lining, while laser scanning allows testing on surface situations of tunnel liners (e.g., water seepage).

\section{Final Remarks and Future Perspectives}

The use of GPR for transport infrastructure assessment is increasingly trustworthy for several purposes as already addressed in this paper. The reliability of the results is enabling a more confident application of GPR together with complementary non-destructive tests for the definition of key performance indicators (KPIs) in order to support the maintenance decisions of transport infrastructure administrations [259,260,263].

Some researchers are focused on the design of innovative devices that facilitates surveying in complex or inaccessible structures such as columns, walls and roofs. One example is the device designed and tested by Hugenschmidt et al. [117] that consists of a support for the antenna in rails moved with an electric motor. The assessment of tall structures, in some cases with difficult accessibility, requires the development of gadgets with the objective of rapid surveying while assuring accurate data acquisition and precise antenna position. In this way, in some cases, the use of drones has been also proposed and tested. The common application consists of the combination of a usual GPR survey with a photogrammetric study by means of an UAV and other techniques [266,318]. However, some authors propose prototypes to mount the GPR on an UAV [334]. This approach requires the design of novel portable antennas [335]. Some proposed devices provide promising results, although the antennas could be improved in order to enhance the signal-to-noise ratio, and additional tests are therefore needed to validate the results and to calibrate the equipment [336]. Further progress could be focused on the development of antennas and UAV systems for surveying structures or parts of the structures with poor accessibility (roofs, tunnels, columns, etc.) and large structures (airports and roads). Data acquisition using an UAV could be used for the surveying of punctual zones of the structures, and combined with more traditional surveys (common offsets, CMP or WARR). Moreover, additional tests could be needed to validate and compare the results with those obtained by using common ground-coupled or air-coupled antennas.

Other interesting field of research is the combination of GPR, and other NDT, with robotic platforms for autonomous surveys. Valuable proposals include a climbing robot supporting a GPR and a camera for the inspection of damage in walls $[337,338]$ or robots specifically designed for disaster management that could integrated different sensors (GPR, LiDAR, cameras, etc.) on the platform [339]. The proposal of a big robotic platform with a large number of sensors for autonomous pavement assessment [340] opens an interesting line of research in the field of structures assessment. The development of those types of devices requires studies for the integration of different sensors in the robotic system and the progress on data fusion to obtain a complete and accurate inspection. An important challenge in this field is the design of low weight equipment and fast and robust protocols of communication, allowing for the visualization of data and interpreted models in real time. The design of antennas to be mounted on robotic platforms for the assessment of zones with difficult accessibility or landmine detection [341] is crucial in the advance of combining cybernetics with NDT surveys. Moreover, most of the ongoing works are tested in simple cases such as detecting rebars or metallic sheets. Most likely, robust and higher 
resolution antenna, as well as precise sensors for positioning might be developed and tested in different environments.

As has already been referred to, the GPR data processing is time-consuming and still a challenge. There is a trend in using artificial intelligence (AI) in automatic processing and detection instead of the common detailed trace-to-trace processing and subjective data interpretation. During the last decade, artificial neural networks associated with machine learning techniques have been successfully applied to improve the GPR processing [342], namely, the inversion approach to locate subsurface targets [343,344], reconstructing highquality relative permittivity maps of tunnel lining [345], rebar detection [346], and railway ballast diagnosis through unsupervised processing [347,348].

Innovative technologies and modelling, such as LiDAR and BIM (building information modelling), when combined with GPR, thermography and electromagnetic location, are critical for transport infrastructures subsurface diagnosis, even more significant in dense urban areas [349]. Highly reliable 2D and 3D mapping became possible in this way. Thus, providing an "accurate" view of the occupied subsurface space, disruptions can be prevented in the case of new constructions, consequently improving safety and accuracy of excavation sites [350,351].

Research financed by H2020 also emphasize the importance of this matter, with the following ongoing projects:

- GEOFIT [352] aims to develop a compact GPR for mapping the underground with an accurate positioning measurement device (e.g., GNSS). Regarding the processing, a retrofitting approach is studied, namely to search for meaningful features in the GPR data. For this purpose, based on the library of patterns of interest developed in this project, the pattern that best fits in the GPR image is found. In this way, a higher level of automation will be achieved through automatic recognition of objects and patterns. An additional objective of GEOFIT is to integrate models of retrofitted buildings and construction sites (as-built BIM) with models of the underground situation.

- Asset4Rail [353] aims "to developing a set of cost efficient and cutting-edge assetspecific measuring and monitoring devices ... The information collected by such devices will then be processed to generate relevant maintenance infrastructure-related information to support asset management decision." One of the main outputs expected from the project is to develop a new product for the NDT inspection of tunnel lining based on GPR, LiDAR and thermal cameras, as well as to develop and validate the drone inspection of tunnels and bridges. Additionally, a future trend is to integrate the monitoring data into BIM models, mainly for tunnels and bridges, enabling maintenance decisions function. "The resulting integrated BIM environment will contain all current capabilities - a 3D BIM model carrying geometry, design information, quantities etc., together with relevant linked documents, 5D costs, 6D maintenance plans and similar - as well as a new capability for sensory readings, both real-time and historical, enabling this data to be displayed side-by-side with all other relevant asset and maintenance information, 3D model data and properties."

- IM-SAFE [354] aims to support the European Commission (EC) and the European Committee for Standardization (CEN) to prepare a new standard in monitoring for optimal maintenance and safety of transport infrastructure based on consolidated and accepted knowledge and experience in the EU and worldwide. Aligned with the topic of this article, IM-SAFE includes the review of surveying technologies used in the condition evaluation and diagnosis of bridges and tunnels (satellite imaging, LiDAR, NDT active and passive testing technologies (such as GPR among others)). Moreover, procedures will be adopted for determining damage detection indicators and actions on structures in risk and safety analysis based on condition survey data, as well as procedures for data quality assurance and digitalization (use of BIM, predictive twin and other digital innovations).

To sum up, all the contributions herein presented have proven the benefits of the wide application of GPR to on-site diagnosis, integration with complementary tests and 
geospatial visualization and management modelling. Nevertheless, there are still open issues mainly focused on the development of algorithms for more efficient data processing and interpretation, in addition to new systems and devices improving data acquisition and quality. Furthermore, digital innovations are expected in a near future, including the integration of GPR data into a GIS/BIM environment, augmented reality and predictive modelling in order to support industry 4.0.

Supplementary Materials: The following are available online at https:/ /www.mdpi.com/2072-429 2/13/4/672/s1, Table S1: Roads: relevant on-site GPR surveys, Table S2: Airports: relevant on-site GPR surveys, Table S3: Railways: relevant on-site GPR surveys, Table S4: Retaining walls: relevant on-site GPR surveys, Table S5: Bridges: relevant on-site GPR surveys, Table S6: Tunneling: relevant on-site GPR surveys.

Author Contributions: M.S., V.P.-G. and S.F. conceived, designed and wrote this review article. All authors have read and agreed to the published version of the manuscript.

Funding: This project has received funding from the European Union's Horizon 2020 research and innovation program under grant agreement No 958171. M.S. acknowledges financial support from the Spanish Ministry of Science and Innovation for a "Ramón y Cajal" contract (RYC2019-026604-I / AEI / 10.13039/501100011033).

Institutional Review Board Statement: Not applicable.

Informed Consent Statement: Not applicable.

Data Availability Statement: Not applicable.

Acknowledgments: The authors would like to thank the Applied Geotechnologies (Geotech) research group of the Universidade de Vigo (Spain), the Geophysics and Earthquake Engineering (GIES) research group of the Universitat Politècnica de Catalunya (Spain), and the Transport Department of the National Laboratory for Civil Engineering (LNEC) in Lisbon (Portugal) to provide the graphic material and results included in this article.

Conflicts of Interest: The authors declare no conflict of interest. The funders had no role in the design of the study; in the collection, analyses, or interpretation of data; in the writing of the manuscript, or in the decision to publish the results.

\section{References}

1. Annan, P. GPR Principles, Procedures E Applications; Sensors and Software Inc.: Mississauga, ON, Canada, 2003 ; p. 278.

2. Daniels, D.J. Ground Penetrating Radar; The institution of Electrical Engineers: London, UK, 2004; p. 726.

3. Jol, H.M. Ground Penetrating Radar: Theory and Applications; Elsevier Science: Amsterdam, The Netherlands, 2009 ; p. 544.

4. ASTM International. ASTM D6432-19, Standard Guide for Using the Surface Ground Penetrating Radar Method for Subsurface Investigation; ASTM International: West Conshohocken, PA, USA, 2019; Available online: www.astm.org (accessed on 11 February 2021). [CrossRef]

5. $\quad$ Department for Transport, Highway Agency. DMRB 3.1.7.: Design Manual for Roads and Bridges, Advice Notes on the Non-Destructive Testing of Highway Structures-Advice Note 3.5 BA 86/2006: Ground Penetrating Radar (GPR), UK; Department for Transport, Highway Agency: Birmingham, UK, 2006; ISBN 0115527788.

6. Highway Agency. DMRB 7.3.2.: Design Manual for Roads and Bridges, Data for Pavement Assessment-Annex 6 HD 29/2008: Ground-Penetrating Radar (GPR), UK; Highway Agency: Birmingham, UK, 2008.

7. European GPR Association. GS1601: The European GPR Association Guidelines for Pavement Structural Surveys; European GPR Association, 2016.

8. Comitato Elettrotecnico Italiano. CEI 306-8: Impiego del Radar per Introspezione del Suolo per Prospezioni ad Opera di Posa di Servizi ed Infrastrutture Sotterranee; Comitato Elettrotecnico Italiano: Milano, MI, USA, 2004.

9. Morey, R.M. Continuous subsurface profiling by impulse radar. In Proceedings of the Conference on Subsurface Exploration for Underground Excavation and Heavy Construction, Henniken, NH, United States, 11-16 August 1974; American Society of Civil Engineers: Reston, VA, USA, 1974; pp. 213-232.

10. Morey, R.M. Detection of subsurface cavities by ground penetrating radar. Highw. Geol. Symp. 1976, $27,28-30$.

11. Caldecott, R.; Poirier, M.; Scofea, D.; Svoboda, D.E.; Terzuoli, A.J. Underground mapping of utility lines using impulse radar. Inst. Electr. Eng. Proc. F Commun. Radar Signal Process. 1988, 135, 343-361. [CrossRef]

12. Osumi, N.; Ueno, K. Detection of buried plant. Inst. Electr. Eng. Proc. F Commun. Radar Signal Process. 1988, 135, 330-342. [CrossRef] 
13. Hironaka, M.C.; Hitchcock, R.D.; Forrest, J.B. Detection of Voids Underground and Under Pavements; Report No. CEL-TN-1449; Naval Civil Engineering Laboratory: Port Hueneme, CA, USA, 1976.

14. Kovacs, A.; Morey, R.M. Detection of Cavities under Concrete Pavement; Report No. CRREL 83-18; Cold Regions Research and Engineering Laboratory, Department of the Army: Hanover, Germany, 1983.

15. Benedetto, A.; Pajewski, L. Civil Engineering Applications of Ground Penetrating Radar; Springer Transactions in Civil and Environmental Engineering; Springer International: New York, NY, USA, 2015. [CrossRef]

16. Wai-Lok Lai, W.; Dérobert, X.; Annan, P. A Review of Ground Penetrating Radar Application in Civil Engineering: A 30-Year Journey from Locating and Testing to Imaging and Diagnosis. NDT E Int. 2018, 96, 58-78. [CrossRef]

17. Pajewski, L.; Fontul, S.; Solla, M. Ground-penetrating radar for the evaluation and monitoring of transport infrastructures. In Innovation in Near-Surface Geophysics. Instrumentation, Application, and Data Processing Methods; Elsevier: Amsterdam, The Netherlands, 2019. [CrossRef]

18. FORMAT poject "Fully Optimised Road Maintenance". In Assessment of High Speed Monitoring Prototype Equipment; Deliverable Report D12; 2004.

19. Hopman, V.; Beuving, E. Repeatability, reproducibility and accuracy of GPR measurements. In Proceedings of the 6th International Conference on BCRRA, Lisbon, Portugal, 24-26 June 2002; Branco, C., Ed.; Balkema: Lisbon, Portugal, 2002.

20. Highways Agency. Pavement Design and Maintenance. Pavement Maintenance Assessment. Structural Assessment Methods; DMRB Volume 7 Section 3 Part 2 (HD 29/94); The Stationary Office: London, UK, 2001.

21. Lorenzo, H.; Rial, F.I.; Pereira, M.; Solla, M. A full non-metallic trailer for GPR road surveys. J. Appl. Geophys. 2011, 75, 490-497. [CrossRef]

22. Plati, C.; Loizos, A. Using ground-penetrating radar for assessing the structural needs of asphalt pavements. Nondestruct. Test. Eval. 2012, 27, 273-284. [CrossRef]

23. AASHTO. Part 2. Chapter 5. Evaluation of Existing Pavements for Rehabilitation. In National Cooperative Highway Research Program 1-37A: Guide for Mechanistic-Empirical Design of New and Rehabilitated Pavement Structures; AASHTO: Washington, DC, USA, 2004.

24. Maser, K.; Scullion, T.; Briggs, R.C. Use of Radar Technology for Pavement Layer Evaluation; Research Report 0930-SF; Research Study Number 2-18-88-930; Texas Transportation Institute, Texas University: Austin, TX, USA, 1991.

25. Al-Qadi, I.L.; Hazim, O.A.; Su, W.; Riad, S.M. Dielectric properties of Portland cement concrete at low radio frequencies. J. Mater. Civ. Eng. 1995, 7, 192-198. [CrossRef]

26. Tannous, B.S. Investigation of Electrical Properties of Earth Materials by Ground Penetrating Radar. Retrospective Theses and Dissertations. Master's Thesis, University of Central Florida, Oviedo, FL, USA, 1987; p. 5082. Available online: https: / / stars.library.ucf.edu/rtd/5082 (accessed on 11 February 2021).

27. Robert, A. Dielectric permittivity of concrete between $50 \mathrm{MHz}$ and $1 \mathrm{GHz}$ and GPR measurements for building materials evaluation. J. Appl. Geophys. 1998, 40, 89-94. [CrossRef]

28. Saarenketo, T. Using ground-penetrating radar and dielectric probe measurements in pavement density quality control. Transp. Res. Rec. 1997, 1575, 34-41. [CrossRef]

29. Maser, K.R. Ground Penetrating Radar Surveys to Characterize Pavement Layer Thickness Variations at GPS Sites (No. SHRP-P-397); Strategic Highway Research Program, National Research Council: Washington, DC, USA, 1994.

30. Gordon, M.O.; Broughton, K.; Hardy, M.S.A. The assessment of the value of GPR imaging of flexible pavements. NDT E Int. 1998, 31, 429-438. [CrossRef]

31. Maser, K.R.; Scullion, T. Automated Pavement Subsurface Profiling Using Radar: Case Studies of Four Experimental Field Sites; Transportation Research Record 1344; Texas Transportation Institute, Texas A\&M University: Bryan, TX, USA, 1992.

32. Maser, K.R. Condition assessment of transportation infrastructure using ground-penetrating radar. J. Infrastruct. Syst. 1996, 2, 94-101. [CrossRef]

33. Hugenschmidt, J.; Partl, M.N.; De Witte, H. GPR inspection of a mountain motorway in Switzerland. J. Appl. Geophys. 1998, 40, 95-104. [CrossRef]

34. Grote, K.; Hubbard, S.; Harvey, J.; Rubin, Y. Evaluation of infiltration in layered pavements using surface GPR reflection techniques. J. Appl. Geophys. 2005, 57, 129-153. [CrossRef]

35. Benedetto, A. Water content evaluation in unsaturated soil using GPR signal analysis in the frequency domain. J. Appl. Geophys. 2010, 71, 26-35. [CrossRef]

36. Loizos, A.; Plati, C. Accuracy of pavement thicknesses estimation using different ground penetrating radar analysis approaches. NDT E Int. 2007, 40, 147-157. [CrossRef]

37. Varela-González, M.; Solla, M.; Martínez-Sánchez, J.; Arias, P. A semi-automatic processing and visualisation tool for groundpenetrating radar pavement thickness data. Autom. Constr. 2014, 45, 42-49. [CrossRef]

38. Lahouar, S.; Al-Qadi, I.L. Automatic detection of multiple pavement layers from GPR data. NDT E Int. 2008, 41, 69-81. [CrossRef]

39. Wang, S.; Zhao, S.; Al-Qadi, I.L. Continuous real-time monitoring of flexible pavement layer density and thickness using ground penetrating radar. NDT E Int. 2018, 100, 48-54. [CrossRef]

40. Solla, M.; Lagüela, S.; González-Jorge, H.; Arias, P. Approach to identify cracking in asphalt pavement using GPR and infrared thermographic methods: Preliminary findings. NDT E Int. 2014, 62, 55-65. [CrossRef] 
41. Rasol, M.A.; Pérez-Gracia, V.; Fernandes, F.M.; Pais, J.C.; Santos-Assunçao, S.; Santos, C.; Sossa, V. GPR laboratory tests and numerical models to characterize cracks in cement concrete specimens, exemplifying damage in rigid pavement. Measurement 2020, 158, 107662. [CrossRef]

42. Rasol, M.A.; Pérez-Gracia, V.; Solla, M.; Pais, J.C.; Fernandes, F.M.; Santos, C. An experimental and numerical approach to combine Ground Penetrating Radar and computational modelling for the identification of early cracking in cement concrete pavements. NDT E Int. 2020, 115, 102293. [CrossRef]

43. Benedetto, A.; Tosti, F.; Ortuani, B.; Giudici, M.; Mele, M. Mapping the spatial variation of soil moisture at the large scale using GPR for pavement applications. Near Surf. Geophys. 2015, 13, 269-278. [CrossRef]

44. Fernandes, F.M.; Fernandes, A.; Pais, J. Assessment of the density and moisture content of asphalt mixtures of road pavements. Constr. Build. Mater. 2017, 154, 1216-1225. [CrossRef]

45. Zhang, J.; Yang, X.; Li, W.; Zhang, S.; Jia, Y. Automatic detection of moisture damages in asphalt pavements from GPR data with deep CNN and IRS method. Autom. Constr. 2020, 113, 103119. [CrossRef]

46. Zhao, S.; Al-Qadi, I. Pavement drainage pipe condition assessment by GPR image reconstruction using FDTD modeling. Constr. Build. Mater. 2017, 154, 1283-1293. [CrossRef]

47. Pedret-Rodes, J.; Martínez-Reguero, A.; Pérez-Gracia, V. GPR Spectra for Monitoring Asphalt Pavements. Remote Sens. 2020, 12, 1749. [CrossRef]

48. Rodés, J.P.; Perez-Gracia, V.; Martínez-Reguero, A. Evaluation of the GPR frequency spectra in asphalt pavement assessment. Constr. Build. Mater. 2015, 96, 181-188. [CrossRef]

49. Liu, H.; Deng, Z.; Han, F.; Xia, Y.; Liu, Q.H.; Sato, M. Time-frequency analysis of air-coupled GPR data for identification of delamination between pavement layers. Constr. Build. Mater. 2017, 154, 1207-1215. [CrossRef]

50. ASTM. Standard Test Method for Determining the Thickness of Bound Pavement Layers Using Short-Pulse Radar; Non-destructive testing of pavement structures; ASTM D4748; ASTM: West Conshohocken, PA, USA, 2004.

51. Saarenketo, T. Recommendations for guidelines for the use of GPR in asphalt air voids content measurement. Mara Nord Project; Europeiska Unionen: Brussels, Belgium, 2012.

52. Pajewski, L.; Vrtunski, M.; Bugarinovic, Ž.; Ristic, A.; Govedarica, M.; Van der Wielen, A.; Grégoire, C.; Van Geem, C.; Dérobert, X.; Borecky, V.; et al. GPR system performance compliance according to COST Action TU1208 guidelines. Ground Penetrating Radar 2018, 1, 104-122. [CrossRef]

53. ASTM. ASTM D6087-08(2015)e1. In Standard Test Method for Evaluating Asphalt-Covered Concrete Bridge Decks Using Ground Penetrating Radar; ASTM International: West Conshohocken, PA, USA, 2015; Available online: www.astm.org (accessed on 11 February 2021). [CrossRef]

54. Silva, L.A.; Borges, W.R.; Cunha, L.S.; Branco, M.G.C.; Farias, M.M. Use of GPR to identify metal bars and layer thickness in a rigid pavement. Geotech. Geophys. Site Charact. 2013, 4, 1341-1346.

55. Al-Qadi, I.L.; Lahouar, S. Measuring rebar cover depth in rigid pavements with ground-penetrating radar. Transp. Res. Rec. 2005, 1907, 80-85. [CrossRef]

56. Rasol, M.A.; Pérez-Gracia, V.; Fernandes, F.M.; Pais, J.C.; Solla, M.; Santos, C. NDT assessment of rigid pavement damages with ground penetrating radar: Laboratory and field tests. Int. J. Pavement Eng. 2020, 1-16. [CrossRef]

57. Alani, A.M.; Lantini, L. Recent Advances in Tree Root Mapping and Assessment Using Non-destructive Testing Methods: A Focus on Ground Penetrating Radar. Surv. Geophys. 2020, 41, 605-646. [CrossRef]

58. Vafidis, A.; Economou, N.; Dimitriadis, K. Time varying zero-phase filtering of GPR data for imaging pavement layers. In Proceedings of the 73rd EAGE Conference and Exhibition Incorporating SPE EUROPEC 2011 (pp. cp-238), Vienna, Austria, 23-27 May 2011; European Association of Geoscientists \& Engineers: Houten, The Netherlands, 2011. [CrossRef]

59. Grégoire, C.; Van Geem, C. Use of radar in road investigation BRRC experience. In Proceedings of the 7th International Workshop on Advanced Ground Penetrating Radar, Nantes, France, 2-5 July 2013; IEEE: New York, NY, USA, 2013. [CrossRef]

60. Al-Qadi, I.L.; Lahouar, S. Measuring layer thicknesses with GPR-Theory to practice. Constr. Build. Mater. 2005, 19, 763-772. [CrossRef]

61. Le Bastard, C.; Baltazart, V.; Wang, Y.; Saillard, J. Thin-pavement thickness estimation using GPR with high-resolution and superresolution methods. IEEE Trans. Geosci. Remote Sens. 2007, 45, 2511-2519. [CrossRef]

62. Loulizi, A.; Al-Qadi, I.L.; Lahouar, S. Optimization of ground-penetrating radar data to predict layer thicknesses in flexible pavements. J. Transp. Eng. 2003, 129, 93-99. [CrossRef]

63. Liu, H.; Sato, M. In situ measurement of pavement thickness and dielectric permittivity by GPR using an antenna array. NDT E Int. 2014, 64, 65-71. [CrossRef]

64. Stryk, J. Road diagnostics-ground penetrating radar possibilities. Intersectii/Intersect. 2008, 5, 48-57.

65. Diamanti, N.; Redman, D. Field observations and numerical models of GPR response from vertical pavement cracks. J. Appl. Geophys. 2012, 81, 106-116. [CrossRef]

66. Krysiński, L.; Sudyka, J. GPR abilities in investigation of the pavement transversal cracks. J. Appl. Geophys. 2013, 97, 27-36. [CrossRef]

67. Fernandes, F.M.; Pais, J.C. Laboratory observation of cracks in road pavements with GPR. Constr. Build. Mater. 2017, 154, 1130-1138. [CrossRef] 
68. Torbaghan, M.E.; Li, W.; Metje, N.; Burrow, M.; Chapman, D.N.; Rogers, C.D. Automated detection of cracks in roads using ground penetrating radar. J. Appl. Geophys. 2020, 179, 104118. [CrossRef]

69. Saarenketo, T.; Scullion, T. Road evaluation with ground penetrating radar. J. Appl. Geophys. 2000, 43, 119-138. [CrossRef]

70. Al-Qadi, I.L.; Lahouar, S.; Loulizi, A. Successful application of ground-penetrating radar for quality assurance-quality control of new pavements. Transp. Res. Rec. 2003, 1861, 86-97. [CrossRef]

71. Saarenketo, T. Measuring Electromagnetic Properties of Asphalt for Pavement Quality Control and Defect Mapping; Roadscanners: Ravaniemi, Finland, 2009.

72. Poikajärvi, J.; Peisa, K.; Herronen, T.; Aursand, P.O.; Maijala, P.; Narbro, A. GPR in road investigations-equipment tests and quality assurance of new asphalt pavement. Nondestruct. Test. Eval. 2012, 27, 293-303. [CrossRef]

73. Grote, K.; Hubbard, S.; Rubin, Y. GPR monitoring of volumetric water content in soils applied to highway construction and maintenance. Lead. Edge 2002, 21, 482-504. [CrossRef]

74. Plati, C.; Loizos, A. Estimation of in-situ density and moisture content in HMA pavements based on GPR trace reflection amplitude using different frequencies. J. Appl. Geophys. 2013, 97, 3-10. [CrossRef]

75. Fontul, S. Structural Evaluation of Flexible Pavements Using Non-Destructive Tests. Ph.D. Thesis, University of Coimbra, Coimbra, Portugal, 2004.

76. Song, X.; Wu, R.; Liu, J. Underground diseases identification of airport runway using GPR. In Proceedings of the Progress in Electromagnetics Research, Xi'an, China, 22-26 March 2010; Volume 93.

77. Graczyk, M.; Krysinski, L.; Topczewski, Ł.; Sudyka, J. The use of three-dimensional analysis of GPR data in evaluation of operational safety of airfield pavements. Transp. Res. Procedia 2016, 14, 3704-3712. [CrossRef]

78. Ni, J.C.; Cheng, W.C. Trial grouting under rigid pavement: A case history in Magong Airport, Penghu. J. Test. Eval. 2012, 40, 107-118. [CrossRef]

79. Doler, D.; Kovačič, B. Improved decision-making geo-information system for continuous monitoring of deformations on airport infrastructure. Isprs Int. J. Geo-Inf. 2019, 8, 1. [CrossRef]

80. Marecos, V.; Fontul, S.; Antunes, M.L.; Solla, M. Assessment of a concrete pre-stressed runway pavement with ground penetrating radar. In Proceedings of the 8th International Workshop on Advanced Ground Penetrating Radar (IWAGPR), Florence, Italy, 7-10 July 2015; pp. 1-4. [CrossRef]

81. Yi, L.; Zou, L.; Sato, M. Practical approach for high-resolution airport pavement inspection with the Yakumo multistatic array ground-penetrating radar system. Sensors 2018, 18, 2684. [CrossRef] [PubMed]

82. Borges, W.R.; da Silva, L.A.; da Cunha, L.S.; Branco, R.M.G.C.; de Farias, M.M. GPR Applied to Rigid Pavement from Santos Dumont Airport, RJ. Braz. J. Geophys. 2014, 32, 225-234. [CrossRef]

83. Mocnik, A.; Dossi, M.; Forte, E.; Zambrini, R.; Zamariolo, A.; Pipan, M. Ground Penetrating Radar applications for roads and airport pavements investigations. Geophysics 2015, 56, 951-960.

84. Fontul, S.; Antunes, M.L.; Fortunato, E.; Oliveira, M. Practical application of GPR in transport infrastructure survey. In Proceedings of the International Conference on Advanced Characterisation of Pavement and Soil Engineering Materials, Athens, Greece, 20-22 June 2007.

85. Zou, L.; Yi, L.; Sato, M. On the use of lateral wave for the interlayer debonding detecting in an asphalt airport pavement using a multistatic GPR system. IEEE Trans. Geosci. Remote Sens. 2020, 58, 4215-4224. [CrossRef]

86. Kadioglu, S. Research of the sea-filled airport OGU in the Black Sea, Turkey, using ground penetrating radar method. Constr. Build. Mater. 2018, 158, 1123-1133. [CrossRef]

87. Jørgensen, A.S.; Andreasen, F. Mapping of permafrost surface using ground-penetrating radar at Kangerlussuaq Airport, western Greenland. Cold Reg. Sci. Technol. 2007, 48, 64-72. [CrossRef]

88. Yannan, L.; Zhaoran, X. Study on the Application of GPR in the Void Detection of Airport Pavement. J. Henan Sci. Technol. 2015, $13,38$.

89. Sussman, T. Application of Ground-Penetrating Radar to Railway Track Substructure Maintenance Management. Ph.D. Thesis, University of Massachusetts Amherst, Amherst, MA, USA, 1999.

90. Basye, C.; Wilk, S.; Gao, Y. Ground Penetrating Radar (GPR) Technology Evaluation and Implementation; Federal Railroad Administration, Office of Research, Development and Technology: Washington, DC, USA, 2020; p. 20590.

91. Kathage, A.; Niessen, J.; White, G.; Bell, N. Fast Inspection of Railway Ballast By Means of Impulse GPR Equipped with Horn Antennas. Railway Engineering-2005, The Eighth International Conference. Available online: https://www.ndt.net/article/v1 0n09/kathage/kathage.htm (accessed on 11 February 2021).

92. Manacorda, G.; Morandi, D.; Sarri, A.; Staccone, G. A customized GPR system for railroad tracks verification. In Proceedings of the SPIE-The International Society for Optical Engineering, Santa Barbara, CA, USA, 12 April 2002. [CrossRef]

93. Al-Qadi, I.L.; Xie, W.; Jones, D.L.; Roberts, R. Development of a time-frequency approach to quantify railroad ballast fouling condition using ultrawide band ground-penetrating radar data. Int. J. Pavement Eng. 2010, 11, 269-279. [CrossRef]

94. Khakiev, Z.; Shapovalov, V.L.; Kruglikov, A.; Yavna, V. GPR determination of physical parameters of railway structural layers. J. Appl. Geophys. 2014, 106, 139-145. [CrossRef]

95. Fontul, S.; Fortunato, E.; De Chiara, F.; Burrinha, R.; Marco Baldeiras, M. Railways Track Characterization Using Ground Penetrating Radar. Advances in Transportation Geotechnics 3. The 3rd International Conference on Transportation Geotechnics (ICTG 2016). Procedia Eng. 2016, 143, 1193-1200. [CrossRef] 
96. Plati, C.; Loizos, A.; Papavasiliou, V. Inspection of railroad ballast using geophysical method. Int. J. Pavement Eng. 2010, 11, 309-317. [CrossRef]

97. Hyslip, J.P.; Smith, S.S.; Olhoeft, G.R.; Selig, E.T. Assessment of Railway Track Substructure Condition Using Ground Penetrating Radar. In Proceedings of the Annual Conference of AREMA, Chicago, IL, USA, 5-7 October 2003.

98. Xiao, J.; Liu, L. Permafrost Subgrade Condition Assessment Using Extrapolation by Deterministic Deconvolution on Multifrequency GPR Data Acquired Along the Qinghai-Tibet Railway. IEEE J. Sel. Top. Appl. Earth Obs. Remote Sens. 2016, 9, 83-90. [CrossRef]

99. Saarenketo, T.; Silvast, M.; Noukka, J. Using GPR on Railways to Identify Frost Susceptible Areas. Proceedings of 6th International Conference on Railway Engineering, London, UK, 3 April-1 May 2003; p. 11.

100. Vorster, D.J.; Gräbe, P.J. The use of ground-penetrating radar to develop a track substructure characterisation model. J. S. Afr. Inst. Civ. Eng. 2013, 55, 69-78.

101. Leng, Z.; Al-Qadi, I.L. Railroad Ballast Evaluation Using Ground-Penetrating Radar: Laboratory Investigation and Field Validation. Transp. Res. Rec. J. Transp. Res. Board 2010, 2159, 110-117. [CrossRef]

102. De Chiara, F. Improving of Railway Track Diagnosis Using Ground Penetrating Radar. Ph.D. Thesis, Sapienza University of Rome, Rome, Italy, 2014.

103. De Bold, R.; O'connor, G.; Morrissey, J.P.; Forde, M. Benchmarking large scale GPR experiments on railway ballast. Constr. Build. Mater. 2015, 92, 31-42. [CrossRef]

104. Roberts, R.; Schutz, A.; Al-Qadi, I.L.; Tutumluer, E.; Boyle, J. Characterizing Railroad Ballast Using GPR: Recent Experiences in the United States. In Proceedings of the 2007 th International Workshop on Advanced Ground Penetrating Radar, IWAGPR, Naples, Italy, 27-29 June 2007. [CrossRef]

105. Fernandes, F.; Pereira, M.; Gomes Correia, A.; Lourenço, P.; Caldeira, L. Assessment of layer thickness and uniformity in railway embankments with ground penetrating radar. In Adv. Transp. Geotech.; Ellis, E., Thom, N., Yu, H.-S., Dawson, A., McDowell, G., Eds.; CRC Press: Boca Raton, FL, USA, 2008; pp. 571-575.

106. Bianchini Ciampoli, L.; Calvi, A.; D’Amico, F. Railway Ballast Monitoring by GPR: A Test Site Investigation. Remote Sens. 2019, 11, 2381. [CrossRef]

107. Benedetto, F.; Tosti, F.; Alani, A.M. An Entropy-Based Analysis of GPR Data for the Assessment of Railway Ballast Conditions. IEEE Trans. Geosci. Remote Sens. 2017, 55, 3900-3908. [CrossRef]

108. Solla, M.; Fontul, S. Non-destructive tests for railway evaluation: Detection of fouling and joint interpretation of GPR data and track geometric parameters. Ground Penetrating Radar 2018, 1, 75-103. [CrossRef]

109. Tosti, F.; Bianchini Ciampoli, L.; Calvi, A.; Alani, A.M.; Benedetto, A. An investigation into the railway ballast dielectric properties using different GPR antennas and frequency systems. NDT E Int. 2018, 93, 131-140. [CrossRef]

110. Su, L.J.; Indraratna, B.; Rujikiatkamjorn, C. Non-destructive assessment of rail track condition using ground penetrating radar. In Proceedings of the 13th International Conference of the International Association for Computer Methods and Advances in Geomechanics, Melbourne, Australia, 9-11 May 2011; Khalili, N., Oeser, M., Eds.; Centre for Infrastructure Engineering and Safety: Sydney, Australia, 2011; pp. 478-482.

111. Ciampoli, L.B.; Artagan, S.S.; Tosti, F.; Gagliardi, V.; Alani, A.M.; Benedetto, A. A comparative investigation of the effects of concrete sleepers on the GPR signal for the assessment of railway ballast. In Proceedings of the 17th International Conference on Ground Penetrating Radar (GPR), Rapperswil, Switzerland, 18-21 June 2018; pp. 1-4. [CrossRef]

112. Colla, C.; Krause, M.; Maierhofer, C.; Hohberger, J.J.; Simmer, H. Combination of NDT techniques for site investigation of non-ballasted railway tracks. NDT E Int. 2002, 35, 95-105. [CrossRef]

113. Huang, J.; Su, Q.; Liu, T.; Wang, W. Behavior and Control of the Ballastless Track-Subgrade Vibration Induced by High-Speed Trains Moving on the Subgrade Bed with Mud Pumping. Hindawishock Vib. 2019, 2019, 1-14. [CrossRef]

114. Brutus, O.; Tauber, G. Guide to Asset Management of Earth Retaining Structures; US Department of Transportation, Federal Highway Administration, Office of Asset Management: Washington, DC, USA, 2009; pp. 1-120.

115. Huston, D.R.; Pelczarski, N.V.; Esser, B. Inspection of bridge columns and retaining walls with electromagnetic waves. In Proceedings of the Smart Structures and Materials, Smart Systems for Bridges, Structures, and Highways, Newport Beach, CA, USA, 30 July 2001; International Society for Optics and Photonics: Bellingham, WA, USA, 2001; Volume 4330, pp. 66-76.

116. Hugenschmidt, J.; Kalogeropoulos, A. The inspection of retaining walls using GPR. J. Appl. Geophys. 2009, 67, 335-344. [CrossRef]

117. Hugenschmidt, J.; Kalogeropoulos, A.; Soldovieri, F.; Prisco, G. Processing strategies for high-resolution GPR concrete inspections. NDT E Int. 2010, 43, 334-342. [CrossRef]

118. Beben, D.; Anigacz, W.; Ukleja, J. Diagnosis of bedrock course and retaining wall using GPR. NDT E Int. 2013, 59, 77-85. [CrossRef]

119. Ukleja, J.; Bęben, D.; Anigacz, W. Determination of the railway retaining wall dimensions and its foundation in difficult terrain and utility. Agh J. Min. Geoengin. 2012, 36, 299-308.

120. Solla, M.; González-Jorge, H.; Álvarez, M.X.; Arias, P. Application of non-destructive geomatic techniques and FDTD modeling to metrical analysis of stone blocks in a masonry wall. Constr. Build. Mater. 2012, 36, 14-19. [CrossRef]

121. Santos-Assunçao, S.; Dimitriadis, K.; Konstantakis, Y.; Perez-Gracia, V.; Anagnostopoulou, E.; Gonzalez-Drigo, R. Groundpenetrating radar evaluation of the ancient Mycenaean monument Tholos Acharnon tomb. Near Surf. Geophys. 2016, 14, 197-205. [CrossRef] 
122. McCann, D.M.; Forde, M.C. Review of NDT methods in the assessment of concrete and masonry structures. NDT E Int. 2001, 34, 71-84. [CrossRef]

123. Bhandari, N.M.; Kumar, P. Structural health monitoring and assessment of masonry arch bridges. Proceedings of National Conference on Advances in Bridge Engineering (ABE), Roorkee, India, 24-25 March 2006; pp. 115-132.

124. Orbán, Z.; Gutermann, M. Assessment of masonry arch railway bridges using nondestructive in-situ testing methods. Eng. Struct. 2009, 31, 2287-2298. [CrossRef]

125. Rehman, S.K.U.; Ibrahim, Z.; Memon, S.A.; Jameel, M. Nondestructive test methods for concrete bridges: A review. Constr. Build. Mater. 2016, 107, 58-86. [CrossRef]

126. Dabous, S.A.; Feroz, S. Condition Monitoring of Bridge Infrastructure Using Non-Contact Testing Technologies: A Comprehensive Review. Autom. Constr. 2020, 116, 103224. [CrossRef]

127. Ural, A.; Oruç, S.; Dogangün, A.; Tulik, O.I. Turkish historical arch bridges and their deteriorations and failures. Eng. Fail. Anal. 2008, 15, 43-53. [CrossRef]

128. Solla, M.; Lorenzo, H.; Novo, A.; Rial, F.I. Ground-penetrating Radar Assessment of the Medieval Arch Bridge of San Antón, Galicia, Spain. Archaeol. Prospect. 2010, 17, 223-232. [CrossRef]

129. Solla, M.; Lorenzo, H.; Rial, F.I.; Novo, A. GPR evaluation of the Roman masonry arch bridge of Lugo (Spain). NDT E Int. 2011, 44, 8-12. [CrossRef]

130. Solla, M.; Riveiro, B.; Lorenzo, H.; Armesto, J. Ancient Stone bridge surveying by ground-penetrating radar and numerical modeling methods. J. Bridge Eng. 2014, 19, 110-119. [CrossRef]

131. Solla, M.; Lorenzo, H.; Riveiro, B.; Rial, F.I. Non-destructive methodologies in the assessment of the masonry arch bridge of Traba, Spain. Eng. Fail. Anal. 2011, 18, 828-835. [CrossRef]

132. Alani, A.M.; Tosti, F.; Banks, K.; Biancini-Ciampoli, L.; Benedetto, A. Non-destructive assessment of a historic masonry arch bridge using ground penetrating radar and 3D laser scanner. In Proceedings of the IMEKO International Conference on Metrology for Archaeology and Cultural Heritage, Lecce, Italy, 23-25 October 2017.

133. Solla, M.; Asorey-Cacheda, R.; Núñez-Nieto, X.; Conde-Carnero, B. Evaluation of historical bridges through recreation of GPR models with the FDTD algorithm. NDT E Int. 2016, 77, 19-27. [CrossRef]

134. Trela, C.; Wöstmann, J.; Kruschwitz, S. Contribution of radar measurements to the inspection and condition assessment of railway bridges-Case study at a historic masonry arch bridge in Oleśnica/Poland. Wit Trans. Built Environ. 2008, 97, 535-544. [CrossRef]

135. Fauchard, C.; Antoine, R.; Bretar, F.; Lacogne, J.; Fargier, Y.; Maisonnave, C.; Guilbert, V.; Marjerie, P.; Thérain, P.F.; Dupont, J.P.; et al. Assessment of an ancient bridge combining geophysical and advanced photogrammetric methods: Application to the Pont De Coq, France. J. Appl. Geophys. 2013, 98, 100-112. [CrossRef]

136. Bergamo, O.; Campione, G.; Donadello, S.; Russo, G. In-situ NDT testing procedure as an integral part of failure analysis of historical masonry arch bridges. Eng. Fail. Anal. 2015, 57, 31-55. [CrossRef]

137. Solla, M.; Lorenzo, H.; Rial, F.I.; Novo, A. Ground-penetrating radar for the structural evaluation of masonry bridges: Results and interpretational tools. Constr. Build. Mater. 2012, 29, 458-465. [CrossRef]

138. Kalogeropoulos, A.; Brühwiler, E. High-resolution 3D condition survey of a masonry arch bridge using Ground Penetrating Radar. In Proceedings of the First Middle East Conference on Smart Monitoring, Assessment and Rehabilitation of Civil Structures, Dubai, United Arab Emirates, 8-10 February 2011.

139. Arias, P.; Armesto, J.; Di-Capua, D.; González-Drigo, R.; Lorenzo, H.; Pérez-Gracia, V. Digital photogrammetry, GPR and computational analysis of structural damages in a mediaeval bridge. Eng. Fail. Anal. 2007, 14, 1444-1457. [CrossRef]

140. Pérez-Gracia, V.; Di Capua, D.; Caselles, O.; Rial, F.; Lorenzo, H.; González-Drigo, R.; Armesto, J. Characterization of a Romanesque bridge in Galicia (Spain). Int. J. Archit. Herit. 2011, 5, 251-263. [CrossRef]

141. Sánchez-Aparicio, L.J.; Bautista-De Castro, A.; Conde, B.; Carrasco, P.; Ramos, L.F. Non-destructive means and methods for structural diagnosis of masonry arch bridges. Autom. Constr. 2019, 104, 360-382. [CrossRef]

142. Lubowiecka, I.; Arias, P.; Riveiro, B.; Solla, M. Multidisciplinary approach to the assessment of historic structures based on the case of a masonry bridge in Galicia (Spain). Comput. Struct. 2011, 89, 1615-1627. [CrossRef]

143. Stavroulaki, M.E.; Riveiro, B.; Drosopoulos, G.A.; Solla, M.; Koutsianitis, P.; Stavroulakis, G.E. Modelling and strength evaluation of masonry bridges using terrestrial photogrammetry and finite elements. Adv. Eng. Softw. 2016, 101, 136-148. [CrossRef]

144. Solla, M.; Lorenzo, H.; Novo, A.; Caamaño, J.C. Structural analysis of the Roman Bibei Bridge (Spain) based on GPR data and numerical modelling. Autom. Constr. 2012, 22, 334-339. [CrossRef]

145. Arêde, A.; Costa, C.; Gomes, A.T.; Menezes, J.E.; Silva, R.; Morais, M.; Gonçalves, R. Experimental characterization of the mechanical behaviour of components and materials of stone masonry railway bridges. Constr. Build. Mater. 2017, 153, 663-681. [CrossRef]

146. Lubowiecka, I.; Armesto, J.; Arias, P.; Lorenzo, H. Historic bridge modelling using laser scanning, ground penetrating radar and finite element methods in the context of structural dynamics. Eng. Struct. 2009, 31, 2667-2676. [CrossRef]

147. Costa, C.; Ribeiro, D.; Jorge, P.; Silva, R.; Arêde, A.; Calçada, R. Calibration of the numerical model of a stone masonry railway bridge based on experimentally identified modal parameters. Eng. Struct. 2016, 123, 354-371. [CrossRef]

148. Russo, S. Integrated assessment of monumental structures through ambient vibrations and ND tests: The case of rialto bridge. J. Cult. Herit. 2016, 19, 402-414. [CrossRef] 
149. Conde, B.; Ramos, L.F.; Oliveira, D.V.; Riveiro, B.; Solla, M. Structural assessment of masonry arch bridges by combination of non-destructive testing techniques and three-dimensional numerical modelling: Application to Vilanova bridge. Eng. Struct. 2017, 148, 621-638. [CrossRef]

150. Cortés-Pérez, J.P.C.; de Sanjosé Blasco, J.J.; Atkinson, A.D.; del Río Pérez, L.M. Assessment of the structural integrity of the Roman bridge of Alcántara (Spain) using TLS and GPR. Remote Sens. 2018, 10, 387. [CrossRef]

151. Bautista-De Castro, A.; Sánchez-Aparicio, L.J.; Carrasco-García, P.; Ramos, L.F.; González-Aguilera, D. A multidisciplinary approach to calibrating advanced numerical simulations of masonry arch bridges. Mech. Syst. Signal Process. 2019, 129, 337-365. [CrossRef]

152. Saarenketo, T.; Maijala, P.; Leppäl“", A. Recommendations for Guidelines for the Use of GPR in Bridge Deck Surveys; Publications of Mara Nord Project. 18p. 2011. Available online: http:/ / maranord.ramk.fi (accessed on 11 February 2021).

153. Hugenschmidt, J. Concrete bridge inspection with a mobile GPR system. Constr. Build. Mater. 2002, 16, 147-154. [CrossRef]

154. Hugenschmidt, J.; Mastrangelo, R. GPR inspection of concrete bridges. Cem. Concr. Compos. 2006, 28, 384-392. [CrossRef]

155. Hasan, M.I.; Yazdani, N. Ground penetrating radar utilization in exploring inadequate concrete covers in a new bridge deck. Case Stud. Constr. Mater. 2014, 1, 104-114. [CrossRef]

156. Beben, D.; Mordak, A.; Anigacz, W. Identification of viaduct beam paremeters using the Ground Penetrating Radar (GPR) technique. NDT E Int. 2012, 49, 18-26. [CrossRef]

157. Simi, A.; Manacorda, G.; Benedetto, A. Bridge deck survey with high resolution Ground Penetrating Radar. In Proceedings of the 14th International Conference on Ground Penetrating Radar (GPR), Shanghai, China, 4-8 June 2012. [CrossRef]

158. Alani, A.M.; Aboutalebi, M.; Kilic, G. Applications of ground penetrating radar (GPR) in bridge deck monitoring and assessment. J. Appl. Geophys. 2013, 97, 45-54. [CrossRef]

159. Varela-Ortiz, W.; Lugo-Cintrón, C.Y.; Velázquez, G.I.; Stanton, T.R. Load testing and GPR assessment for concrete bridges on military installations. Constr. Build. Mater. 2013, 38, 1255-1269. [CrossRef]

160. Dinh, K.; Gucunski, N.; Zayed, T. Automated visualization of concrete bridge deck condition from GPR data. NDT E Int. 2019, 102, 120-128. [CrossRef]

161. Janků, M.; Cikrle, P.; Grošek, J.; Anton, O.; Stryk, J. Comparison of infrared thermography, ground-penetrating radar and ultrasonic pulse echo for detecting delaminations in concrete bridges. Constr. Build. Mater. 2019, 225, 1098-1111. [CrossRef]

162. Rathod, H.; Debeck, S.; Gupta, R.; Chow, B. Applicability of GPR and a rebar detector to obtain rebar information of existing concrete structures. Case Stud. Constr. Mater. 2019, 11, e00240. [CrossRef]

163. Sławski, Ł.; Kosno, Ł.; Świt, G. Evaluation of Precast Pre-post-tensioned Concrete Bridge Beams with the Use of GPR Method. Procedia Eng. 2016, 156, 443-450. [CrossRef]

164. Barnes, C.L.; Trottier, J.F.; Forgeron, D. Improved concrete bridge deck evaluation using GPR by accounting for signal depthamplitude effects. NDT E Int. 2008, 41, 427-433. [CrossRef]

165. Benedetto, A. A three dimensional approach for tracking cracks in bridges using GPR. J. Appl. Geophys. 2013, 97, 37-44. [CrossRef]

166. Varnavina, A.V.; Khamzin, A.K.; Sneed, L.H.; Torgashov, E.V.; Anderson, N.L.; Maerz, N.H.; Boyko, K.J. Concrete bridge deck assessment: Relationship between GPR data and concrete removal depth measurements collected after hydrodemolition. Constr. Build. Mater. 2015, 99, 26-38. [CrossRef]

167. Varnavina, A.V.; Khamzin, A.K.; Torgashov, E.V.; Sneed, L.H.; Goodwin, B.T.; Anderson, N.L. Data acquisition and processing parameters for concrete bridge deck condition assessment using ground-coupled ground penetrating radar: Some considerations. J. Appl. Geophys. 2015, 114, 123-133. [CrossRef]

168. Abouhamad, M.; Dawood, T.; Jabri, A.; Alsharqawi, M.; Zayed, T. Corrosiveness mapping of bridge decks using image-based analysis of GPR data. Autom. Constr. 2017, 80, 104-117. [CrossRef]

169. Dabous, S.A.; Yaghi, S.; Alkass, S.; Moselhi, O. Concrete bridge deck condition assessment using IR Thermography and Ground Penetrating Radar technologies. Autom. Constr. 2017, 81, 340-354. [CrossRef]

170. Diamanti, N.; Annan, P.; Redman, J.D. Concrete bridge deck deterioration assessment using ground penetrating radar (GPR). J. Environ. Eng. Geophys. 2017, 22, 121-132. [CrossRef]

171. Dinh, K.; Gucunski, N.; Kim, J.; Duong, T. Method for attenuation assessment of GPR data from concrete bridge decks. NDT E Int. 2017, 92, 50-58. [CrossRef]

172. Varnavina, A.V.; Sneed, L.H.; Khamzin, A.K.; Torgashov, E.V.; Anderson, N.L. An attempt to describe a relationship between concrete deterioration quantities and bridge deck condition assessment techniques. J. Appl. Geophys. 2017, 142, 38-48. [CrossRef]

173. Ghodoosi, F.; Bagchi, A.; Zayed, T.; Hosseini, M.R. Method for developing and updating deterioration models for concrete bridge decks using GPR data. Autom. Constr. 2018, 91, 133-141. [CrossRef]

174. Sun, H.; Pashoutani, S.; Zhu, J. Nondestructive Evaluation of Concrete Bridge Decks with Automated Acoustic Scanning System and Ground Penetrating Radar. Sens. (Basel) 2018, 18, 1955. [CrossRef]

175. Rhee, J.-Y.; Choi, J.-J.; Kee, S.-H. Evaluation of the Depth of Deteriorations in Concrete Bridge Decks with Asphalt Overlays Using Air-Coupled GPR: A Case Study from a Pilot Bridge on Korean Expressway. Int. J. Concr. Struct. Mater. 2019, 13, 23. [CrossRef]

176. Agred, K.; Klysz, G.; Balayssac, J.P. Location of reinforcement and moisture assessment in reinforced concrete with a double receiver GPR antenna. Constr. Build. Mater. 2018, 188, 1119-1127. [CrossRef]

177. Wang, Z.W.; Zhou, M.; Slabaugh, G.G.; Zhai, J.; Fang, T. Automatic Detection of Bridge Deck Condition From Ground Penetrating Radar Images. IEEE Trans. Autom. Sci. Eng. 2011, 8, 633-640. [CrossRef] 
178. Kaur, P.; Dana, K.J.; Romero, F.A.; Gucunski, N. Automated GPR rebar analysis for robotic bridge deck evaluation. IEEE Trans. Cybern. 2016, 46, 2265-2276. [CrossRef]

179. Dinh, K.; Gucunski, N.; Duong, T.H. An algorithm for automatic localization and detection of rebars from GPR data of concrete bridge decks. Autom. Constr. 2018, 89, 292-298. [CrossRef]

180. Dinh, K.; Gucunski, N.; Duong, T.H. Migration-based automated rebar picking for condition assessment of concrete bridge decks with ground penetrating radar. NDT E Int. 2018, 98, 45-54. [CrossRef]

181. Asadi, P.; Gindy, M.; Álvarez, M.; Asadi, A. A computer vision based rebar detection chain for automatic processing of concrete bridge deck GPR data. Autom. Constr. 2020, 112, 103106. [CrossRef]

182. Ma, X.; Liu, H.; Wang, M.L.; Birken, R. Automatic detection of steel rebar in bridge decks from ground penetrating radar data. J. Appl. Geophys. 2018, 158, 93-102. [CrossRef]

183. Alani, A.M.; Aboutalebi, M.; Kilic, G. Integrated health assessment strategy using NDT for reinforced concrete bridges. NDT $E$ Int. 2014, 61, 80-94. [CrossRef]

184. ITA/AITES. Settlements induced by tunneling in Soft Ground. Tunn. Undergr. Space Technol. 2007, 22, 119-149. [CrossRef]

185. ASTM. ASTM D6429-99(2011)e1. In Standard Guide for Selecting Surface Geophysical Methods (Withdrawn 2020); ASTM International: West Conshohocken, PA, USA, 2011. [CrossRef]

186. Abraham, O.; Dérobert, X. Non-destructive testing of fired tunnel walls: The Mont-Blanc Tunnel case study. NDT E Int. 2003, 36, 411-418. Available online: www.astm.org (accessed on 11 February 2021). [CrossRef]

187. Xie, X.; Liu, Y.; Huang, H.; Du, J.; Zhang, F.; Liu, L. Evaluation of grout behind the lining of shield tunnels using groundpenetrating radar in the Shanghai Metro Line, China. J. Geophys. Eng. 2007, 4, 253-261. [CrossRef]

188. Parkinson, G.; Ékes, C. Ground Penetrating Radar Evaluation of Concrete Tunnel Linings. In Proceedings of the 12th International Conference on Ground Penetrating Radar (GPR), Birmingham, UK, 16-19 June 2008.

189. Zhang, F.; Xie, X.; Huang, H. Application of ground penetrating radar in grouting evaluation for shield tunnel construction. Tunn. Undergr. Space Technol. 2010, 25, 99-107. [CrossRef]

190. Li, C.; Li, M.-J.; Zhao, Y.-G.; Liu, H.; Wan, Z.; Xu, J.-C.; Xu, X.-P.; Chen, Y.; Wang, B. Layer recognition and thickness evaluation of tunnel lining based on ground penetrating radar measurements. J. Appl. Geophys. 2011, 73, 45-48. [CrossRef]

191. Liu, X.; Sun, Q.; Liu, P. The application of Ground Penetrating Radar in detection of the water delivery tunnel lining. In Proceedings of the International Conference on Remote Sensing, Environment and Transportation Engineering, Nanjing, China, 24-26 June 2011. [CrossRef]

192. Yu, H.; Ouyang, Y.; Chen, H. Application of Ground Penetrating Radar to Inspect the Metro Tunnel. In Proceedings of the 14th International Conference on Ground Penetrating Radar (GPR), Shanghai, China, 4-8 June 2012. [CrossRef]

193. Xie, X.; Zeng, C. Non-destructive evaluation of shield tunnel condition using GPR and 3D laser scanning. In Proceedings of the 14th International Conference on Ground Penetrating Radar (GPR), Shanghai, China, 4-8 June 2012. [CrossRef]

194. Xiong, X.; Zhou, Q.; Zhou, J.; Ma, Y.; Wang, K. Application of GPR Technique and Research on high-speed railway tunnel. In Proceedings of the 14th International Conference on Ground Penetrating Radar (GPR), Shanghai, China, 4-8 June 2012. [CrossRef]

195. Lei, X.; Hui-lin, Z.; Zhen, S.; Si-hao, T.; Guo-qing, L.; Jian, Z. GPR evaluation of the Damaoshan highway tunnel: A case study. NDT E Int. 2013, 59, 68-76. [CrossRef]

196. Yu, Q.-M.; Zhou, H.-L.; Wang, Y.-H.; Duan, R.-X. Quality monitoring of metro grouting behind segment using ground penetrating radar. Constr. Build. Mater. 2016, 110, 189-200. [CrossRef]

197. Zan, Y.W.; Su, G.F.; Li, Z.L. A Train-mounted GPR System for Fast and Efficient Monitoring of Tunnel Health Conditions. In Proceedings of the 16th International Conference on Ground Penetrating Radar (GPR), Hong Kong, China, 13-16 June 2016. [CrossRef]

198. Xiongyao, X.; Li, Z.; Biao, Z. Real-time detection technology of synchronous grouting for shield tunnel and analysis of grouting effect. In Proceedings of the 17th International Conference on Ground Penetrating Radar (GPR), Rapperswill, Switzerland, 18-21 June 2018. [CrossRef]

199. Cao, Y.; Liu, Q.; Tao, L. Application of Ground Penetrating Radar for Detecting Grouting Quality in Highway Tunnel. In Proceedings of the 8th Joint International Information Technology and Artificial Intelligence Conference (ITAIC), Chongqing, China, 24-26 May 2019. [CrossRef]

200. Tang, S.; Bai, X. Study on Application of GPR to Quality Detection of Tunnel Lining. Appl. Mech. Mater. 2013, 333-335, 1611-1616. [CrossRef]

201. Kilic, G.; Eren, L. Neural network based inspection of voids and karst conduits in hydro-electric power station tunnels using GPR. J. Appl. Geophys. 2018, 151, 194-204. [CrossRef]

202. Cardarelli, E.; Marrone, C.; Orlando, L. Evaluation of tunnel stability using integrated geophysical methods. J. Appl. Geophys. 2003, 52, 93-102. [CrossRef]

203. Arosio, D.; Munda, S.; Zanzi, L.; Longoni, L.; Papini, M. GPR investigations to assess the state of damage of a concrete water tunnel. J. Environ. Eng. Geophys. 2012, 17, 159-169. [CrossRef]

204. Prego, F.J.; Solla, M.; Núñez-Nieto, X.; Arias, P. Assessing the Applicability of Ground-Penetrating Radar to Quality Control in Tunneling Construction. J. Constr. Eng. Manag. 2016, 142, 06015006. [CrossRef] 
205. Ismail, M.A.; Abas, A.A.; Arifin, M.H.; Ismail, M.N.; Othman, N.A.; Setu, A.; Ahmad, M.R.; Shah, M.K.; Amin, S.; Sarah, T. Integrity inspection of main access tunnel using ground penetrating radar. In Proceedings of the IOP Conference Series: Materials Science and Engineering 271, Global Congress on Construction, Material and Structural Engineering (GCoMSE), Johor Bahru, Malaysia, 28-29 August 2017. [CrossRef]

206. Zan, Y.; Li, Z.; Su, G.; Zhang, X. An innovative vehicle-mounted GPR technique for fast and efficient monitoring of tunnel lining structural conditions. Case Stud. Nondestruct. Test. Eval. 2016, 6, 63-69. [CrossRef]

207. Alani, A.M.; Banks, K. Applications of Ground Penetrating Radar in the Medway Tunnel-Inspection of Structural Joints. In Proceedings of the 15th International Conference on Ground Penetrating Radar (GPR), Brussels, Belgium, 30 June-4 July 2014. [CrossRef]

208. Alani, A.M.; Tosti, F. GPR applications in structural detailing of a major tunnel using different frequency antenna systems. Constr. Build. Mater. 2018, 158, 1111-1122. [CrossRef]

209. Stryk, J.; Matula, R.; Pospíšil, K.; Dérobert, X.; Simonin, J.M.; Alani, A.M. Comparative measurements of ground penetrating radars used for road and bridge diagnostics in the Czech Republic and France. Constr. Build. Mater. 2017, 154, 1199-1206. [CrossRef]

210. ME91/16: Methodologies for the Use of Ground-Penetrating Radar in Pavement Condition Surveys; Belgian Road 445 Research Centre: Brussels, Belgium, 2016.

211. Solla, M.; González-Jorge, H.; Lorenzo, H.; Arias, P. Uncertainty evaluation of the $1 \mathrm{GHz}$ GPR antenna for the estimation of concrete asphalt thickness. Measurement 2013, 46, 3032-3040. [CrossRef]

212. Li, X.T.; Wang, D.Y.; Zhang, X.N. A high-accuracy calibration method for thickness measurements of asphalt pavement using ground penetrating radar. SATC 2006, 2006, 305-312.

213. Fauchard, C.; Dérobert, X.; Cariou, J.; Côte, P. GPR performances for thickness calibration on road test sites. NDT E Int. 2003, 36, 67-75. [CrossRef]

214. Hu, J.; Vennapusa, P.K.; White, D.J.; Beresnev, I. Pavement thickness and stabilised foundation layer assessment using groundcoupled GPR. Nondestruct. Test. Eval. 2016, 31, 267-287. [CrossRef]

215. Zhao, S.; Al-Qadi, I.L. Development of an analytic approach utilizing the extended common midpoint method to estimate asphalt pavement thickness with 3-D ground-penetrating radar. NDT E Int. 2016, 78, 29-36. [CrossRef]

216. Lahouar, S.; Al-Qadi, I.L.; Loulizi, A.; Clark, T.M.; Lee, D.T. Approach to determining in situ dielectric constant of pavements: Development and implementation at interstate 81 in Virginia. Transp. Res. Rec. 2002, 1806, 81-87. [CrossRef]

217. Al-Qadi, I.L.; Lahouar, S. Use of GPR for thickness measurement and quality control of flexible pavements. J. Assoc. Asph. Paving Technol. 2004, 73, 501-528.

218. Al-Qadi, I.L.; Lahouar, S.; Loulizi, A. Ground-Penetrating Radar Calibration at the Virginia Smart Road and Signal Analysis to Improve Prediction of Flexible Pavement Layer Thicknesses; Virginia Center for Transportation Innovation and Research: Charlottesville, VA, USA, 2005.

219. Diamanti, N.; Annan, A.P. Air-launched and ground-coupled GPR data. In Proceedings of the 2017 11th European Conference on Antennas and Propagation (EUCAP), Paris, France, 19-24 March 2017; IEEE: New York, NY, USA, 2017; pp. 1694-1698. [CrossRef]

220. Dong, Z.; Ye, S.; Gao, Y.; Fang, G.; Zhang, X.; Xue, Z.; Zhang, T. Rapid detection methods for asphalt pavement thicknesses and defects by a vehicle-mounted ground penetrating radar (GPR) system. Sensors 2016, 16, 2067. [CrossRef]

221. Hoegh, K.; Khazanovich, L.; Dai, S.; Yu, T. Evaluating asphalt concrete air void variation via GPR antenna array data. Case Stud. Nondestruct. Test. Eval. 2015, 3, 27-33. [CrossRef]

222. Dérobert, X.; Fauchard, C.; Côte, P.; Le Brusq, E.; Guillanton, E.; Dauvignac, J.Y.; Pichot, C. Step-frequency radar applied on thin road layers. J. Appl. Geophys. 2001, 47,317-325. [CrossRef]

223. Marecos, V.; Solla, M.; Fontul, S.; Antunes, V. Assessing the pavement subgrade by combining different non-destructive methods. Constr. Build. Mater. 2017, 135, 76-85. [CrossRef]

224. Diallo, M.C.; Cheng, L.Z.; Rosa, E.; Gunther, C.; Chouteau, M. Integrated GPR and ERT data interpretation for bedrock identification at Cléricy, Québec, Canada. Eng. Geol. 2019, 248, 230-241. [CrossRef]

225. Colagrande, S.; Ranalli, D.; Tallini, M. Ground penetrating radar assessment of flexible road pavement degradation. Int. J. Geophys. 2011, 2011, 989135. [CrossRef]

226. Plati, C.; Loizos, A.; Gkyrtis, K. Integration of non-destructive testing methods to assess asphalt pavement thickness. NDT E Int. 2020, 115, 102292. [CrossRef]

227. Scullion, T.; Saarenketo, T. Integrating ground penetrating radar and falling weight deflectometer technologies in pavement evaluation. In Nondestructive Testing of Pavements and Backcalculation of Moduli; ASTM International: West Conshohocken, PA, USA, 2000; Volume 3. [CrossRef]

228. Marecos, V.; Fontul, S.; de Lurdes Antunes, M.; Solla, M. Evaluation of a highway pavement using non-destructive tests: Falling weight deflectometer and ground penetrating radar. Constr. Build. Mater. 2017, 154, 1164-1172. [CrossRef]

229. Evans, R.D.; Frost, M.; Stonecliffe-Jones, M.; Dixon, N. A review of pavement assessment using ground penetrating radar (GPR). In Proceedings of the 12th International Conference on Ground Penetrating Radar, Birmingham, UK, 16-19 June 2008.

230. Marecos, V.; Fontul, S.; Solla, M.; de Lurdes Antunes, M. Evaluation of the feasibility of Common Mid-Point approach for air-coupled GPR applied to road pavement assessment. Measurement 2018, 128, 295-305. [CrossRef] 
231. Maser, K.R. Measurement of as-built conditions using ground penetrating radar. In Proceedings of the Structural Materials Technology: An NDT Conference, San Diego, CA, USA, 20-23 February 1996; pp. 61-67.

232. Al-Qadi, I.L.; Lahouar, S.; Jiang, K.; MeGhee, K.K.; Mokarem, D. Validation of ground penetration radar accuracy for estimating pavement layer thicknesses. In Proceedings of the Transportation Research Board 84th Annual Meeting, Washington, DC, USA, 9-13 January 2005.

233. Schmidtgen, B.D.; Milne, T.I.; Saarenketo, T. Road management data assimilation and quality control of asphalt and bituminous pavements using GPR. In Proceedings of the 10th Conference on Asphalt Pavements for Southern Africa [CAPSA11], KwaZuluNatal, South Africa, 11-14 September 2011.

234. Benedetto, A.; Benedetto, F.; Tosti, F. GPR applications for geotechnical stability of transportation infrastructures. Nondestruct. Test. Eval. 2012, 27, 253-262. [CrossRef]

235. Lagüela, S.; Solla, M.; Puente, I.; Prego, F.J. Joint use of GPR, IRT and TLS techniques for the integral damage detection in paving. Constr. Build. Mater. 2018, 174, 749-760. [CrossRef]

236. Le Bastard, C.; Pan, J.; Wang, Y.; Sun, M.; Todkar, S.S.; Baltazart, V.; Pinel, N.; Ihamouten, A.; Derobert, X.; Bourlier, C. A Linear Prediction and Support Vector Regression-Based Debonding Detection Method Using Step-Frequency Ground Penetrating Radar. IEEE Geosci. Remote Sens. Lett. 2018, 16, 367-371. [CrossRef]

237. Todkar, S.S.; Le Bastard, C.; Baltazart, V.; Ihamouten, A.; Dérobert, X. Performance assessment of SVM-based classification techniques for the detection of artificial debondings within pavement structures from stepped-frequency A-scan radar data. NDT E Int. 2019, 107, 102128. [CrossRef]

238. Ercoli, M.; Di Matteo, L.; Pauselli, C.; Mancinelli, P.; Frapiccini, S.; Talegalli, L.; Cannata, A. Integrated GPR and laboratory water content measures of sandy soils: From laboratory to field scale. Constr. Build. Mater. 2018, 159, 734-744. [CrossRef]

239. Venmans, A.A.; van de Ven, R.; Kollen, J. Rapid and non-intrusive measurements of moisture in road constructions using passive microwave radiometry and GPR-full scale test. Procedia Eng. 2016, 143, 1244-1251. [CrossRef]

240. Bianchini Ciampoli, L.; Tosti, F.; Economou, N.; Benedetto, F. Signal processing of GPR data for road surveys. Geosciences 2019, 9 , 96. [CrossRef]

241. Puente, I.; Solla, M.; González-Jorge, H.; Arias, P. Validation of mobile LiDAR surveying for measuring pavement layer thicknesses and volumes. NDT E Int. 2013, 60, 70-76. [CrossRef]

242. Khamzin, A.K.; Varnavina, A.V.; Torgashov, E.V.; Anderson, N.L.; Sneed, L.H. Utilization of air-launched ground penetrating radar (GPR) for pavement condition assessment. Constr. Build. Mater. 2017, 141, 130-139. [CrossRef]

243. Shangguan, P.; Al-Qadi, I.L. Calibration of FDTD simulation of GPR signal for asphalt pavement compaction monitoring. IEEE Trans. Geosci. Remote Sens. 2014, 53, 1538-1548. [CrossRef]

244. Bala, D.C.; Garg, R.D.; Jain, S.S. Rebar detection using GPR: An emerging non-destructive QC approach. International Journal of Engineering Research and Applications (IJERA) 2011, 1, 2111-2117.

245. Zhou, F.; Chen, Z.; Liu, H.; Cui, J.; Spencer, B.F.; Fang, G. Simultaneous estimation of rebar diameter and cover thickness by a GPR-EMI dual sensor. Sensors 2018, 18, 2969. [CrossRef] [PubMed]

246. Kim, N.; Kim, K.; An, Y.K.; Lee, H.J.; Lee, J.J. Deep learning-based underground object detection for urban road pavement. Int. J. Pavement Eng. 2018, 1-13. [CrossRef]

247. Solla, M.; Lagüela, S.; Fernández, N.; Garrido, I. Assessing Rebar Corrosion through the Combination of Nondestructive GPR and IRT Methodologies. Remote Sens. 2019, 11, 1705. [CrossRef]

248. Sossa, V.; Pérez-Gracia, V.; González-Drigo, R.; A Rasol, M. Lab Non Destructive Test to Analyze the Effect of Corrosion on Ground Penetrating Radar Scans. Remote Sens. 2019, 11, 2814. [CrossRef]

249. Hong, S.; Lai, W.W.L.; Wilsch, G.; Helmerich, R.; Helmerich, R.; Günther, T.; Wiggenhauser, H. Periodic mapping of reinforcement corrosion in intrusive chloride contaminated concrete with GPR. Constr. Build. Mater. 2014, 66, 671-684. [CrossRef]

250. Baltrušaitis, A.; Vaitkus, A.; Smirnovs, J. Asphalt Layer Density and Air Voids Content: GPR and Laboratory Testing Data Reliance. Balt. J. Road Bridge Eng. 2020, 15, 93-110. [CrossRef]

251. Zhong, Y.; Wang, Y.; Zhang, B.; Li, X.; Li, S.; Zhong, Y.; Hao, M.; Gao, Y. Prediction Model of Asphalt Content of Asphalt Mixture Based on Dielectric Properties. Adv. Civ. Eng. 2020, 2020, 1-10. [CrossRef]

252. Gao, J.; Yuan, D.; Tong, Z.; Yang, J.; Yu, D. Autonomous pavement distress detection using ground penetrating radar and region-based deep learning. Measurement 2020, 164, 108077. [CrossRef]

253. Tong, Z.; Gao, J.; Yuan, D. Advances of deep learning applications in ground-penetrating radar: A survey. Constr. Build. Mater. 2020, 258, 120371. [CrossRef]

254. Giannakis, I.; Giannopoulos, A.; Warren, C. A machine learning-based fast-forward solver for ground penetrating radar with application to full-waveform inversion. IEEE Trans. Geosci. Remote Sens. 2019, 57, 4417-4426. [CrossRef]

255. Tong, Z.; Yuan, D.; Gao, J.; Wei, Y.; Dou, H. Pavement-distress detection using ground-penetrating radar and network in networks. Constr. Build. Mater. 2020, 233, 117352. [CrossRef]

256. Ozkaya, U.; Seyfi, L. Deep dictionary learning application in GPR B-scan images. Signalimage Video Process. 2018, 12, 1567-1575. [CrossRef]

257. Tong, Z.; Gao, J.; Zhang, H. Recognition, location, measurement, and 3D reconstruction of concealed cracks using convolutional neural networks. Constr. Build. Mater. 2017, 146, 775-787. [CrossRef] 
258. Kim, N.; Kim, S.; An, Y.K.; Lee, J.J. A novel 3D GPR image arrangement for deep learning-based underground object classification. Int. J. Pavement Eng. 2019, 1-12. [CrossRef]

259. Muller, W. A comparison of TSD, FWD and GPR field measurements. In Proceedings of the International Symposium NonDestructive Testing in Civil Engineering (NDT-CE), Berlin, Germany, 15-17 September 2015.

260. Maser, K.; Schmalzer, P.; Gerber, A.; Poorbaugh, J. Implementation of the Traffic Speed Deflectometer (TSD) for Network Level Pavement Management; Infrasense. Pavement Evaluation: Woburn, MA, USA, 2019.

261. Maser, K.; Schmalzer, P.; Shaw, W.; Carmichael, A. Integration of Traffic Speed Deflectometer and Ground-Penetrating Radar for Network-Level Roadway Structure Evaluation. Transp. Res. Rec. 2017, 2639, 55-63. [CrossRef]

262. Katicha, S.; Shrestha, S.; Flintsch, G.; Diefenderfer, B. Network Level Pavement Structural Testing with the Traffic Speed Deflectometer; Final Report VTRC 21-R4; Virginia Transportation Research Council: Charlottesville, VA, USA, 2020.

263. Lenngren, C.; Bergström, J.; Ersson, B. Using Ground Penetrating Radar for Assessing Highway Pavement Thickness. In Proceedings of the SPIE-The International Society for Optical Engineering, San Diego, CA, USA, 6 July 2020. [CrossRef]

264. Yuan, C.; Cai, H. Spatial reasoning mechanism to enable automated adaptive trajectory planning in ground penetrating radar survey. Autom. Constr. 2020, 114, 103157. [CrossRef]

265. Miccinesi, L.; Pieraccini, M. A GPR Able to Detect Its Own Position Using Fixed Corner Reflectors on Surface. IEEE Trans. Geosci. Remote Sens. 2020, 1-8. [CrossRef]

266. Šarlah, N.; Podobnikar, T.; Mongus, D.; Ambrožič, T.; Mušič, B. Kinematic GPR-TPS Model for Infrastructure Asset Identification with High 3D Georeference Accuracy Developed in a Real Urban Test Field. Remote Sens. 2019, 11, 1457. [CrossRef]

267. Gabryś, M.; Ortyl, Ł. Georeferencing of Multi-Channel GPR-Accuracy and Efficiency of Mapping of Underground Utility Networks. Remote Sens. 2020, 12, 2945. [CrossRef]

268. Wu, Y.; Shen, F.; Xu, D. Ground-penetrating radar-based underground environmental perception radar for robotic system. Int. J. Adv. Robot. Syst. 2020, 17, 1729881420921642. [CrossRef]

269. Eskandari Torbaghan, M.; Kaddouh, B.; Abdellatif, M.; Metje, N.; Liu, J.; Jackson, R.; Rogeres, C.D.; Chapman, D.N.; Fuentes, R.; Miodownik, M.; et al. Robotic and autonomous systems for road asset management: A position paper. Proc. Inst. Civ. Eng.-Smart Infrastruct. Constr. 2020, 172, 83-93. [CrossRef]

270. Rodriguez-Vaqueiro, Y.; Vázquez-Cabo, J.; Gonzalez-Valdes, B.; Pino, A.; Álvarez, Y.; Garcia-Fernandez, M.; Las-Heras, F.; Arboleya, A. Array of Antennas for a GPR system onboard a UAV. In Proceedings of the 2019 IEEE International Symposium on Antennas and Propagation and USNC-URSI Radio Science Meeting, Atlanta, GA, USA, 7-12 July 2019; IEEE: New York, NY, USA, 2019; pp. 821-822. [CrossRef]

271. Pan, Y.; Zhang, X.; Sun, M.; Zhao, Q. Object-based and supervised detection of potholes and cracks from the pavement images acquired by UAV. Int. Arch. Photogramm. Remote Sens. Spat. Inf. Sci. 2017, 42, 209-217. [CrossRef]

272. Garcia-Fernandez, M.; Alvarez-Lopez, Y.; Las Heras, F.; Gonzalez-Valdes, B.; Rodriguez-Vaqueiro, Y.; Pino, A.; Arboleya-Arboleya, A. GPR system onboard a uav for non-invasive detection of buried objects. In Proceedings of the 2018 IEEE International Symposium on Antennas and Propagation E USNC/URSI National Radio Science Meeting, Boston, MA, USA, 8-13 July 2018; IEEE: New York, NY, USA, 2018; pp. 1967-1968.

273. EN 13848-5: 2017. In Railway Applications-Track-Track Geometry Quality_Part 5: Geometric Quality Levels—Plain Line, Switches and Crossings; BSI: London, UK, 2017.

274. Esveld, C. Modern Railway Track; MRT-Productions: Zaltbommel, The Netherlands, 2001.

275. Fortunato, E. Renovação de Plataformas Ferroviárias. Estudos Relativos à Capacidade de Carga. Ph.D. Thesis, University of Porto, Porto, Portugal, 2005. (In Portuguese).

276. Saarenketo, T. Electrical Properties of Road Materials and Subgrade Soils and the Use of Ground Penetrating Radar in Traffic Infrastructure Surveys. Ph.D. Thesis, Faculty of Science, University of Oulu, Oulu, Finland, 2006.

277. Loizos, A.; Silvast, M.; Dimitrellou, S. Railway trackbed assessment using the GPR technique. Adv. Charact. Pavement Soil Eng. Mater. 2007, 1, 1817-1826.

278. De Chiara, F.; Fontul, S.; Fortunato, E. GPR Laboratory Tests for Railways Materials Dielectric Properties Assessment. Remote Sens. 2014, 6, 9712-9728. [CrossRef]

279. Liu, S.; Lu, Q.; Li, H.; Wang, Y. Estimation of Moisture Content in Railway Subgrade by Ground Penetrating Radar. Remote Sens. 2020, 12, 2912. [CrossRef]

280. Shao, W.; Bouzerdoum, A.; Phung, S.L.; Su, L.; Indraratna, B. Automatic Classification of Ground-Penetrating-Radar Signals for Railway-Ballast Assessment. IEEE Trans. Geosci. Remote Sens. 2011, 49, 3961-3972. [CrossRef]

281. Al-Qadi, I.L.; Xie, W.; Roberts, R. Scattering Analysis of Railroad Ballast Using Ground Penetrating Radar. J. Nondestruct. Test. Eval. 2008, 41, 441-447. [CrossRef]

282. Xie, W.; Al-Qadi, I.L.; Jones, D.L.; Roberts, R. Development of a Time-Frequency Approach to Quantify Railroad Ballast Fouling Condition Using UWB GPR Data. In Proceedings of the 87th TRB Annual Meetings, Paper No. 08-1846, Washington, DC, USA, 13-17 January 2008.

283. Fontul, S.; Paixão, A.; Solla, M.; Pajewski, L. Railway Track Condition Assessment at Network Level by Frequency Domain Analysis of GPR Data. Remote Sens. 2018, 10, 559. [CrossRef]

284. Al-Qadi, I.; Xie, W.; Roberts, R. Optimization of antenna configuration in multiple-frequency ground penetrating radar system for railroad substructure assessment. NDT E Int. 2010, 43, 20-28. [CrossRef] 
285. Anbazhagan, P.; Su, L.; Indraratna, B.; Rujikiatkamjorn, C. Model track studies on fouled ballast using ground penetrating radar and multichannel analysis of surface wave. J. Appl. Geophys. 2011, 74, 175-184. [CrossRef]

286. Fortunato, E.; Fontul, S.; Paixão, A.; Cruz, N.; Cruz, J.; Asseiceiro, F. Reabilitação de uma Linha Férrea de Mercadorias-Aspetos Geotécnicos da via (Rehabilitation of a Freight Railway Line-Geotechnical Aspects of the Track). Jornal Geotecnia No 131, July 2014; Sociedade Portuguesa de Geotecnia; pp. 95-112. Available online: https://spgeotecnia.pt/uploads/jgeot201413106.pdf (accessed on 11 February 2021). (In Portuguese).

287. Roadscanners. GPR Survey on Railway Sections between Montevideo_Paso de los Toros in Uruguay; Project Report; Roadscanners: Rovaniemi, Finland, 2017; (consulted on October 2020).

288. Riveiro, B.; Solla, M. (Eds.) Non-Destructive Techniques for the Evaluation of Structures and Infrastructure; CRC Press: London, UK, 2016; ISBN 9781138028104.

289. Zarembski, A.; Yurlov, D.; Palese, J.; Attoh-Okine, N. Relationship between Track Geometry Defects and Measured Track Subsurface Condition; Federal Railroad Administration Report DOT/FRA/ORD-20/07; Federal Railroad Administration: Washington, DC, USA, 2020.

290. Smekal, A.; Berggren, E.G.; Silvast, M. Monitoring and substructure condition assessment of existing railway lines for upgrading to higher axle loads and speeds. In Proceedings of the 7th World Congress on Railway Research, Montreal, QC, Canada, 5-7 June 2006.

291. Brough, M.; Stirling, A.; Ghataora, G.; Madelin, K. Evaluation of railway trackbed and formation: A case study. NDT E Int. 2003, 36, 145-156. [CrossRef]

292. Lamas-Lopez, F.; Cui, Y.J.; Calon, N.; Costa d'Aguiar, S. Geotechnical auscultation of a French conventional railway track-bed for maintenance purposes. Soils Found 2016, 56, 225-240. [CrossRef]

293. Zarembski, A.M.; Grissom, G.T.; Euston, T.L. On the Use of Ballast Inspection Technology for the Management of Track Substructure. Transp. Infrastruct. Geotech. 2014, 1, 83-109. [CrossRef]

294. Hu, F.; Leijen, F.J.v.; Chang, L.; Wu, J.; Hanssen, R.F. Monitoring Deformation along Railway Systems Combining Multi-Temporal InSAR and LiDAR Data. Remote Sens. 2019, 11, 2298. [CrossRef]

295. Jung, J.; Kim, D.-J.; Palanisamy Vadivel, S.K.; Yun, S.-H. Long-term deflection monitoring for bridges using $X$ and C band time-series SAR interferometry. Remote Sens. 2019, 11, 1258. [CrossRef]

296. Bianchini Ciampoli, L.; Gagliardi, V.; Ferrante, C.; Calvi, A.; D'Amico, F.; Tosti, F. Displacement monitoring in airport runways by persistent scatterers SAR Interferometry. Remote Sens. 2020, 12, 3564. [CrossRef]

297. Bianchini Ciampoli, L.; Gagliardi, V.; Clementini, C.; Latini, D.; Del Frate, F.; Benedetto, A. Transport infrastructure monitoring by InSAR and GPR data fusion. Surv. Geophys. 2020, 41, 371-394. [CrossRef]

298. D'Amico, F.; Gagliardi, V.; Bianchini Ciampoli, L.; Tosti, F. Integration of InSAR and GPR techniques for monitoring transition areas in railway bridges. NDT E Int. 2020, 115, 102291. [CrossRef]

299. TRACKSCAN_A Practical, Portable and Robust Scanning System Using Infrastructure Inspection Radar (IIR) for the Investigation of Rail Track Substructure, Ballast and Tunnel Infrastructure. H20202 Project Grant agreement ID: 700138. Cordis. 2016. Available online: https:/ / cordis.europa.eu/project/id/700138/reporting (accessed on 11 February 2021).

300. Railview. Ground Penetrating Radar for the Rail Industry. 2020. Available online: https://www.railview.co.uk/sevices (accessed on 11 February 2021).

301. DESTination RAIL Decision Support Tool for Rail Infrastructure Managers. Project Reference: 636285 . Available online: http: / / www.destinationrail.eu/ (accessed on 11 February 2021).

302. Hugenschmidt, J.; Mastrangelo, R. The inspection of large retaining walls using GPR. In Proceedings of the 20074 th International Workshop on Advanced Ground Penetrating Radar, Napoli, Italy, 27-29 June 2007; IEEE: New York, NY, USA, 2007 ; pp. $267-271$.

303. Lualdi, M.; Zanzi, L.; Binda, L. Acquisition and processing requirements for high quality $3 \mathrm{D}$ reconstructions from GPR investigations. In Proceedings of the Proceedings, International Symposium Non-Destructive Testing in Civil Engineering (NDT-CE), Berlin, Germany, 16-19 September 2003.

304. Soldovieri, F.; Persico, R.; Utsi, E.; Utsi, V. The application of inverse scattering techniques with ground penetrating radar to the problem of rebar location in concrete. NDT E Int. 2006, 39, 602-607. [CrossRef]

305. Soldovieri, F.; Hugenschmidt, J.; Persico, R.; Leone, G. A linear inverse scattering algorithm for realistic GPR applications. Near Surf. Geophys. 2007, 5, 29-42. [CrossRef]

306. Li, S.; Feng, X.T.; Li, Z.; Zhang, C.; Chen, B. Evolution of fractures in the excavation damaged zone of a deeply buried tunnel during TBM construction. Int. J. Rock Mech. Min. Sci. 2012, 55, 125-138. [CrossRef]

307. Liu, L.; Shi, Z.; Peng, M.; Tsoflias, G.P. Investigation of Geological Anomalies at Pile Foundation Location in Urban Karst Areas Using Single Borehole Radar. Geosciences 2020, 10, 232. [CrossRef]

308. Kavanagh, J.; Bowers, K.H.; Brady, K.C. The Use of Ground Penetrating Radar in the Investigation of Masonry Retaining Walls; Traffic and Transport Resource Centre, Transport Research Laboratory: Hong Kong, China, 1999.

309. Athanasopoulos Zekkos, A.; Lynch, J.; Zekkos, D.; Grizi, A.; Admassu, K.; Benhamida, B.; Spino, R.J.; Mikolajczyk, M. Asset Management for Retaining Walls; Technical Report; University of Michigan: Ann Arbor, MI, USA; Volume 1001, pp. 42125-48109.

310. Wiggenhauser, H.; Behrens, M.; Moser, D.; Moryson, R.M.; Pudovikov, S.; Herrmann, H.G. Non-destructive assessment of retaining wall of former coal mine plant: Zerstörungsfreie Prüfung der Stützmauer einer ehemaligen Kohlegrube. Mauerwerk 2018, 22, 175-186. [CrossRef] 
311. Santos-Assunçao, S.; Perez-Gracia, V.; Salinas, V.; Caselles, O.; Gonzalez-Drigo, R.; Pujades, L.G.; Lantada, N. GPR backscattering intensity analysis applied to detect paleochannels and infilled streams for seismic nanozonation in urban environments. IEEE $J$. Sel. Top. Appl. Earth Obs. Remote Sens. 2015, 9, 167-177. [CrossRef]

312. Salinas Naval, V.; Santos-Assunçao, S.; Pérez-Gracia, V. GPR clutter amplitude processing to detect shallow geological targets. Remote Sens. 2018, 10, 88. [CrossRef]

313. Bao, Y.; Ghasr, M.T.; Ying, K.; Chen, G.; Zoughi, R. Microwave Synthetic Aperture Radar Imaging for Nondestructive Evaluation of Mechanically Stabilized Earth Walls. Mater. Eval. 2017, 75, 177-184.

314. RILEM TC 127-MS: Non Destructive Tests for Masonry Materials and Structures. Materials and Structures/Matériaux et Constructions, Volume 34, pp. 134-143. April 2001. Available online: www.rilem.org (accessed on 11 February 2021).

315. Diamanti, N.; Giannopoulos, A.; Forde, M. Numerical modelling and experimental verification of GPR to investigate ring separation in brick masonry arch bridges. NDT E Int. 2008, 41, 354-363. [CrossRef]

316. Diamanti, N.; Giannopoulos, A. Employing ADI-FDTD subgrids for GPR numerical modelling and their application to study ring separation in brick masonry arch bridges. Near Surf. Geophys. 2011, 9, 245-256. [CrossRef]

317. Solla, M.; Lagüela, S.; Riveiro, B.; Lorenzo, H. Non-destructive testing for the analysis of moisture in the masonry arch bridge of Lubians (Spain). Struct. Control Health Monit. 2013, 20, 1366-1376. [CrossRef]

318. Biscarini, C.; Catapano, I.; Cavalagli, N.; Ludeno, G.; Pepe, F.A.; Ubertini, F. UAV photogrammetry, infrared thermography and GPR for enhancing structural and material degradation evaluation of the Roman masonry bridge of Ponte Lucano in Italy. NDT E Int. 2020, 115, 102287. [CrossRef]

319. Alani, A.M.; Tosti, F.; Bianchini Ciampoli, L.; Gagliardi, V.; Benedetto, A. An integrated investigative approach in health monitoring of masonry arch bridges using GPR and InSAR technologies. NDT E Int. 2020, 115, 102288. [CrossRef]

320. Puente, I.; Solla, M.; González-Jorge, H.; Arias, P. NDT documentation and evaluation of the Roman bridge of Lugo using GPR and mobile and static LiDAR. J. Perform. Constr. Facil. 2015, 29, 06014004. [CrossRef]

321. Stryk, J.; Alani, A.M.; Matula, R.; Pospisil, K. Innovative Inspection Procedures for Effective GPR Surveying of Critical Transport Infrastructures (Pavements, Bridges and Tunnels). In Civil Engineering Applications of Ground Penetrating Radar; Springer Transactions in Civil and Environmental Engineering: Berlin/Heidelberg, Germany, 2015. [CrossRef]

322. SHRP 2- report S2-R06A-RR-1. In Nondestructive Testing to Identify Concrete Bridge Deck Deterioration; Transportation Research Board: Washington, DC, USA, 2013; Available online: www.TRB.org/SHRP2 (accessed on 11 February 2021).

323. BASt-Report B55. Examination of GPR in Combination with Magnetic Techniques for the Determination of Moisture and Salinity of Concrete Bridge Decks with Asphalt Cover; Federal Highway Research Institute; Bundesanstalt für Straßenwesen. 2007. Available online: www.bast.de (accessed on 11 February 2021).

324. Document B10-Recommendation for Nondestructive Testing of Civil Engineering Structures by GPR; German Society for NonDestructive Testing (DGZfP): Berlin, Germany, 2008.

325. AASHTO R 37-04. Standard Practice for Application of Ground Penetrating Radar (GPR) to Highways; American Association of State and Highway Transportation Officials: Washington, DC, USA, 2004.

326. ACI 228.2R-98 (Reapproved 2004). Nondestructive Test Methods for Evaluation of Concrete in Structures; American Concrete Institute: Farmington Hills, MI, USA, 1998.

327. NCHRP Research Report 848. In Inspection Guidelines for Bridge Post-Tensioning and Stay Cable Systems Using NDE Methods; TRB's National Cooperative Highway Research Program: Washington, DC, USA, 2017. [CrossRef]

328. Lalagüe, A.; Lebens, M.A.; Hoff, I.; Grøv, E. Detection of rockfall on a tunnel concrete lining with ground-penetrating radar (GPR). Rock Mech. Rock Eng. 2016, 49, 2811-2823. [CrossRef]

329. Balaguer, C.; Montero, R.; Victores, J.G.; Martínez, S.; Jardón, A. Towards fully automated tunnel inspection: A survey and future trends. In Proceedings of the 31st International Symposium on Automation and Robotics in Construction and Mining (ISARC 2014), Sydney, Australia, 9-11 July 2014. [CrossRef]

330. Xie, X.Y.; Chen, Y.F.; Zhou, B. Data processing of backfill grouting detected by GPR in shield tunnel and research on equipment of GPR antenna. In Proceedings of the 16th International Conference on Ground Penetrating Radar (GPR), Hong Kong, China, 13-16 June 2016. [CrossRef]

331. SHRP-2 Report S2-R06G-RR-1. In Mapping Voids, Debonding, Delaminations, Moisture, and Other Defects behind or within Tunnel Linings; Transportation Research Board: Washington, DC, USA, 2014; Available online: www.TRB.org/SHRP2 (accessed on 11 February 2021).

332. Lyu, Y.; Wang, H.; Gong, J. GPR detection of tunnel lining cavities and reverse-time migration imaging. Appl. Geophys. 2020, 17, 1-7. [CrossRef]

333. Karlovšek, J.; Scheuermann, A.; Willimas, D.J. Investigation of voids and cavities in Bored Tunnels using GPR. In Proceedings of the 14th International Conference on Ground Penetrating Radar (GPR), Shanghai, China, 4-8 June 2012. [CrossRef]

334. Garcia-Fernandez, M.; Alvarez-Lopez, Y.; Las Heras, F. Autonomous airborne 3D SAR imaging system for subsurface sensing: UWB-GPR on board a UAV for landmine and IED detection. Remote Sens. 2019, 11, 2357. [CrossRef]

335. Wu, K.; Rodriguez, G.A.; Zajc, M.; Jacquemin, E.; Clément, M.; De Coster, A.; Lambot, S. A new drone-borne GPR for soil moisture mapping. Remote Sens. Environ. 2019, 235, 111456. [CrossRef]

336. Šipoš, D.; Gleich, D. A Lightweight and Low-Power UAV-Borne Ground Penetrating Radar Design for Landmine Detection. Sensors 2020, 20, 2234. [CrossRef] 
337. Howlader, M.O.F.; Sattar, T.P.; Dudley, S. Development of a Wall Climbing Robotic Ground Penetrating Radar System for Inspection of Vertical Concrete Structures. Int. J. Mech. Mechatron. Eng. 2016, 10, 1382-1388.

338. Yangí, L.; Yang, G.; Liu, Z.; Chang, Y.; Jiang, B.; Awad, Y.; Xiao, J. Wall-climbing robot for visual and GPR inspection. In Proceedings of the 2018 13th IEEE Conference on Industrial Electronics and Applications (ICIEA), Wuhan, China, 31 May-2 June 2018; IEEE: New York, NY, USA, 2018; pp. 1004-1009. [CrossRef]

339. Bertolino, M.; Tanzi, T.J. Towards 3D Simulation for Disaster Intervention Robot Behaviour Assessment. Adv. Radio Sci. 2020, 18, 23-32. [CrossRef]

340. Gibb, S.; La, H.M.; Le, T.; Nguyen, L.; Schmid, R.; Pham, H. Nondestructive evaluation sensor fusion with autonomous robotic system for civil infrastructure inspection. J. Field Robot. 2018, 35, 988-1004. [CrossRef]

341. Pochanin, G.; Varianytsia-Roshchupkina, L.; Ruban, V.; Pochanina, I.; Falorni, P.; Borgioli, G.; Capineri, L.; Bechtel, T. Design and simulation of a "single transmitter-four receiver" impulse GPR for detection of buried landmines. In Proceedings of the 20179 th International Workshop on Advanced Ground Penetrating Radar (IWAGPR), Edinburgh, UK, 28-30 June 2017; IEEE: New York, NY, USA, 2017; pp. 1-5. [CrossRef]

342. Travassos, X.L.; Avila, S.L.; Ida, N. Artificial Neural Networks and Machine Learning techniques applied to Ground Penetrating Radar: A review. Appl. Comput. Inform. 2020. [CrossRef]

343. Liu, T.; Su, Y.; Huang, C. Inversion of Ground Penetrating Radar Data Based on Neural Networks. Remote Sens. 2018, 10, 730. [CrossRef]

344. Kang, M.-S.; An, Y.-K. Frequency-Wavenumber Analysis of Deep Learning-based Super Resolution 3D GPR Images. Remote Sens. 2020, 12, 3056. [CrossRef]

345. Liu, B.; Ren, Y.; Liu, H.; Xu, H.; Wang, Z.; Cohn, A.; Jiang, P. GPRInvNet: Deep Learning-Based Ground Penetrating Radar Data Inversion for Tunnel Lining; Cornell University: Ithaca, NY, USA, 2020.

346. Asadi, P.; Gindy, M.; Alvarez, M. A Machine Learning Based Approach for Automatic Rebar Detection and Quantification of Deterioration in Concrete Bridge Deck Ground Penetrating Radar B-scan Images. Ksce J. Civ. Eng. 2019, 23, 2618-2627. [CrossRef]

347. Zhang, Y.; Venkatachalam, A.; Xia, T. Ground-penetrating radar railroad ballast inspection with an unsupervised algorithm to boost the region of interest detection efficiency. J. Appl. Remote Sens. 2015, 9, 1-19. [CrossRef]

348. Xu, X.; Lei, Y.; Yang, F. Railway Subgrade Defect Automatic Recognition Method Based on Improved Faster R-CNN. Sci. Program. 2018, 2018, 4832972. [CrossRef]

349. Deshpande, J. Geographical Information System \& Building Information Modelling; ADCC Infocad IT Services: Dubai, United Arab Emirates, 2020.

350. Solla, M.; Gonçalves, L.M.S.; Gonçalves, G.; Francisco, C.; Puente, I.; Providência, P.; Gaspar, F.; Rodrigues, H. A Building Information Modeling Approach to Integrate Geomatic Data for the Documentation and Preservation of Cultural Heritage. Remote Sens. 2020, 12, 4028. [CrossRef]

351. Šarlah, N.; Podobnikar, T.; Ambrožič, T.; Mušič, B. Application of Kinematic GPR-TPS Model with High 3D Georeference Accuracy for Underground Utility Infrastructure Mapping: A Case Study from Urban Sites in Celje, Slovenia. Remote Sens. 2020, 12, 1228. [CrossRef]

352. GEOFIT "Deployment of Novel GEOthermal Systems, Technologies and Tools for Energy Efficient Building retroFITting" Project (Grant Agreement ID 792210) (May 2018-April 2022). Available online: https:/ / cordis.europa.eu/project/id/792210 (accessed on 24 December 2020).

353. Assets4Rail "Measuring, Monitoring and Data Handling for Railway Assets; Bridges, Tunnels, Tracks and Safety Systems" Project (Grant Agreement ID 826250) (December 2018-May 2021). Available online: https:/ / cordis.europa.eu/project/id/826250 (accessed on 24 December 2020).

354. IM-SAFE “Harmonised Transport Infrastructure Monitoring in Europe for Optimal Maintenance and Safety" Project (Grant Agreement ID 958171). (November 2020-April 2023). Available online: https:/ / cordis.europa.eu/project/id/958171/pl (accessed on 30 November 2020). 